Portland State University

PDXScholar

Summer 7-26-2018

\title{
Reliability of Solder Joints in Embedded Packages Using Finite Element Methods
}

Valeri Aisha Yunusa

Portland State University

Follow this and additional works at: https://pdxscholar.library.pdx.edu/open_access_etds

Part of the Mechanical Engineering Commons

Let us know how access to this document benefits you.

\section{Recommended Citation}

Yunusa, Valeri Aisha, "Reliability of Solder Joints in Embedded Packages Using Finite Element Methods" (2018). Dissertations and Theses. Paper 4558.

https://doi.org/10.15760/etd.6443

This Thesis is brought to you for free and open access. It has been accepted for inclusion in Dissertations and Theses by an authorized administrator of PDXScholar. Please contact us if we can make this document more accessible: pdxscholar@pdx.edu. 
Reliability of Soldier Joints in Embedded Packages using Finite Element Method

by

Valeri Aisha Yunusa

A thesis submitted in partial fulfillment of the requirements for the degree of

Master of Science
in
Mechanical Engineering

Thesis Committee:

Sung Yi, Chair

Faryar Etesami

Chien Wern

Portland State University

2018 


\begin{abstract}
Solder joints serve as both mechanical and electrical connections between elements in a package. They are subjected to shear strains generated as a result of the different behaviors of the elements in the package (tension and compression) due to the differences in coefficients of thermal expansion during service conditions.
\end{abstract}

Some of the causes of solder joint failures are due to the following:

Vibration: small rapid displacements of parts of the assembly. This is not necessarily an issue with electronic components but larger parts like automobiles.

Humidity: the package being exposed to water or ionic species can undergo corrosion if an electrical bias exists resulting in electrical opens or electrical shorts if the corrosion products are electrically conductive.

Thermal Aging: this occurs during the lifetime of the solder interconnects, the package can be exposed to high ambient temperature or high dissipated heat during use. The micro-structure of the solder joint becomes more coarse and brittle.

Mechanical Shock: the package undergoes shock during a short term exposure to high loads.

Thermo-mechanical fatigue: this type of failure arises as a result of the solder joints going through cyclic strains, due to different coefficients of thermal expansion of individual components in the package during service. 
The most prevalent long-term reliability issues that can cause interconnect failure are thermal aging and thermo-mechanical fatigue [1]. This study aims to evaluate the reliability of solder joints using finite element method, considering solder joint failure due to thermo-mechanical fatigue.

Three variations of the BGA (Ball Grid Array) package are evaluated using the finite element analysis. The SAC305 series lead (pb) free alloy of $96.5 \%$ tin, $3 \%$ silver, and $0.5 \%$ copper is employed for this study. 


\section{Acknowledgements}

I would like to express my gratitude to God almighty for his grace and guidance, my adviser Dr. Sung Yi and Dr. Hormoz Zareh for their help and support during this venture. And my colleagues Sadhana Radhakrishnan, Songlong Wu and Chinh $\mathrm{Vu}$ who also helped me in one way or another during this research.

I am also grateful to my friends and family for their believe and support through my journey, especially my mother Dr. Roseline Yunusa Vakkai, without her constant push and guidance I wouldn't have made it this far in my life. 


\section{Contents}

1 Introduction $\quad 1$

1.1 SAC305 Solder Joint . . . . . . . . . . . . . . . . . . . 2

1.2 Effect of solder joint geometry for reliability of ball grid array assembly 4

1.2.1 Crack initiation and propagation . . . . . . . . . . . . 4

2 Verification Studies $\quad 7$

2.1 Anand viscoplastic constitutive model . . . . . . . . . . . . . . . 7

2.1.1 One dimensional case (uni-axial loading) . . . . . . . . . . 8

2.1.2 Theoretical Formulation of Uniaxial Stress- Strain Response . 10

2.1.3 Theoretical Formulation of Creep Response . . . . . . . . . . . 11

2.1.4 Experimental data compared to various Anand Model Parameters 15

3 Simulation $\quad 34$

3.1 Finite Element Model . . . . . . . . . . . . . . . . . . . . 34

3.1.1 Temperature Cycles . . . . . . . . . . . . . . . . 37

3.1.2 Finite Element Modeling . . . . . . . . . . . . . . . . . . 38

Sine Hyperbolic law . . . . . . . . . . . . . . . . . . . . . . 39

4 Results $\quad 40$

4.1 Case 1 (2 Dies in the molding compound both .12mm) . . . . . . . 43

4.2 Case 2 (2 Dies in the molding compound both .15mm) . . . . . . . 51

4.3 Case 3 (2 Dies in the molding compound both .18mm) . . . . . . . 59

5 Fatigue Life Prediction $\quad 68$

5.1 Fatigue Life Prediction of Solder joints . . . . . . . . . . . . . . 68

5.1.1 Plastic Strain Fatigue Model (Total Strain Fatigue Model) . 69

Coffin Mason Fatigue Model . . . . . . . . . . . . . . . . . . . 69

Basquin's Fatigue Model . . . . . . . . . . . 70

6 Conclusions $\quad 74$ 


\section{List of Figures}

$1.1 \mathrm{Sn}-\mathrm{Ag}-\mathrm{Cu}$ ternary phase diagram $[2] \ldots \ldots \ldots \ldots$

1.2 Binary phase diagram (a) $\mathrm{Sn}-\mathrm{Ag}$ and (b) $\mathrm{Sn}-\mathrm{Cu}[2] \ldots \ldots$

1.3 Microphotographs of solder joints with different heights and shapes; (a) Single bump barrel shaped; (b) Triple-stacked hourglass-shaped;

(c) Triple-stacked barrel shaped; (d) Triple-stacked column-shaped [3]. 5

2.1 Stress vs Strain at $298 \mathrm{~K}$ and strain rate of $.001 / \mathrm{s} \ldots \ldots \ldots$

2.2 Stress vs Strain at $323 \mathrm{~K}$ and strain rate of $.001 / \mathrm{s} \ldots \ldots \ldots \ldots$

2.3 Stress vs Strain at 348K and strain rate of $.001 / \mathrm{s} \ldots \ldots \ldots$

2.4 Stress vs Strain at $373 \mathrm{~K}$ and strain rate of $.001 / \mathrm{s} \ldots \ldots \ldots$

2.5 Stress vs Strain at $398 \mathrm{~K}$ and strain rate of $.001 / \mathrm{s} \ldots \ldots \ldots$

2.6 Stress vs Strain at $298 \mathrm{~K}$ and strain rate of $.0001 / \mathrm{s} \ldots \ldots \ldots \ldots . . . .21$

2.7 Stress vs Strain at 323K and strain rate of .0001/s . . . . . . . . 22

2.8 Stress vs Strain at 348K and strain rate of $.0001 / \mathrm{s} \ldots \ldots \ldots \ldots$

2.9 Stress vs Strain at $373 \mathrm{~K}$ and strain rate of $.0001 / \mathrm{s} \ldots \ldots \ldots \ldots . . .24$

2.10 Stress vs Strain at 398K and strain rate of $.0001 / \mathrm{s} \ldots \ldots \ldots \ldots$

2.11 Stress vs Strain at $298 \mathrm{~K}$ and strain rate of $.00001 / \mathrm{s} \ldots \ldots \ldots$

2.12 Stress vs Strain at 323K and strain rate of $.00001 / \mathrm{s} \ldots \ldots . . . .27$

2.13 Stress vs Strain at $348 \mathrm{~K}$ and strain rate of $.00001 / \mathrm{s} \ldots \ldots \ldots$

2.14 Stress vs Strain at $373 \mathrm{~K}$ and strain rate of $.00001 / \mathrm{s} \ldots \ldots . . .29$

2.15 Stress vs Strain at $398 \mathrm{~K}$ and strain rate of $.00001 / \mathrm{s} \ldots \ldots \ldots$

2.16 Error between Anand parameters and Experimental Data at strain rate of $.001 / \mathrm{s}$ vs Temperature $(\mathrm{K}) \ldots \ldots \ldots$

2.17 Error between Anand parameters and Experimental Data at strain rate of $.0001 / \mathrm{s}$ vs Temperature $(\mathrm{k}) \ldots \ldots . \ldots 32$

2.18 Error between Anand parameters and Experimental Data at strain rate of $.00001 / \mathrm{s}$ vs Temperature $(\mathrm{K}) \ldots \ldots \ldots$

3.1 Embedded device geometry used for analysis . . . . . . . . . . . . 34

3.2 Sections of Embedded device geometry used for analysis . . . . . . 35

3.3 Temperature Cycle vs Time $(\mathrm{s}) \ldots \ldots \ldots \ldots$

3.4 Boundary condition applied to embedded device . . . . . . . . . 39

4.1 Numbering(Identifying) Solder joint . . . . . . . . . . . . . . . 40

4.2 Solder joint on PCB . . . . . . . . . . . . . . . . . . . . . . 41

4.3 Creep Strain on Solder joint J10, Temperature Cycle vs Time(s) . . . 43 
4.4 Normal Stress (S11) on Solder joint J10, Temperature Cycle vs Time(s) 44

4.5 Normal Stress (S22) on Solder joint J10, Temperature Cycle vs Time(s) 45

4.6 Normal Stress (S33) on Solder joint J10, Temperature Cycle vs Time(s) 46

4.7 Shear Stress (S12) on Solder joint J10, Temperature Cycle vs Time(s) 47

4.8 Shear Stress (S13) on Solder joint J10, Temperature Cycle vs Time(s) 48

4.9 Shear Stress (S23) on Solder joint J10, Temperature Cycle vs Time(s) 49

4.10 Creep Dissipation Energy for the whole model vs Time(S) . . . . . 50

4.11 Creep Strain on Solder joint J10, Temperature Cycle vs Time(s) . . . 51

4.12 Normal Stress (S11) on Solder joint J10, Temperature Cycle vs Time(s) 52

4.13 Normal Stress (S22) on Solder joint J10, Temperature Cycle vs Time(s) 53

4.14 Normal Stress (S33) on Solder joint J10, Temperature Cycle vs Time(s) 54

4.15 Shear Stress (S12) on Solder joint J10, Temperature Cycle vs Time(s) 55

4.16 Shear Stress (S13) on Solder joint J10, Temperature Cycle vs Time(s) 56

4.17 Shear Stress (S23) on Solder joint J10, Temperature Cycle vs Time(s) 57

4.18 Creep Dissipation Energy for the whole model vs Time(S) . . . . . 58

4.19 Creep Strain on Solder joint J10, Temperature Cycle vs Time(s) . . . 59

4.20 Normal Stress (S11) on Solder joint J10, Temperature Cycle vs Time(s) 60

4.21 Normal Stress (S22) on Solder joint J10, Temperature Cycle vs Time(s) 61

4.22 Normal Stress (S33) on Solder joint J10, Temperature Cycle vs Time(s) 62

4.23 Shear Stress (S12) on Solder joint J10, Temperature Cycle vs Time(s) 63

4.24 Shear Stress (S13) on Solder joint J10, Temperature Cycle vs Time(s) 64

4.25 Shear Stress (S23) on Solder joint J10, Temperature Cycle vs Time(s) 65

4.26 Creep Dissipation Energy for the whole model vs Time(S) . . . . . 66

5.1 Number of cycles to failure $\mathrm{N}_{f} \ldots \ldots \ldots \ldots \ldots \ldots$

5.2 Number of reversals to failure $2 \mathrm{~N}_{f} \ldots \ldots \ldots \ldots \ldots \ldots \ldots$ 


\section{List of Tables}

2.1 Anand parameters . . . . . . . . . . . . . . 16

3.1 Dimensions of Geometry . . . . . . . . . . . . . . . . . . . . . . . . . . 35

3.2 Material Properties . . . . . . . . . . . . . . . . 36

4.1 Percentage Difference in Equivalent Creep Strain Amplitude between cases . . . . . . . . . . . . . . . . 67

5.1 Strain-Life Parameters for SAC305 . . . . . . . . . . . . . . 71

5.2 Number of cycles to failure for individual cases . . . . . . . . . . . . . 72 


\section{Chapter 1}

\section{Introduction}

Predicting solder joint fatigue has been one of the industry's most challenging problem. The newest generation of computer and electronic components feature extremely small package sizes with large number of connections [4]. The trends in the industry have evolved from leaded through hole mounted devices to leadless solder ball arrays. The pitch sizes of the solder arrays become finer as interconnect sizes shrink with time, which makes solder joint failure a dominant cause of package failure. Solder interconnects perform 3 functions (mechanical, electrical and thermal):

1. Electrical function: it serves as an electrical connection path from the silicon chip to the circuitry on the substrate within the package, and copper traces on the PCB. 2. Mechanical function: it also serves as a mechanical support for elements which are interconnected.

3. Thermal function: during service time, as the power of the chips arise, heat dissipation becomes a critical issue that can affect the performance of the electronic package. Solder joints help in heat dissipation.

Soldier joints can undergo large strain effects as a result of small fluctuations in temperature. The magnitude of this effect depends on the joint thickness and coefficient of thermal expansion (CTE) of the different materials used for the package. The micro-structure of the solder joint is eventually affected as a combination of the change in temperature of the package and the resulting strain associated with the change in temperature. The micro structure begins coarsening and eventually crack initiation and propagation begin. 
The Ball Grid Array (BGA) package is widely used in electronic products as it can satisfy many requirements such as high I/O density, small profile, high performance and low cost, better electrical and thermal performance, etc. Therefore, the BGA package is employed for this study.

\subsection{SAC305 Solder Joint}

The transition to lead-free solder happened to coincide with a dramatic increase in portable electronic products. The passage of the European Union directive on the restriction of the use of hazardous substances in Electrical and Electronic Equipments has made the drive towards worldwide adoption of lead free solder unstoppable for electronics packaging[5]. $\mathrm{Sn}-\mathrm{Ag}-\mathrm{Cu}(\mathrm{SAC})$ is now recognized as the standard lead free solder alloy for packaging interconnects in the electronics industry [2].

Under typical conditions, the SAC alloy is significantly more creep resistant compared to the tin-lead alloy due to differences in microstructures (such as fine $A g_{3} \mathrm{Sn}$ (sliver-tin alloy) phases in the matrix) [5].

Thermal cycle condition profile and component type play a huge role on the reliability of SAC alloys relative to the tin-lead. For example, using 1206 ceramic chip resistors on FR4 board when thermo-cycled between 0 and $100^{\circ} \mathrm{C}$ (with $10{ }^{\circ} \mathrm{C} / \mathrm{min}$ ramp rate and 5 mins dwell), the reliability of the tin-lead was greater than $\mathrm{Sn}-3.5 \mathrm{Ag}$ when thermo cycled between -55 and $125^{\circ} \mathrm{C}$.

The present Study will be conducting investigation on the SAC305 series which is a lead $(\mathrm{Pb})$ free alloy of $96.5 \%$ tin, $3 \%$ silver, and $0.5 \%$ copper. It's almost eutectic (solid melting temperature is almost the same as liquid melting temperature). Typical melting temperature is around $217^{\circ} \mathrm{C}(490 \mathrm{~K})$ for solid and $220^{\circ} \mathrm{C}(493 \mathrm{~K})$ for liquid state. 


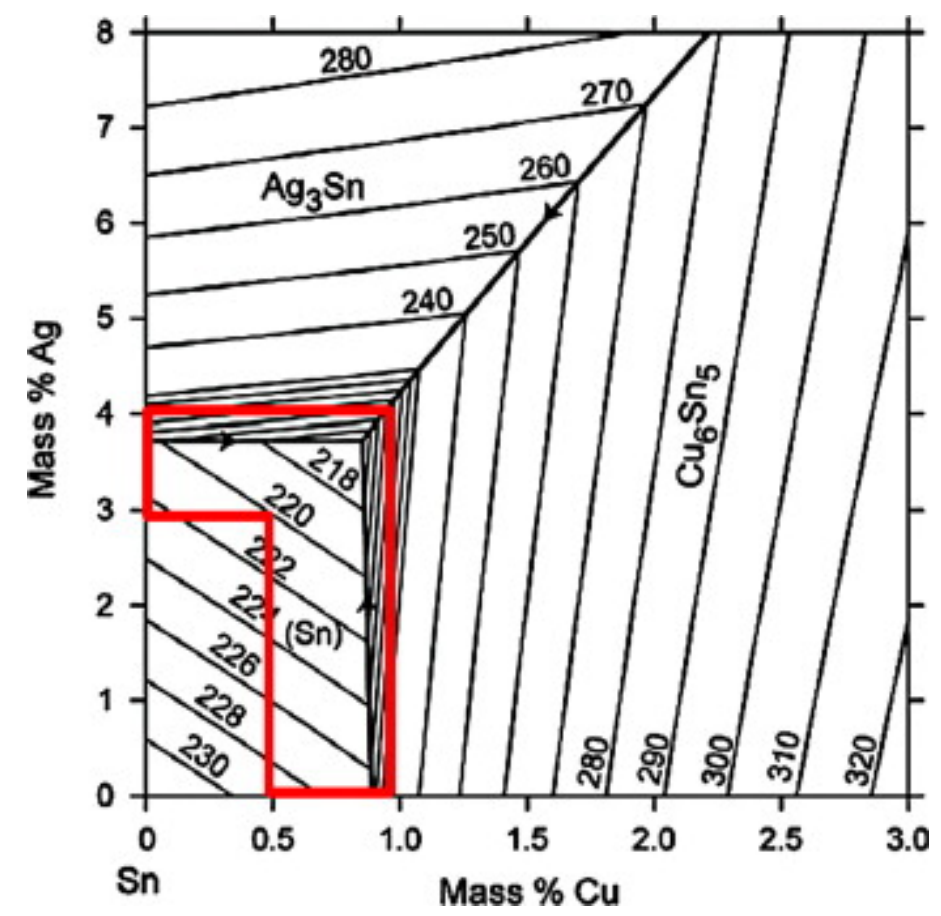

Figure 1.1: $\mathrm{Sn}-\mathrm{Ag}-\mathrm{Cu}$ ternary phase diagram [2]
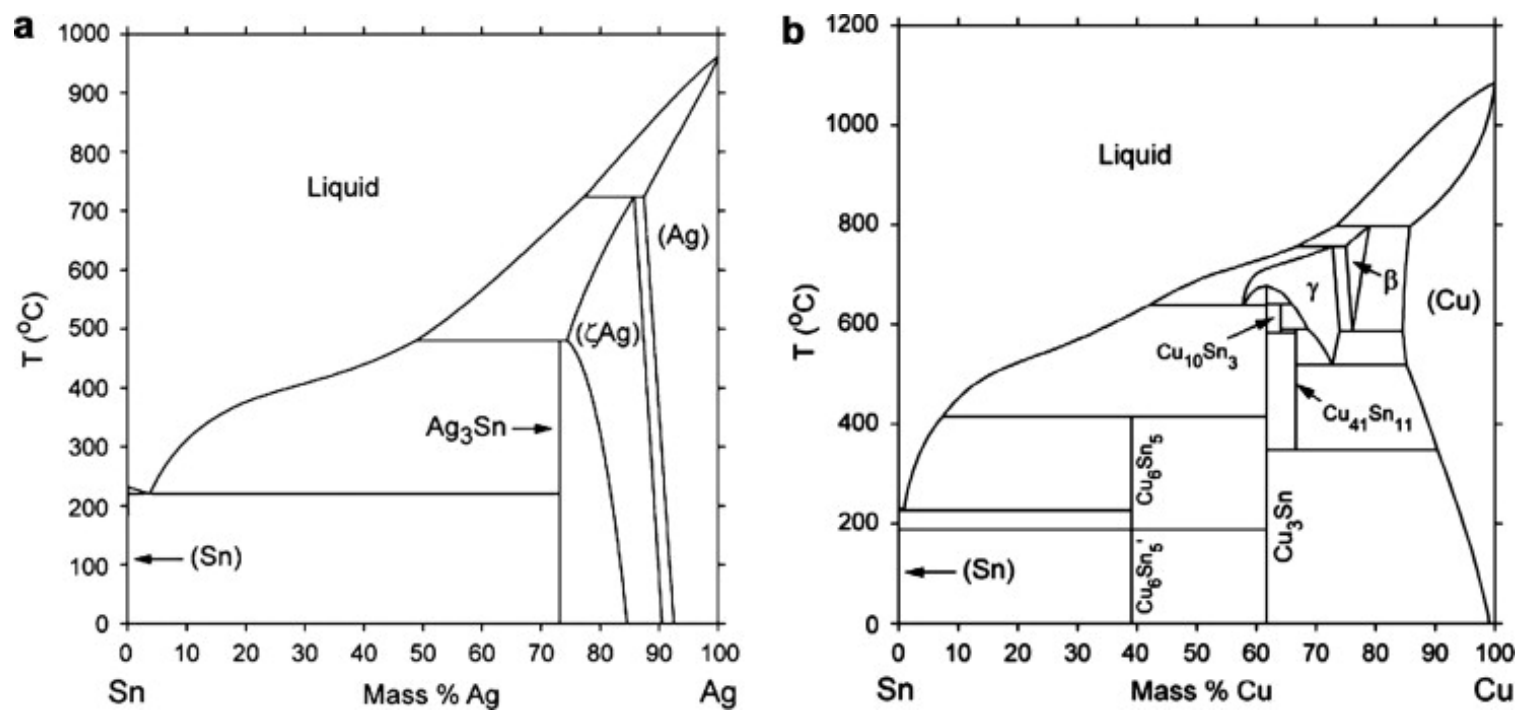

Figure 1.2: Binary phase diagram (a) $\mathrm{Sn}-\mathrm{Ag}$ and (b) $\mathrm{Sn}-\mathrm{Cu}[2]$ 


\subsection{Effect of solder joint geometry for reliability of ball grid array assembly}

Several factors affect solder joint reliability such as joint geometry, under fill material, substrate material, interface metallurgy and board materials. Packages are modified by changing solder joint geometry, board material, etc. to improve its functionality.

Lau et al.(2014) conducted finite element analysis simulation to predict the number of life cycles to failure of different solder joint geometries and printed circuit board $(\mathrm{PCB})$ properties, the results showed the different sites of the crack initiation and propagation in the different cases and also equivalent creep strains experienced by the different solder joint profiles.

Five different geometries were examined; the barrel shaped, column shaped and 3 different hour-glassed shaped profiles (different aspect ratios and shape factor) mounted on a rigid PCB and a flexible PCB. This gave ten different variations of the package to predict the most reliable package.

The results concluded that the locations of the critical joints varies due to the solder joint geometry, and PCB properties. The accumulated volume-weighted average creep density of the barrel shaped solder joints for the FPCB were higher than that of the RPCB, which was different from the general perspective that the increase in flexibility would improve solder joint reliability [6]. Joints experiencing the most equivalent creep strain (CEEQ) also known as the critical joints are most likely to fail first.

\subsubsection{Crack initiation and propagation}

Barrel shaped and column solder joints experience crack initiation first at the corner of the interface between the substrate and the solder joint due to high thermal 
stress concentration. Hour glass shaped solder joints experience lower stress concentration at the corner of the joint for both FPCB and RPCB. Their smaller contact angle reduces the order of the sigularity thereby reducing the stress and strain field near contact angles [6]. Therefore, the maximum equivalent creep strain is found in the midsection of the joint.

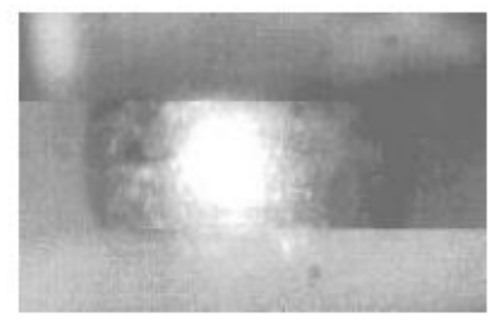

(a)

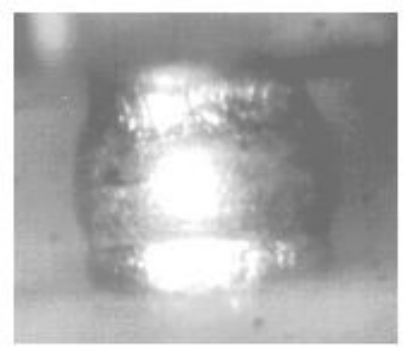

(c)

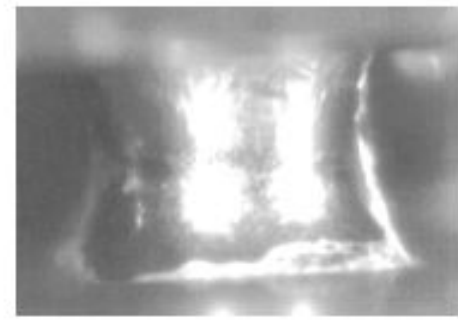

(b)

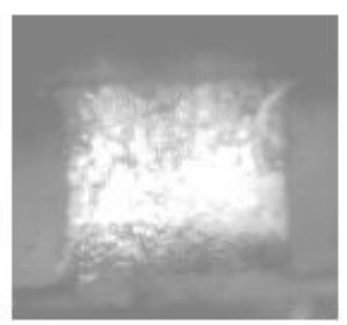

(d)

Figure 1.3: Microphotographs of solder joints with different heights and shapes; (a) Single bump barrel shaped; (b) Triple-stacked hourglass-shaped; (c) Triple-stacked barrel shaped; (d) Triple-stacked column-shaped [3].

This study aims at investigating the reliability of the barrel-shaped solder joints in a BGA package, by analyzing the magnitude of stress and strain imposed on the critical solder joint (which is most likely the first joint to fail in the package) and the effect of increasing die thickness in the package. Finite element analysis would be used to predict the number of cycles to failure of the solder joints using the critical solder joint ( $J 10^{\text {th }}$ solder joint). Due to differences in the CTE, the behavior of the elements in the package differ when exposed to different temperatures. The critical solder joint which sits right beneath the edge of the stacked dies experiences the most stress and strain during service due to the effect of the behavior of the die. Three 
different variations of the package would be studied with different die thicknesses of $.12 \mathrm{~mm}, .15 \mathrm{~mm}, .18 \mathrm{~mm}$, double stacked and Embedded in the molding compound, to determine what variation of the package withstands the most service lifetime. 


\section{Chapter 2}

\section{Verification Studies}

Studying the behavior of the SAC305 material is important in investigating the reliability of solder joints. Information obtained from the behavior of the material is important to predicting the performance of the actual material in the package. This section would evaluate the behavior of the material using Anand's viscoplastic constitutive equation at different strain rates and temperature.

The experimental data used in this section is obtained from Motalab et al.(2012) [7] samples which where subjected to uni-axial loading in a tension/torsion mechanical test system. The experimental data are then curve fitted through non-linear regression to obtain the nine Anand Parameters for the present study. Finally, the present studies Anand parameters are plotted against two other proposed parameters which were derived from the same testing method to view the behavior of the solder material at different temperatures and strain rates.

The diameter of the uni axial test sample is $0.3 \mathrm{~mm}$ thick which is similar to the diameter of the solder joint in the present study. This could help improve the prediction of the behavior of the actual solder joint 's micro-structure in the package.

\subsection{Anand viscoplastic constitutive model}

The Anand viscoplastic constitutive model is used to represent deformation behaviours in solder joints. It unifies the creep and rate-independent plastic behaviour of the material by using a stress equation Eq.(2.4), flow equation Eq.(2.5), and the integrated evolution equation Eq.(2.11). It also uses a scalar internal variable " $s "$ 
to represent isotropic resistance to plastic flow offered by the internal state of the material. The model requires no yield condition and no loading/unloading criteria $[7]$.

\subsubsection{One dimensional case (uni-axial loading)}

$$
\sigma=c s ; \quad c>1
$$

where $\mathrm{c}$ is a material parameter which is a function of strain rate and temperature, and $s$ is the internal variable. $s$ is a single scalar used to characterize the internal structure of the material, and represents the isotropic resistance to plastic flow and $\sigma$ stress.

$$
\begin{gathered}
c=\frac{1}{\xi} \sinh ^{-1}\left\{\left[\frac{\dot{\epsilon}_{p}}{A} e^{\frac{Q}{R T}}\right]^{m}\right\} \\
c=c\left(\dot{\epsilon}_{p}, T\right)
\end{gathered}
$$

where $c$ is also a function of inelastic (plastic) strain rate and absolute temperature.

$$
\sigma=\frac{s}{\xi} \sinh ^{-1}\left\{\left[\frac{\dot{\epsilon}_{p}}{A} e^{\frac{Q}{R T}}\right]^{m}\right\}
$$

where $A$ is the pre-exponential factor, $\xi$ the multiplier stress, $R$ the universal gas constant, $m$ the strain rate sensitivity and $Q$ the activation energy, $T$ absolute Temperature and $\dot{\epsilon}_{p}$ is the strain rate. Re-arranging Eq.(2.4) stress equation into the strain rate (flow equation)

$$
\dot{\epsilon}_{p}=A e^{\left(-\frac{Q}{R T}\right)}\left[\sinh \left(\xi \frac{\sigma}{s}\right)\right]^{\frac{1}{m}}
$$


The differential form of the evolution equation for the internal variable $s$ is assumed to be

$$
\dot{s}=h(\sigma, s, T) \dot{\epsilon}_{p}
$$

where $h(\sigma, s, T)$ is associated with dynamic hardening and recovery processes.

$$
\dot{s}=\left[h_{o}\left(1-\frac{s}{s^{*}}\right)^{a} \operatorname{sign}\left(1-\frac{s}{s^{*}}\right)\right] \dot{\epsilon}_{p} ; a>1
$$

where $h_{o}$ is the hardening constants and a strain rate sensitivity of the hardening process, and $s^{*}$ is known to be

$$
s^{*}=\hat{s}\left[\frac{\dot{\epsilon}_{p}}{A} e^{\frac{Q}{R T}}\right]^{n}
$$

where $\hat{s}$ is a coefficient and $n$ is the strain rate sensitivity of the saturation value of the deformation resistance, and $T$ the absolute temperature. Therefore, Eq.(2.7) is rewritten as

$$
d s=h_{o}\left(1-\frac{s}{s^{*}}\right)^{a} d \epsilon_{p}
$$

Integrating Eq.(2.9) yields

$$
s=s^{*}-\left[\left(s^{*}-s_{o}\right)^{(1-a)}+(a-1)\left\{\left(h_{o}\right)\left(s^{*}\right)^{-a}\right\} \epsilon_{p}\right]^{\frac{1}{1-a}}
$$

where $s_{o}$ is $s$ at $t=0$, in other words, $s_{o}=s(0)$. Substituting Eq.(2.8) into (2.10) leads 
to the evolution equation

$$
\begin{gathered}
s=\hat{s}\left[\frac{\dot{\epsilon}_{p}}{A} e^{\frac{Q}{R T}}\right]^{n}-\left[\left[\hat{s}\left[\frac{\dot{\epsilon}_{p}}{A} e^{\frac{Q}{R T}}\right]^{n}-s_{o}\right]^{(1-a)}+(a-1)\left[h_{o}\left(\hat{s}\left[\frac{\dot{\epsilon}_{p}}{A} e^{\frac{Q}{R T}}\right]^{n}\right)^{-a}\right] \epsilon_{p}\right]_{(2.11}^{\frac{1}{1-a}} \\
s=s\left(\dot{\epsilon}_{p}, \epsilon_{p}\right)
\end{gathered}
$$

\subsubsection{Theoretical Formulation of Uniaxial Stress- Strain Re- sponse}

The post yield uniaxial stress-strain response is obtained from substituting Eq.(2.11), the evolution equation into the stress equation Eq.(2.4)

$$
\begin{gathered}
\sigma=\frac{1}{\xi} \sinh ^{-1}\left\{\left[\frac{\dot{\epsilon}_{p}}{A} e^{\frac{Q}{R T}}\right]^{m}\right\} \\
{\left[\hat{s}\left[\frac{\dot{\epsilon}_{p}}{A} e^{\frac{Q}{R T}}\right]^{n}-\left[\left(\hat{s}\left[\frac{\dot{\epsilon}_{p}}{A} e^{\frac{Q}{R T}}\right]^{n}-s_{o}\right)^{(1-a)}+(a-1)\left\{\left(h_{o}\right)\left(\hat{s}\left[\frac{\dot{\epsilon}_{p}}{A} e^{\frac{Q}{R T}}\right]^{n}\right)^{-a}\right\} \epsilon_{p}\right]^{\frac{1}{1-a}}\right.} \\
\sigma=\sigma\left(\dot{\epsilon_{p}}, \epsilon_{p}\right)
\end{gathered}
$$

For a uni-axial tensile test performed at a constant strain rate and temperature, a power law function (nonlinear behavior) is expressed after yielding

$$
\sigma=\sigma\left(\epsilon_{p}\right)
$$


To predict the Anand model UTS (maximum/ saturation stress) and yield stress using Eq.(2.18), the limit as $\epsilon_{P}$ goes to $\infty$ for the Ultimate Tensile Stress. Substituting $s^{*}$ for $s$ in the stress equation Eq.(2.4) yields

$$
\sigma^{*}=\frac{\hat{s}}{\xi}\left[\frac{\dot{\epsilon}_{p}}{A} e^{\frac{Q}{R T}}\right]^{n} \sinh ^{-1}\left\{\left[\frac{\dot{\epsilon}_{p}}{A} e^{\frac{Q}{R T}}\right]^{m}\right\}=U T S
$$

Yield stress $\sigma_{Y}$ is evaluated at limit as $\epsilon_{p}$ goes to 0

$$
\sigma_{Y}=\left.\sigma\right|_{\epsilon_{p} \rightarrow 0}=\frac{s_{0}}{\xi} \sinh ^{-1}\left\{\left[\frac{\dot{\epsilon}_{p}}{A} e^{\frac{Q}{R T}}\right]^{m}\right\}=c s_{0} \equiv \sigma_{0}
$$

where $c$ is a material parameter and $s_{0}$ is the initial internal variable at time $t=0$ Eq.(2.18) uses the saturation stress which is also the UTS relation in Eq.(2.16) and post yield power response.

$$
\sigma=\sigma^{*}-\left[\left(\sigma^{*}-c s_{o}\right)^{(1-a)}+(a-1)\left\{\left(c h_{o}\right)\left(\sigma^{*}\right)^{-a}\right\} \epsilon_{p}\right]^{\frac{1}{1-a}}
$$

\subsubsection{Theoretical Formulation of Creep Response}

Using the flow equations, Eq.(2.5), (2.19), and internal variable equation Eq.(2.11),

$$
\dot{\epsilon}_{p}=A e^{\left(-\frac{Q}{R T}\right)}\left[\sinh \left(\xi \frac{\sigma}{s}\right)\right]^{\frac{1}{m}}
$$

where Eq.(2.11) is

$$
s=\hat{s}\left(\frac{\dot{\epsilon}_{p}}{A} e^{\frac{Q}{R T}}\right)^{n}-\left[\hat{s}\left(\frac{\dot{\epsilon}_{p}}{A} e^{\frac{Q}{R T}}\right)^{n}-s_{o}^{(1-a)}+(a-1)\left[h_{o} \hat{s}\left(\frac{\dot{\epsilon}_{p}}{A} e^{\frac{Q}{R T}}\right)^{n-a}\right] \epsilon_{p}\right]^{\frac{1}{1-a}}
$$


Substituting the internal variable "s" equation, Eq.(2.11) and (2.20) into the flow equation leads to

$$
\dot{\epsilon}_{p}=A e^{\left(-\frac{Q}{R T}\right)}
$$

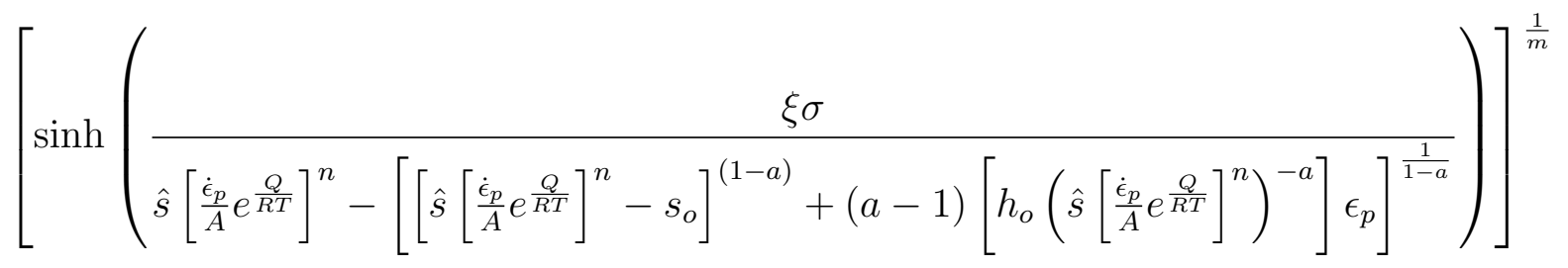

Rearranging Eq.(2.21) severally to solve for the plastic strain yields

$$
\left[\frac{\dot{\epsilon}_{p}}{A e^{\left(-\frac{Q}{R T}\right)}}\right]^{m}=
$$

$\sinh \left(\frac{\xi \sigma}{\hat{s}\left[\frac{\dot{\epsilon}_{p}}{A} e^{\frac{Q}{R T}}\right]^{n}-\left[\left[\hat{s}\left[\frac{\dot{\epsilon}_{p}}{A} e^{\frac{Q}{R T}}\right]^{n}-s_{o}\right]^{(1-a)}+(a-1)\left[h_{o}\left(\hat{s}\left[\frac{\dot{\epsilon}_{p}}{A} e^{\frac{Q}{R T}}\right]^{n}\right)^{-a}\right] \epsilon_{p}\right]^{\frac{1}{1-a}}}\right)$

Taking the inverse sinh of both sides leads to 


$$
\begin{gathered}
\sinh ^{-1}\left[\left[\frac{\dot{\epsilon}_{p}}{A e^{\left(-\frac{Q}{R T}\right)}}\right]^{m}\right]= \\
\left(\frac{\xi \sigma}{\hat{s}\left[\frac{\dot{\epsilon}_{p}}{A} e^{\frac{Q}{R T}}\right]^{n}-\left[\left[\hat{s}\left[\frac{\dot{\epsilon}_{p}}{A} e^{\frac{Q}{R T}}\right]^{n}-s_{o}\right]^{(1-a)}+(a-1)\left[h_{o}\left(\hat{s}\left[\frac{\dot{\epsilon}_{p}}{A} e^{\frac{Q}{R T}}\right]^{n}\right)^{-a}\right] \epsilon_{p}\right]^{\frac{1}{1-a}}}\right)
\end{gathered}
$$

Let us define $\mathrm{B}$, where

$$
B=\hat{s}\left[\frac{\dot{\epsilon}_{p}}{A} e^{\frac{Q}{R T}}\right]^{n}
$$

Then Eq.(2.23) can be rewritten as

$$
\begin{gathered}
\left.\frac{\xi \sigma}{\sinh ^{-1}\left[\left[\frac{\dot{\epsilon}_{p}}{A e^{\left(-\frac{Q}{R T}\right)}}\right]^{m}\right]}=B-\left[B-s_{o}\right]^{(1-a)}+(a-1)\left[h_{o}(B)^{-a}\right] \epsilon_{p}\right]^{\frac{1}{1-a}} \\
\left.\frac{\xi \sigma}{\sinh ^{-1}\left[\left[\frac{\dot{\epsilon}_{p}}{A e^{\left(-\frac{Q}{R T}\right)}}\right]^{m}\right]}-B=-\left[B-s_{o}\right]^{(1-a)}+(a-1)\left[h_{o}(B)^{-a}\right] \epsilon_{p}\right]^{\frac{1}{1-a}} \\
{\left[\frac{\xi \sigma}{\sinh ^{-1}\left[\left[\frac{\dot{\epsilon}_{p}}{A e^{\left(-\frac{Q}{R T}\right)}}\right]^{m}\right]}-B\right]^{(1-a)}=-\left[\left[B-s_{o}\right]^{(1-a)}+(a-1)\left[h_{o}(B)^{-a}\right] \epsilon_{p}\right]} \\
{\left[\frac{\xi \sigma}{\sinh ^{-1}\left[\left[\frac{\dot{\epsilon}_{p}}{A e^{\left(-\frac{Q}{R T}\right)}}\right]^{m}\right]}-B\right]^{(1-a)}+\left[B-s_{o}\right]^{(1-a)}=-(a-1)\left[h_{o}(B)^{-a}\right] \epsilon_{p}}
\end{gathered}
$$


Distributing a negative sign through

$$
-\left[\frac{\xi \sigma}{\sinh ^{-1}\left[\left[\frac{\dot{\epsilon}_{p}}{A e^{\left(-\frac{Q}{R T}\right)}}\right]^{m}\right]}+B\right]^{(1-a)}+\left[B-s_{o}\right]^{(1-a)}=(a-1)\left[h_{o}(B)^{-a}\right] \epsilon_{p}
$$

Therefore plastic strain is

$$
\epsilon_{p}=\frac{\left[-\frac{\xi \sigma}{\sinh ^{-1}\left[\left[\frac{\dot{\epsilon}_{p}}{A e^{\left(-\frac{Q}{R T}\right)}}\right]^{m}\right]}-B-\left[B-s_{o}\right]\right]^{(1-a)}}{(a-1) h_{o}(B)^{-a}}
$$

where

$$
B=\hat{s}\left[\frac{\dot{\epsilon}_{p}}{A} e^{\frac{Q}{R T}}\right]^{n}
$$

Finally

$$
\epsilon_{p}=\frac{\left[\frac{\xi \sigma}{\sinh ^{-1}\left[\left[\frac{\dot{\epsilon}_{p}}{A e^{\left(-\frac{Q}{R T}\right)}}\right]^{m}\right]}-\hat{s}\left[\frac{\dot{\epsilon}_{p}}{A} e^{\frac{Q}{R T}}\right]^{n}-\left[\hat{s}\left[\frac{\dot{\epsilon}_{p}}{A} e^{\frac{Q}{R T}}\right]^{n}-s_{o}\right]\right]^{(1-a)}}{(a-1) h_{o}\left(\hat{s}\left[\frac{\dot{\epsilon}_{p}}{A} e^{\frac{Q}{R T}}\right]^{n}\right)^{-a}}
$$




\subsubsection{Experimental data compared to various Anand Model Parameters}

Experimental data is obtained from a uniaxial tension/torsion thermo mechanical test system conducted by Motalab et al.(2012) [7]. The Anand constants for SAC solders are obtained by using stress-strain or creep data. Experimental data is plotted against Motalab et al.(2012) [7] and Seng et al.(2012) [8] and the present studies

proposed nine Anand parameters at different temperatures(298k, 323k, 348k, 373k, $398 \mathrm{k})$ and strain rates $(.0011 / \mathrm{s}, .00011 / \mathrm{s}, .000011 / \mathrm{s})$

The present study's nine Anand parameters where curve fitted by non-linear regression against the experimental data obtained from Motalab et al.(2012) [7] uniaxial test. The Anand curve from the proposed parameters of the present study is then plotted against Motalab et al.(2012) parameters [7], Seng et al.(2012) parameters [8]. and Motalab et al.(2012) [7] experimental data to predict the behavior of the SAC305 material at different temperatures and strain rates.

The percentage error between the experimental data and Anand proposed parameters are solved using the equation below Eq.(2.31) to determine what proposed parameters best fits the experimental stress/strain data curve with minimal error.

$$
\frac{1}{N} \sum_{i=1}^{N}\left|\frac{\text { Experimental data }_{i}-\text { Anand } \text { Parameter }_{i}}{\text { Experimental data } a_{i}}\right|
$$


Table 2.1: Anand parameters

\begin{tabular}{|l|l|l|l|l|}
\hline \multicolumn{5}{|c|}{ Anand Parameters } \\
\hline Parameters & Units & $\begin{array}{l}\text { Motalab et } \\
\text { al. }(2012)\end{array}$ & $\begin{array}{l}\text { Seng et al. } \\
(2012)\end{array}$ & $\begin{array}{l}\text { Present } \\
\text { Study }\end{array}$ \\
\hline $\begin{array}{l}\text { Pre-exponential factor } \\
\begin{array}{l}\text { Activation energy/Boltzmann's con- } \\
\text { stant }\end{array}\end{array}$ & $\begin{array}{l}\mathrm{A}\left(\mathrm{s}^{-1}\right) \\
\mathrm{Q} / \mathrm{R}\left(K^{\circ}\right)\end{array}$ & $\begin{array}{l}3501 \\
9320\end{array}$ & $\begin{array}{l}5.87 \mathrm{e}+06 \\
7460\end{array}$ & $\begin{array}{l}3101.3 \\
8008.35\end{array}$ \\
$\begin{array}{l}\text { Multiplier of stress } \\
\text { Strain rate sensitivity of stress }\end{array}$ & $\xi$ & 4 & 2 & 4.586 \\
$\begin{array}{l}\text { Deformation resistance saturation } \\
\text { coefficient }\end{array}$ & $\mathrm{m}(\mathrm{Mpa})$ & 0.25 & 0.0942 & 0.1586 \\
$\begin{array}{l}\text { Strain rate sensitivity of saturation } \\
\text { Hardening constant }\end{array}$ & $\mathrm{n}$ & 0.01 & 58.3 & 62.3436 \\
$\begin{array}{l}\text { Strain rate sensitivity of hardening } \\
\text { Deformation resistance }\end{array}$ & $\mathrm{h}_{o}(M p a)$ & 180000 & 0.015 & 0.01 \\
\hline & $\mathrm{a}$ & 1.78 & 1.5 & 120117 \\
$\mathrm{~s}_{o}(M p a)$ & 21 & 45.9 & 1.57901 \\
\hline
\end{tabular}

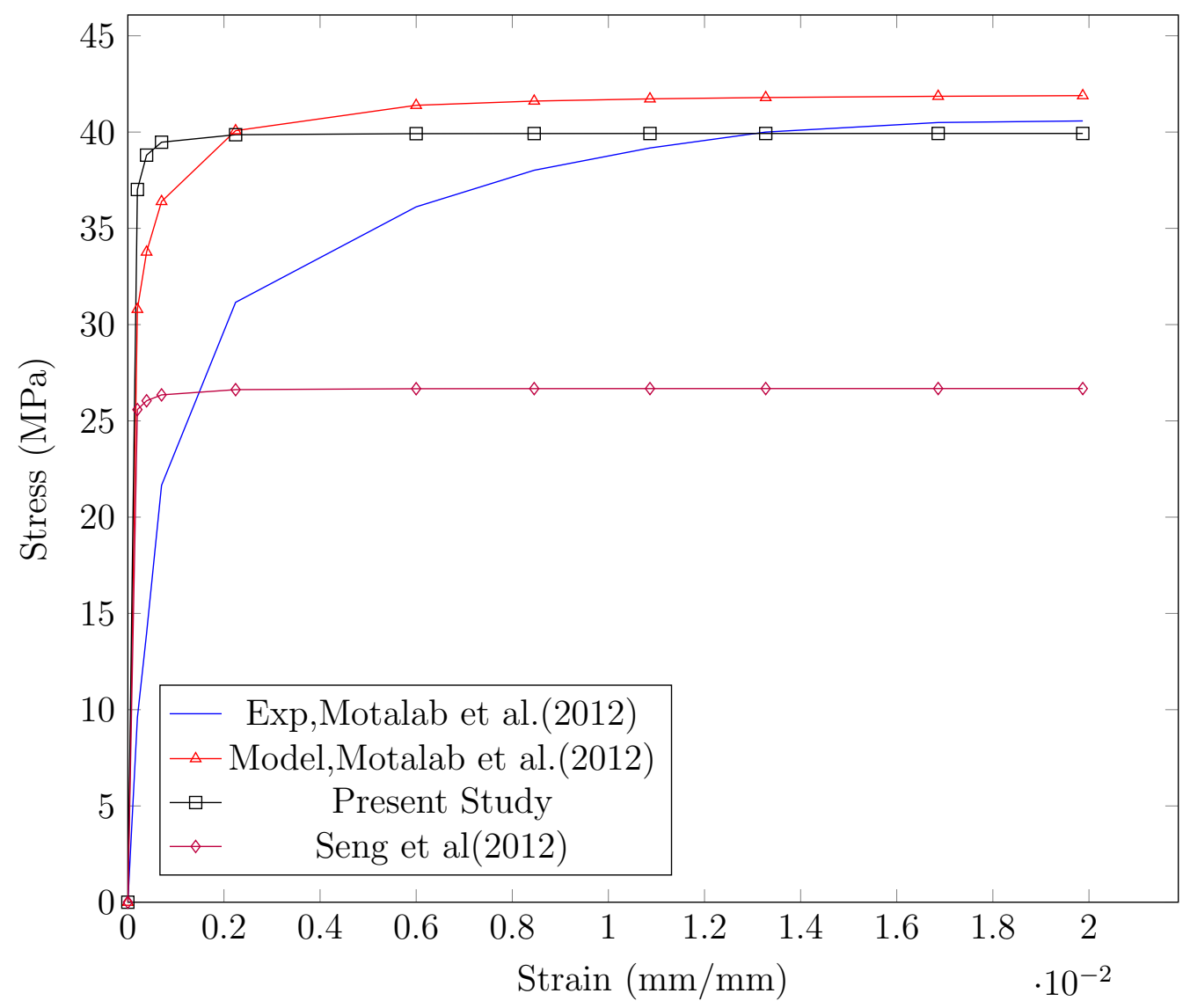

Figure 2.1: Stress vs Strain at $298 \mathrm{~K}$ and strain rate of .001/s 


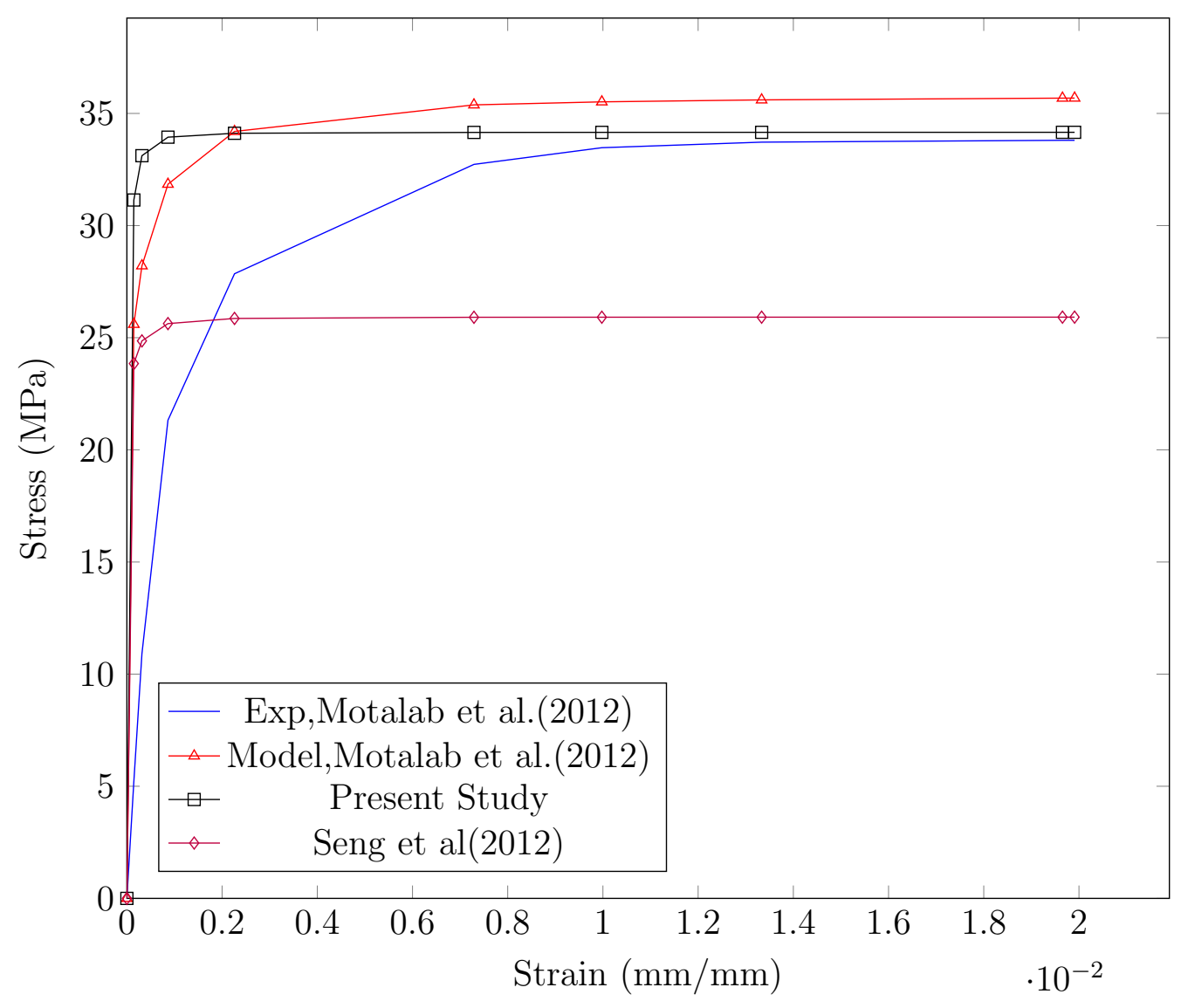

Figure 2.2: Stress vs Strain at $323 \mathrm{~K}$ and strain rate of .001/s 


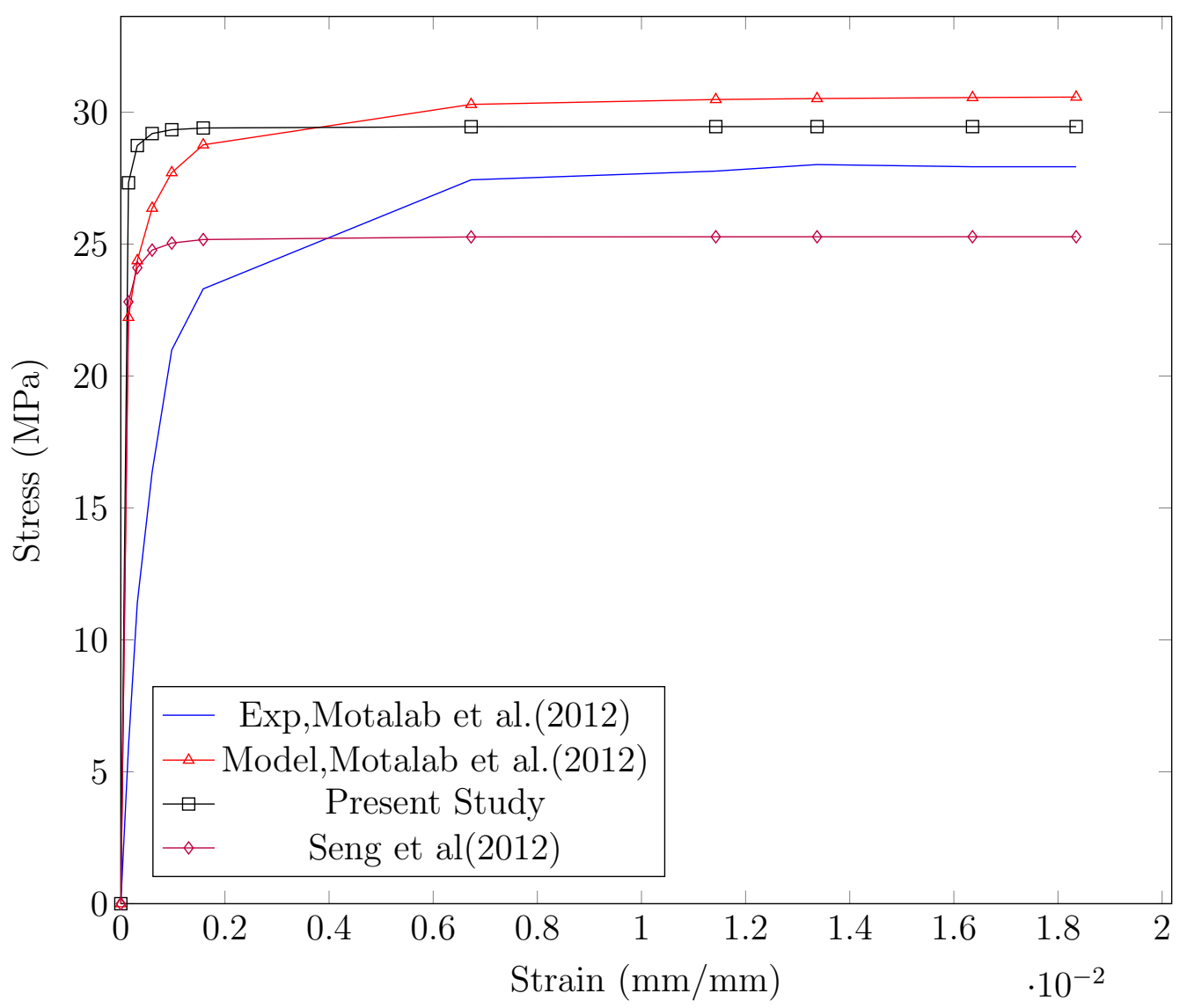

Figure 2.3: Stress vs Strain at 348K and strain rate of .001/s 


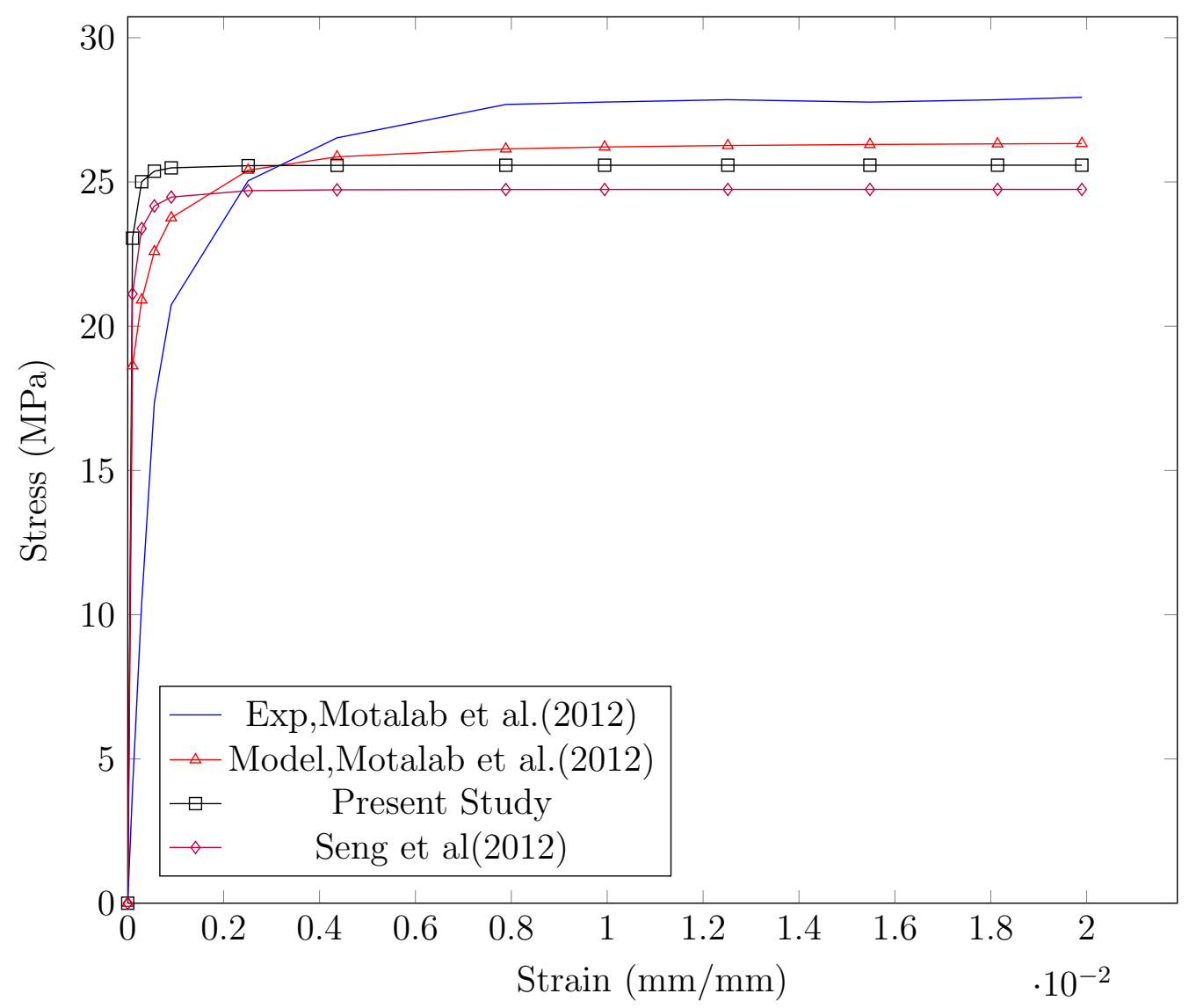

Figure 2.4: Stress vs Strain at 373K and strain rate of .001/s 


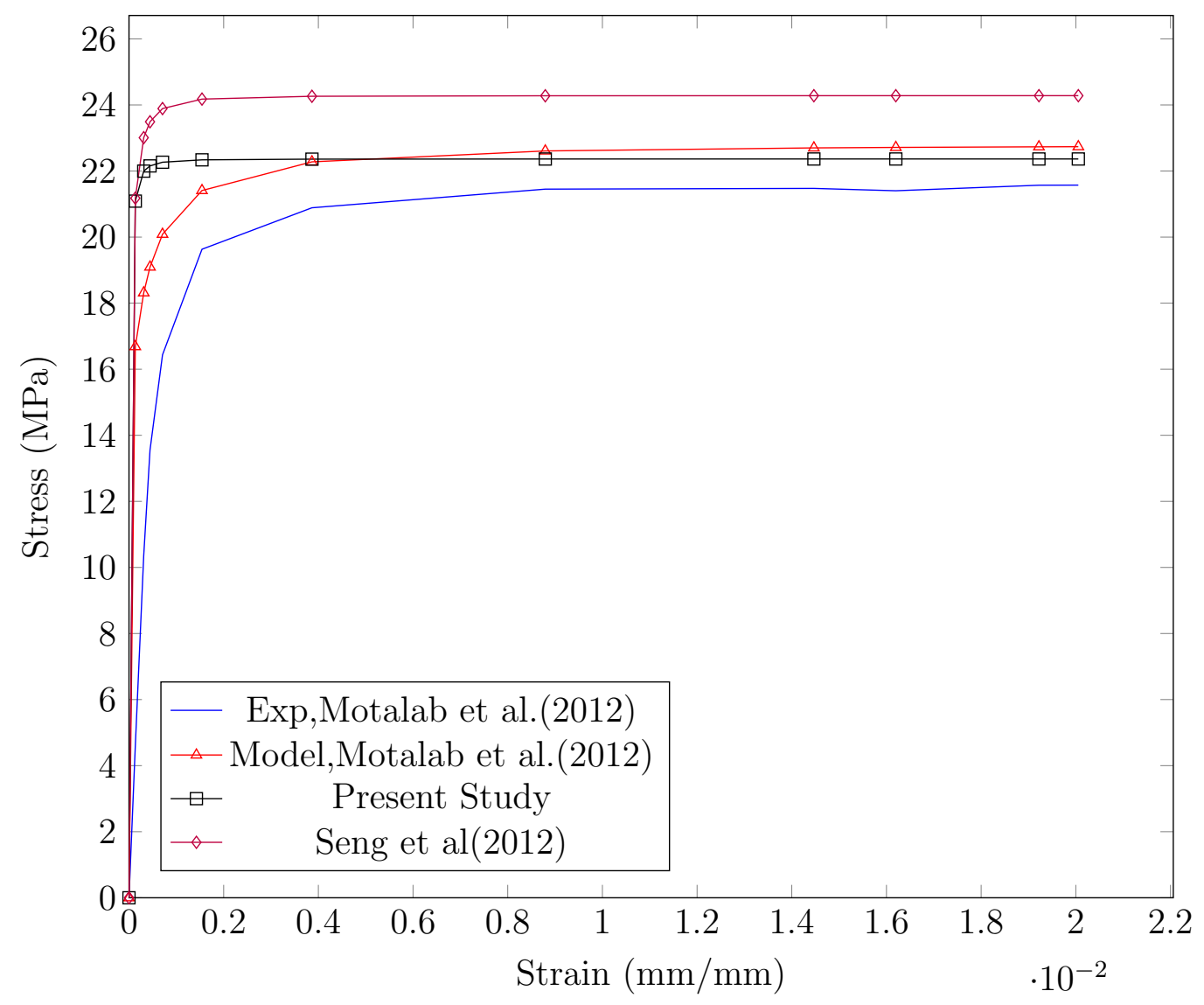

Figure 2.5: Stress vs Strain at 398K and strain rate of .001/s 


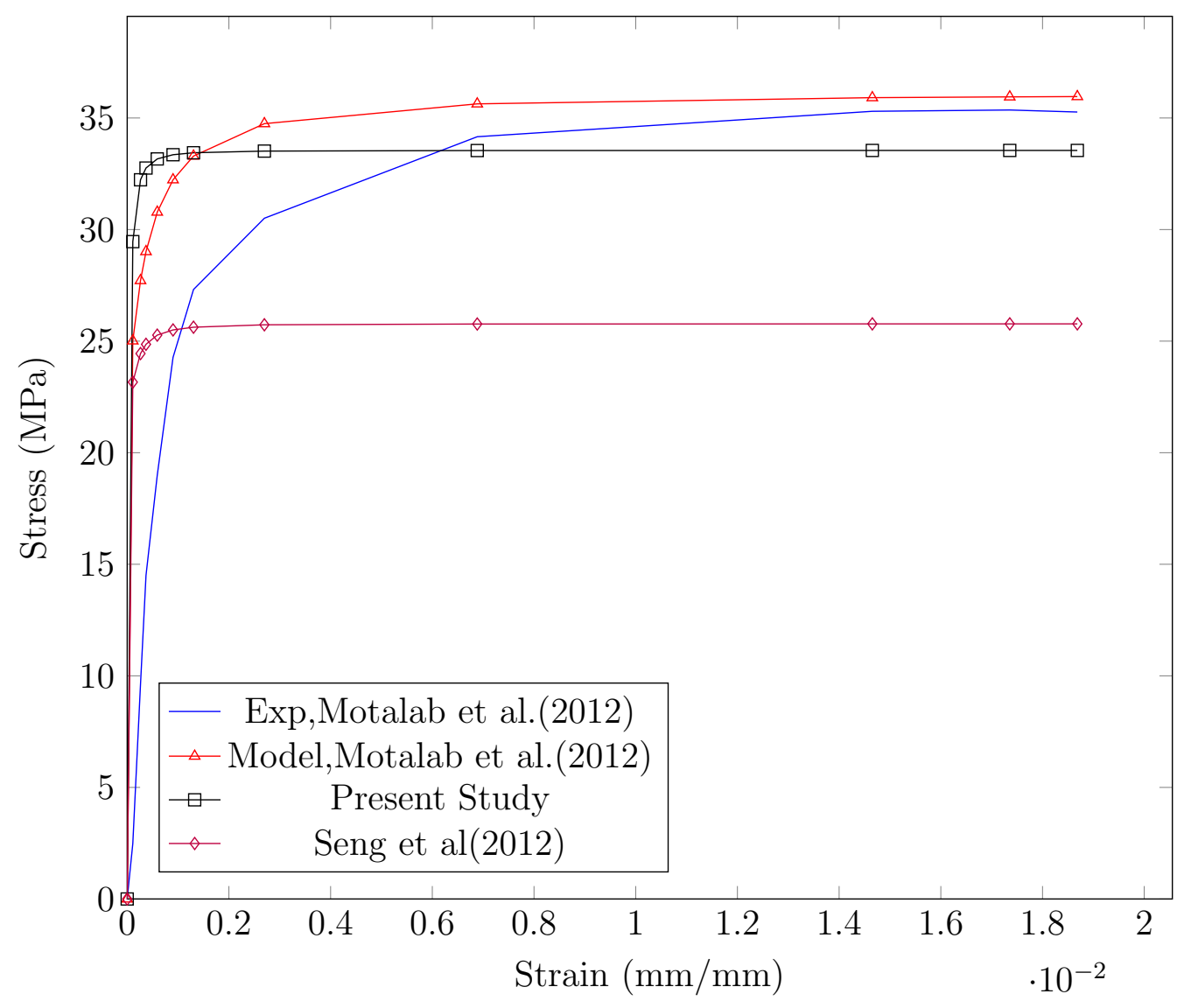

Figure 2.6: Stress vs Strain at 298K and strain rate of .0001/s 


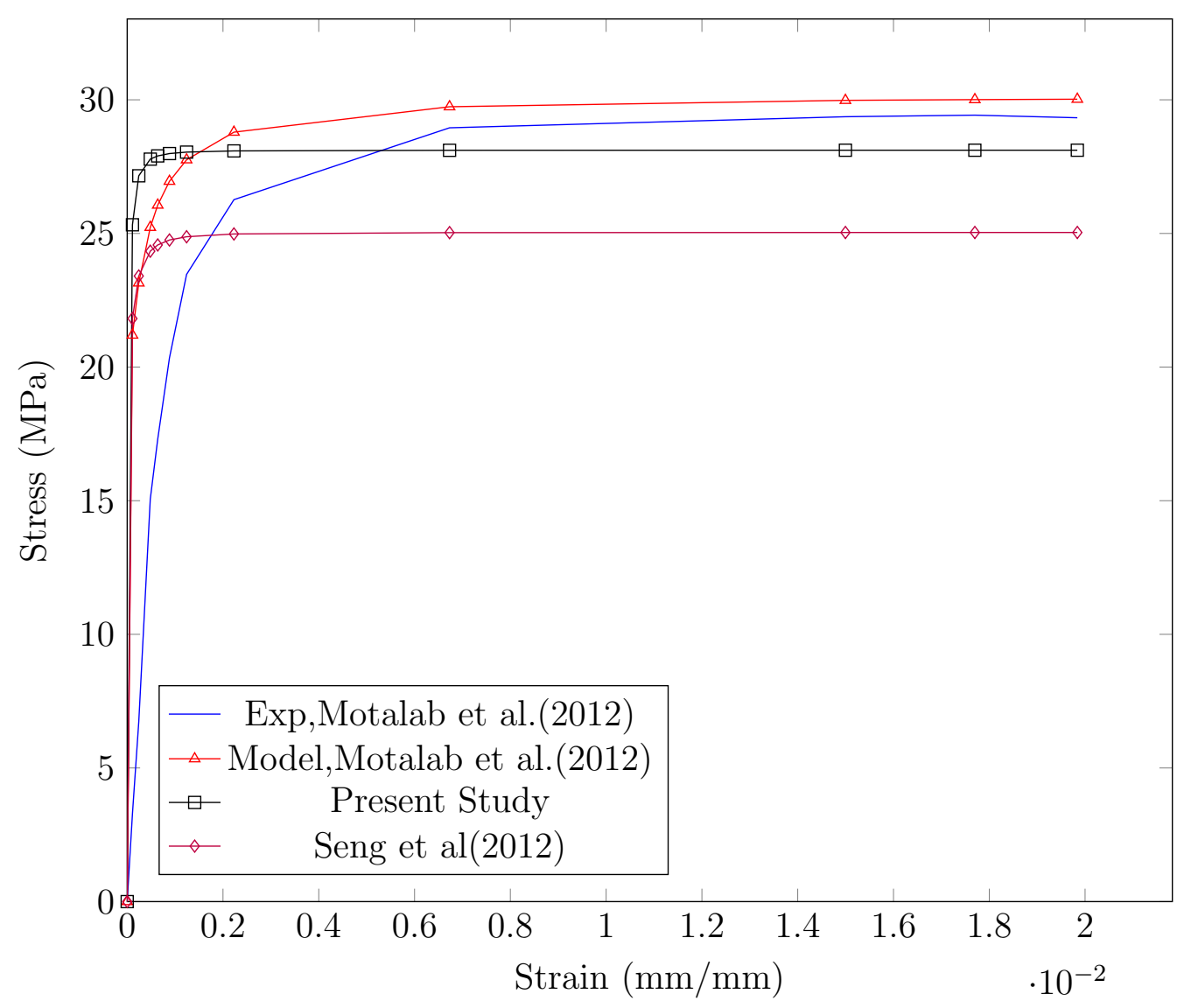

Figure 2.7: Stress vs Strain at 323K and strain rate of .0001/s 


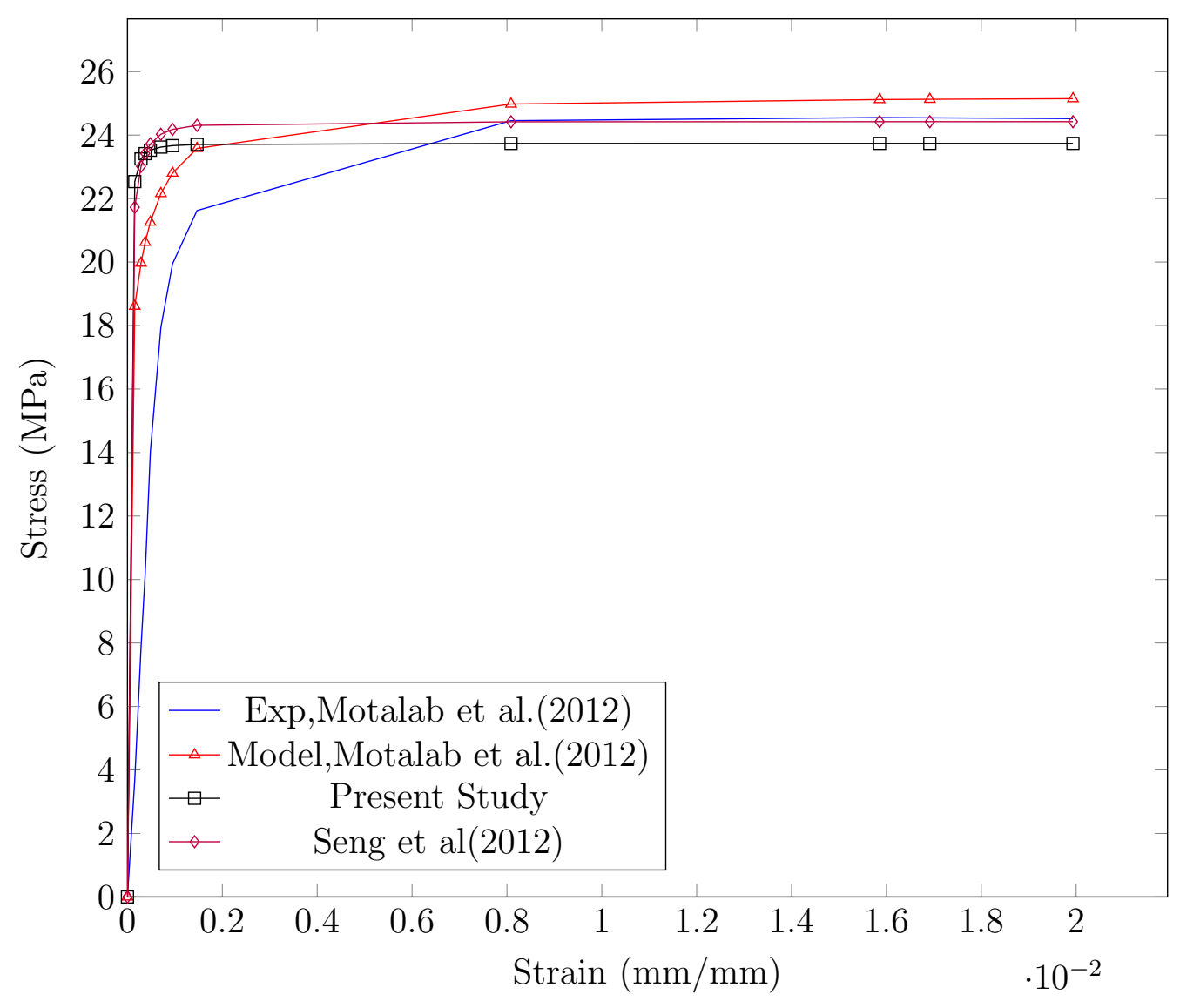

Figure 2.8: Stress vs Strain at 348K and strain rate of .0001/s 


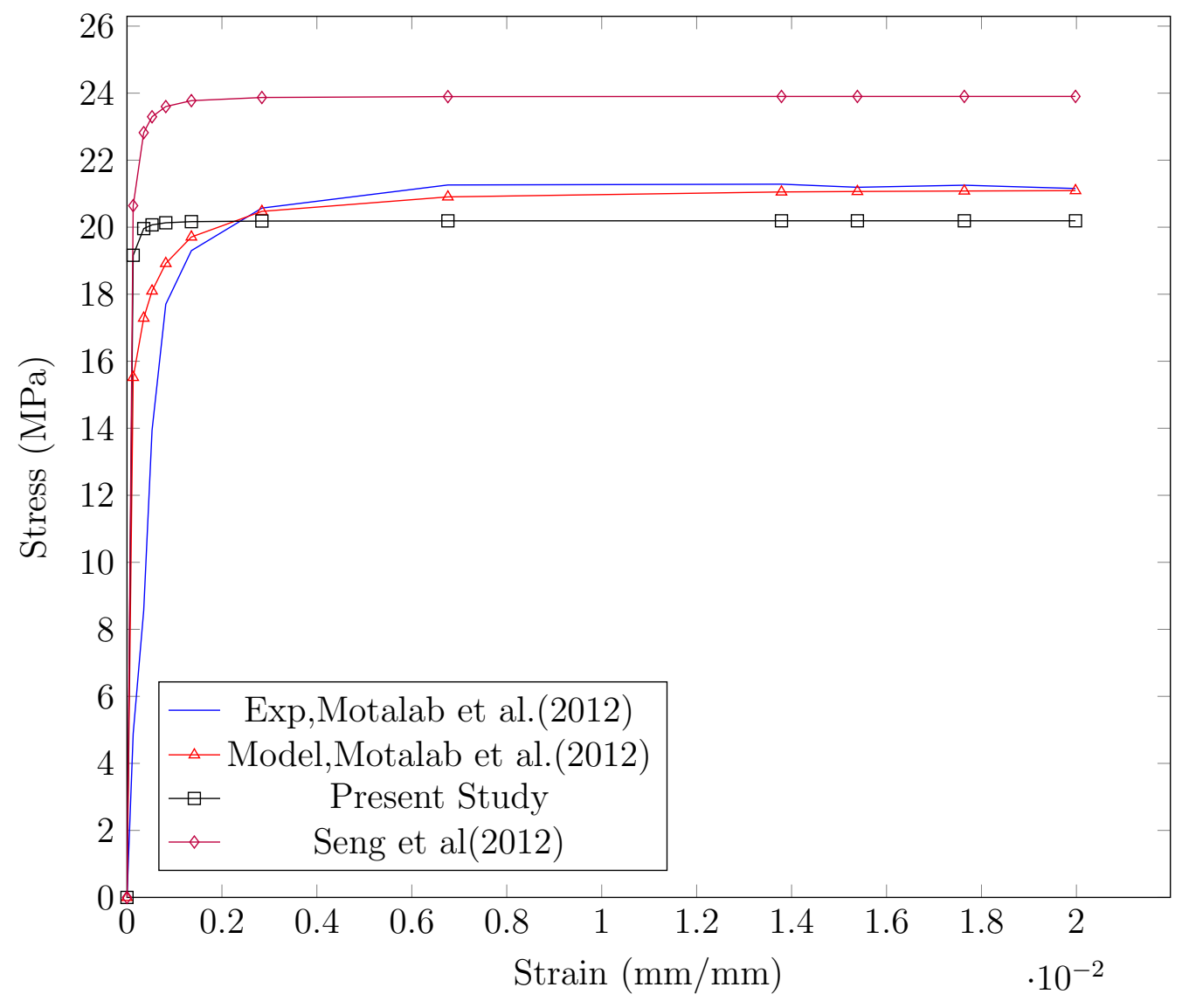

Figure 2.9: Stress vs Strain at $373 \mathrm{~K}$ and strain rate of .0001/s 


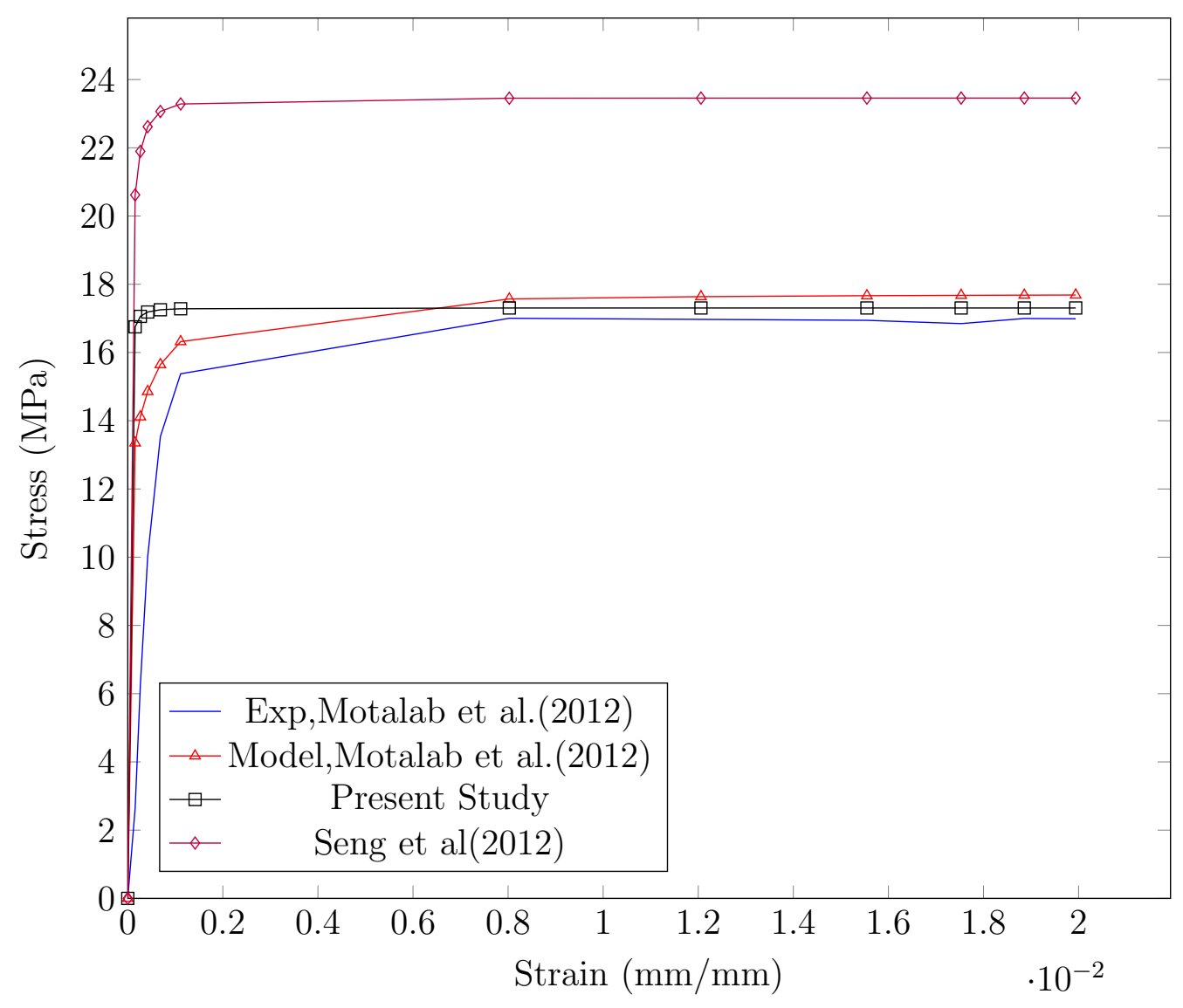

Figure 2.10: Stress vs Strain at 398K and strain rate of .0001/s 


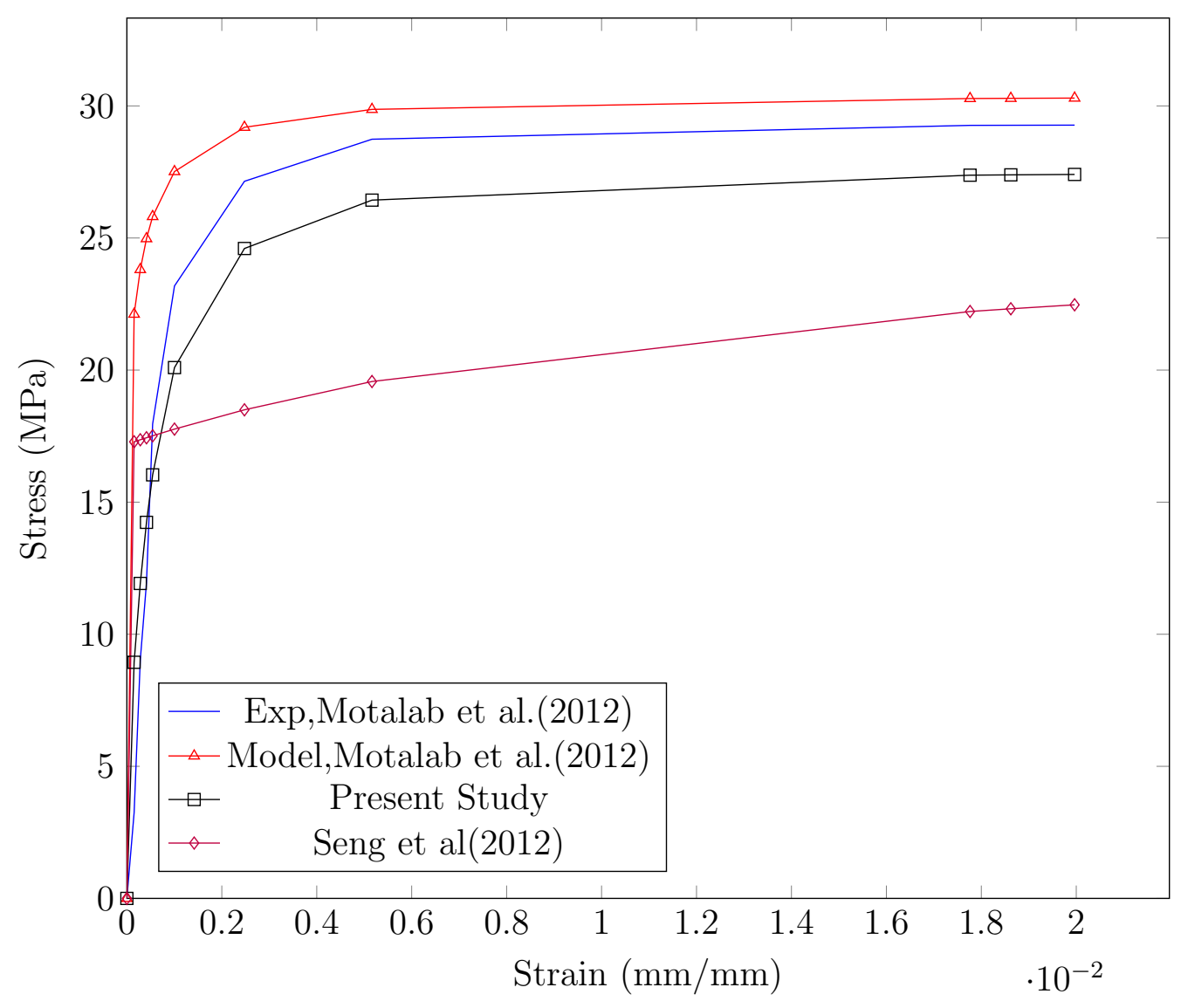

Figure 2.11: Stress vs Strain at 298K and strain rate of .00001/s 


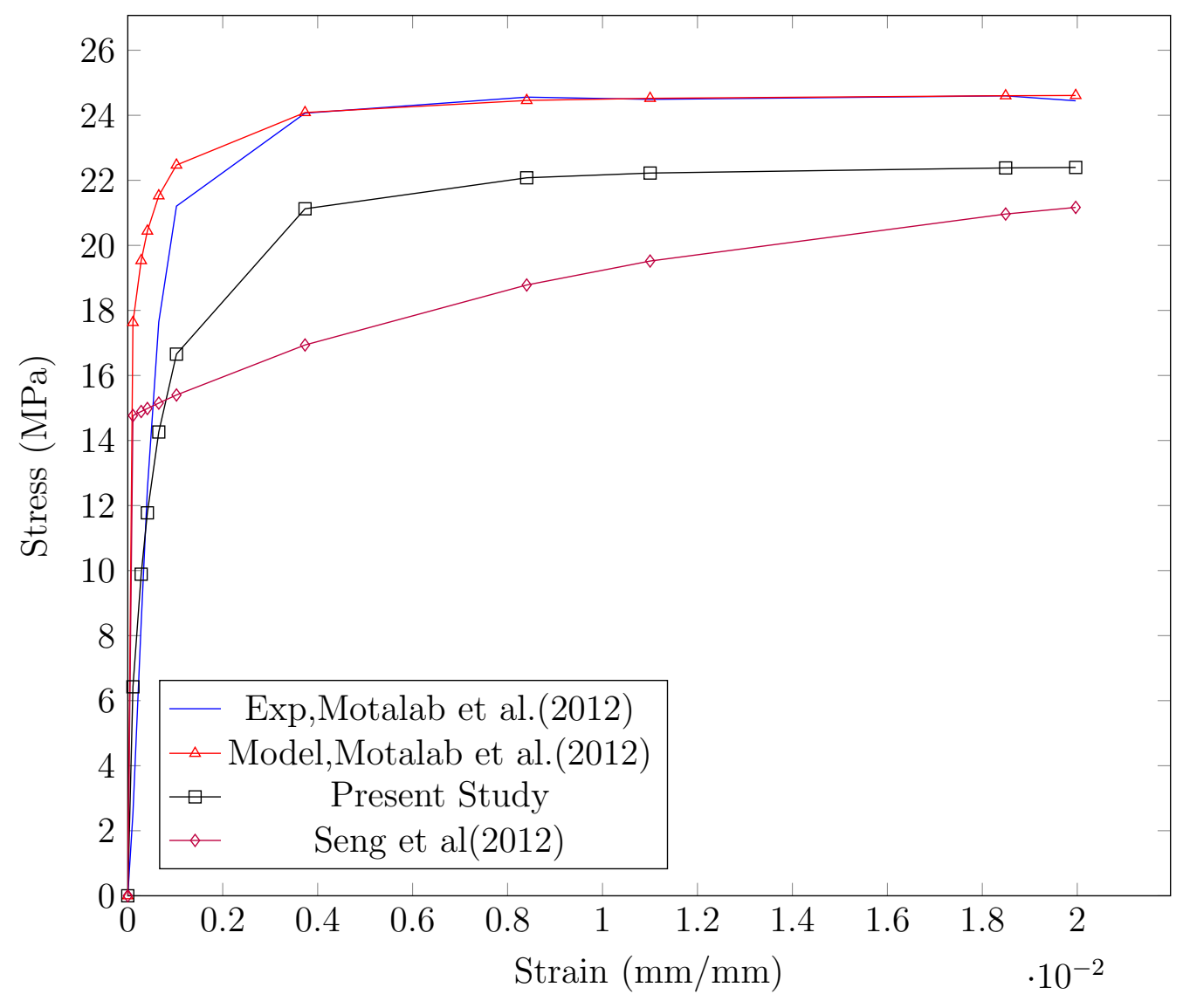

Figure 2.12: Stress vs Strain at 323K and strain rate of .00001/s 


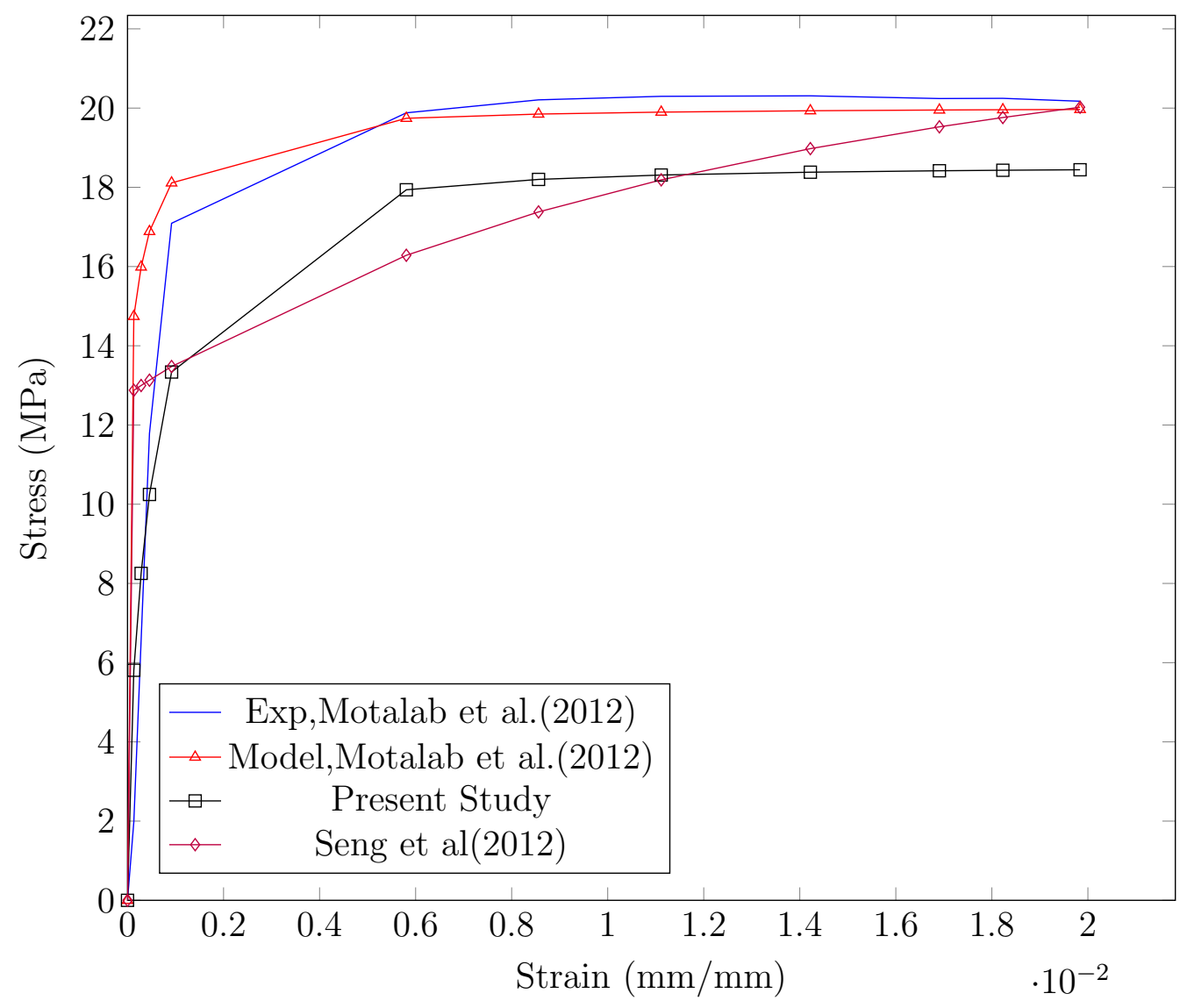

Figure 2.13: Stress vs Strain at 348K and strain rate of .00001/s 


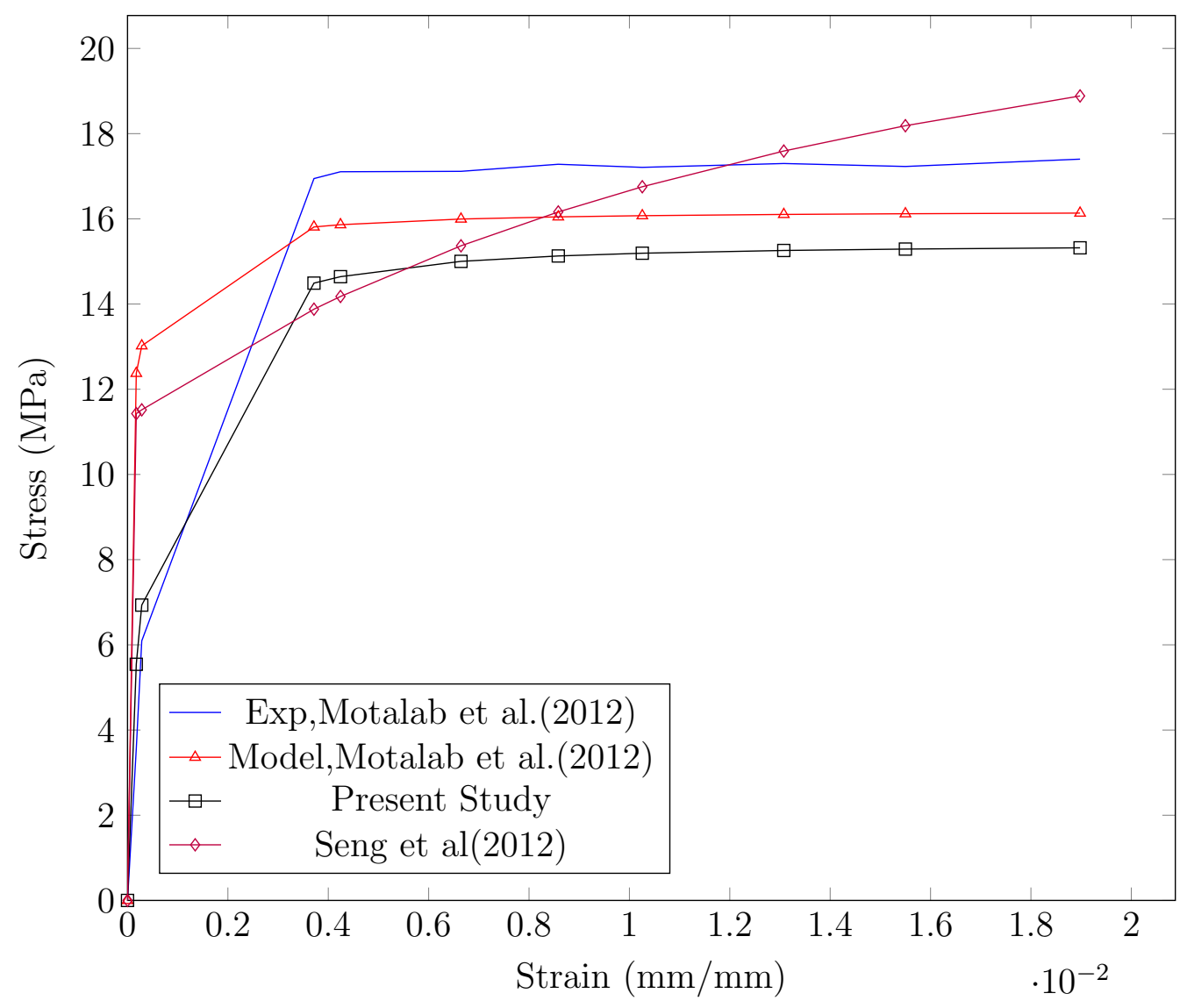

Figure 2.14: Stress vs Strain at 373K and strain rate of .00001/s 


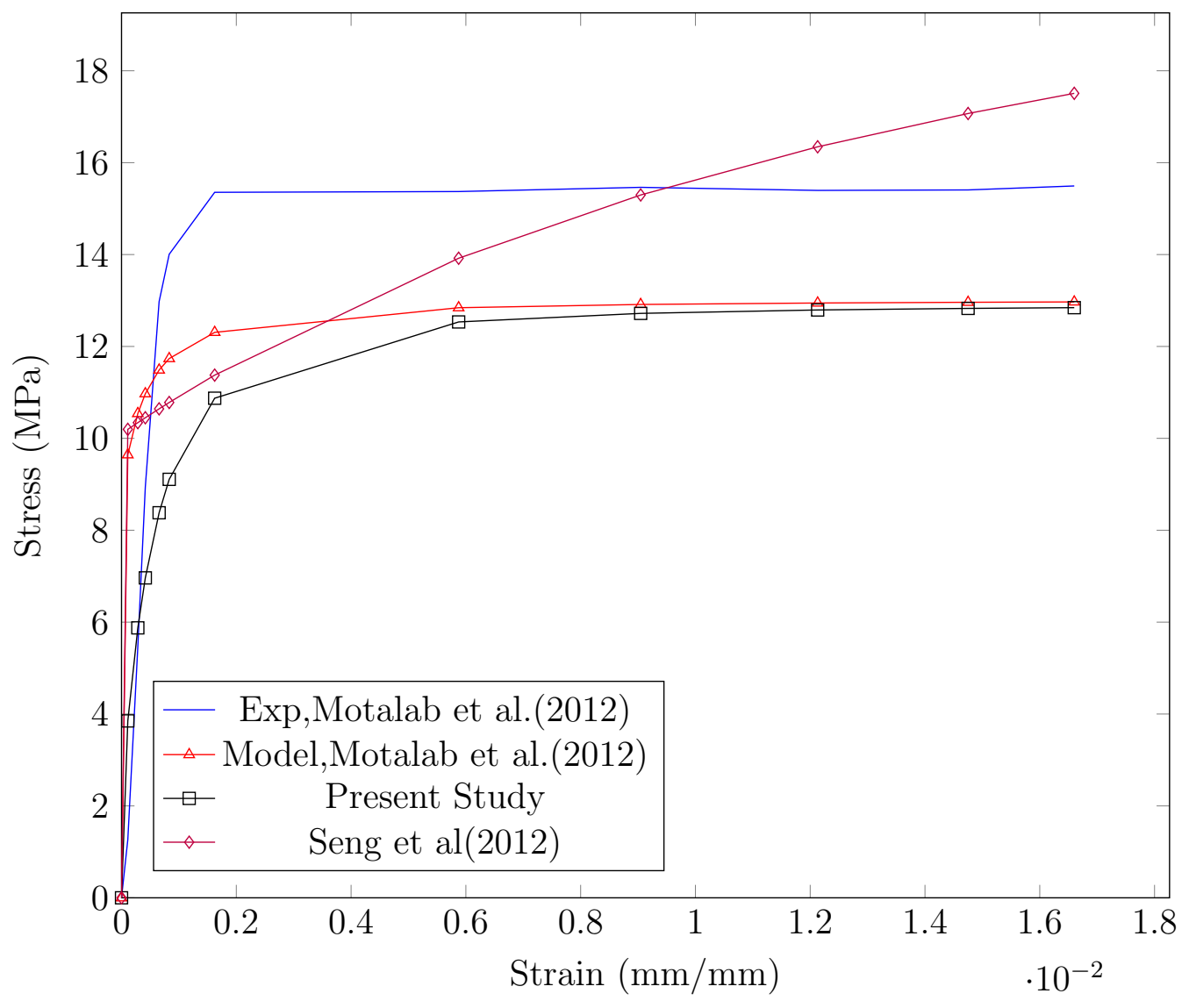

Figure 2.15: Stress vs Strain at 398K and strain rate of .00001/s 


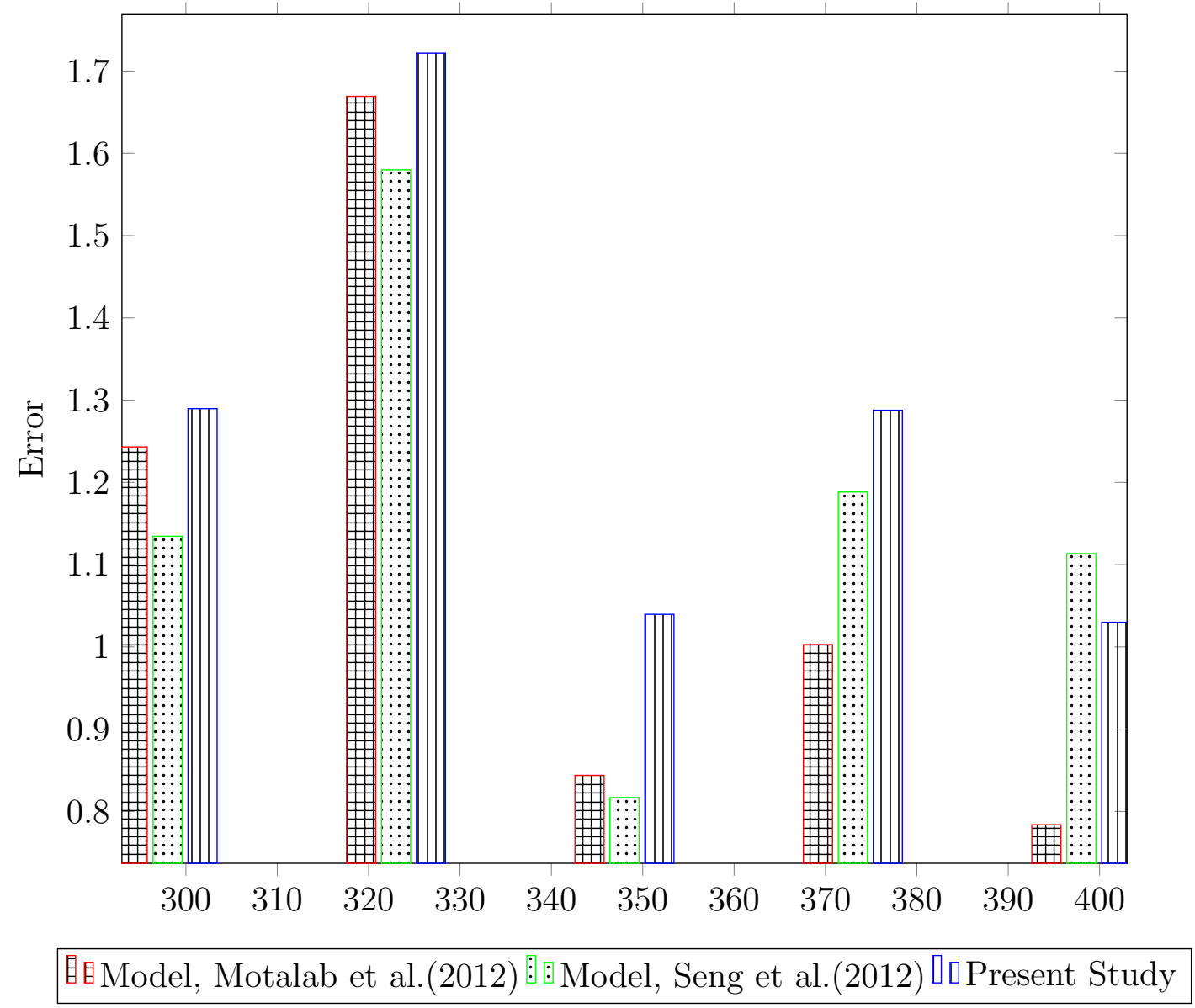

Figure 2.16: Error between Anand parameters and Experimental Data at strain rate of .001/s vs Temperature(K) 


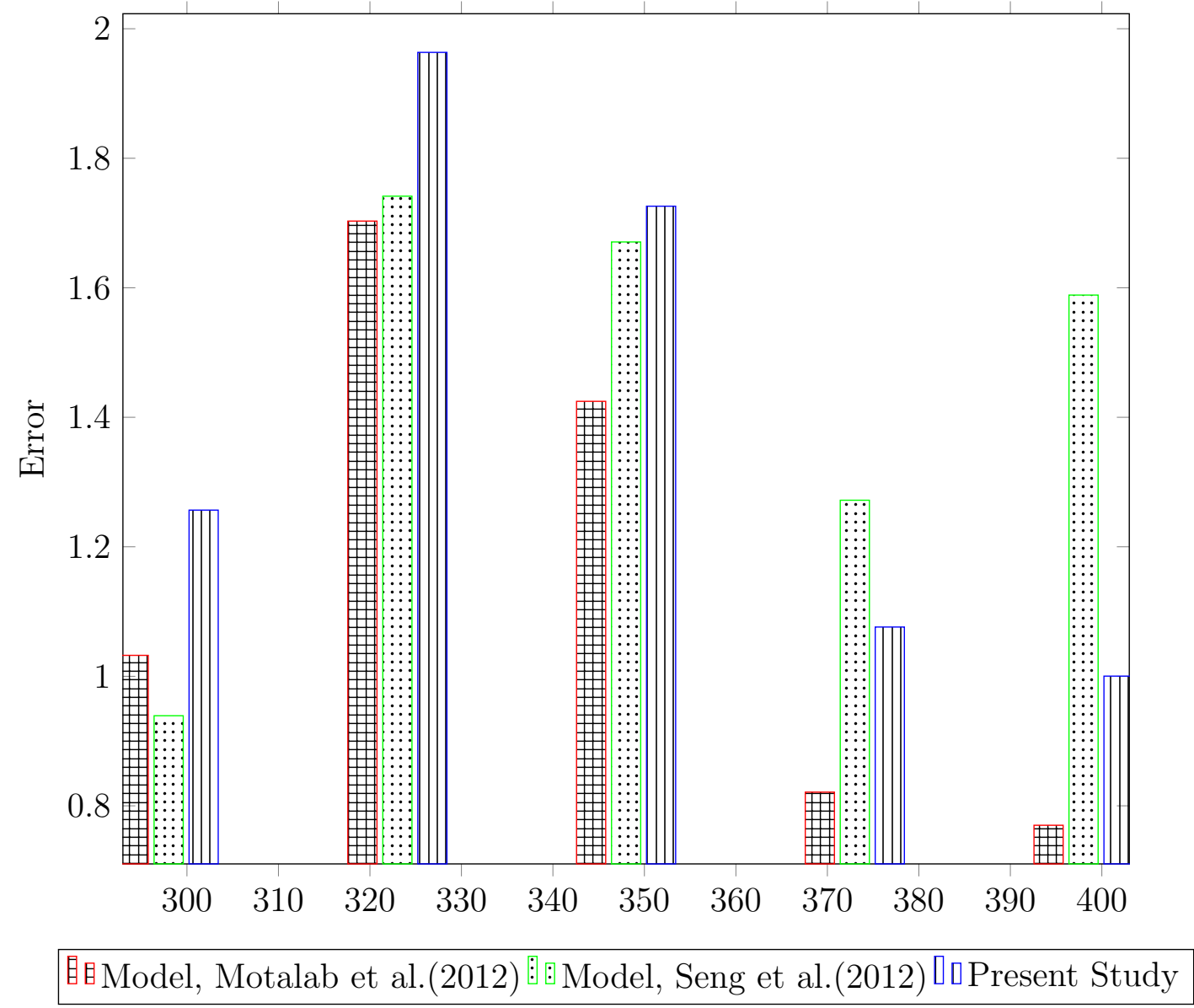

Figure 2.17: Error between Anand parameters and Experimental Data at strain rate of .0001/s vs Temperature(k) 


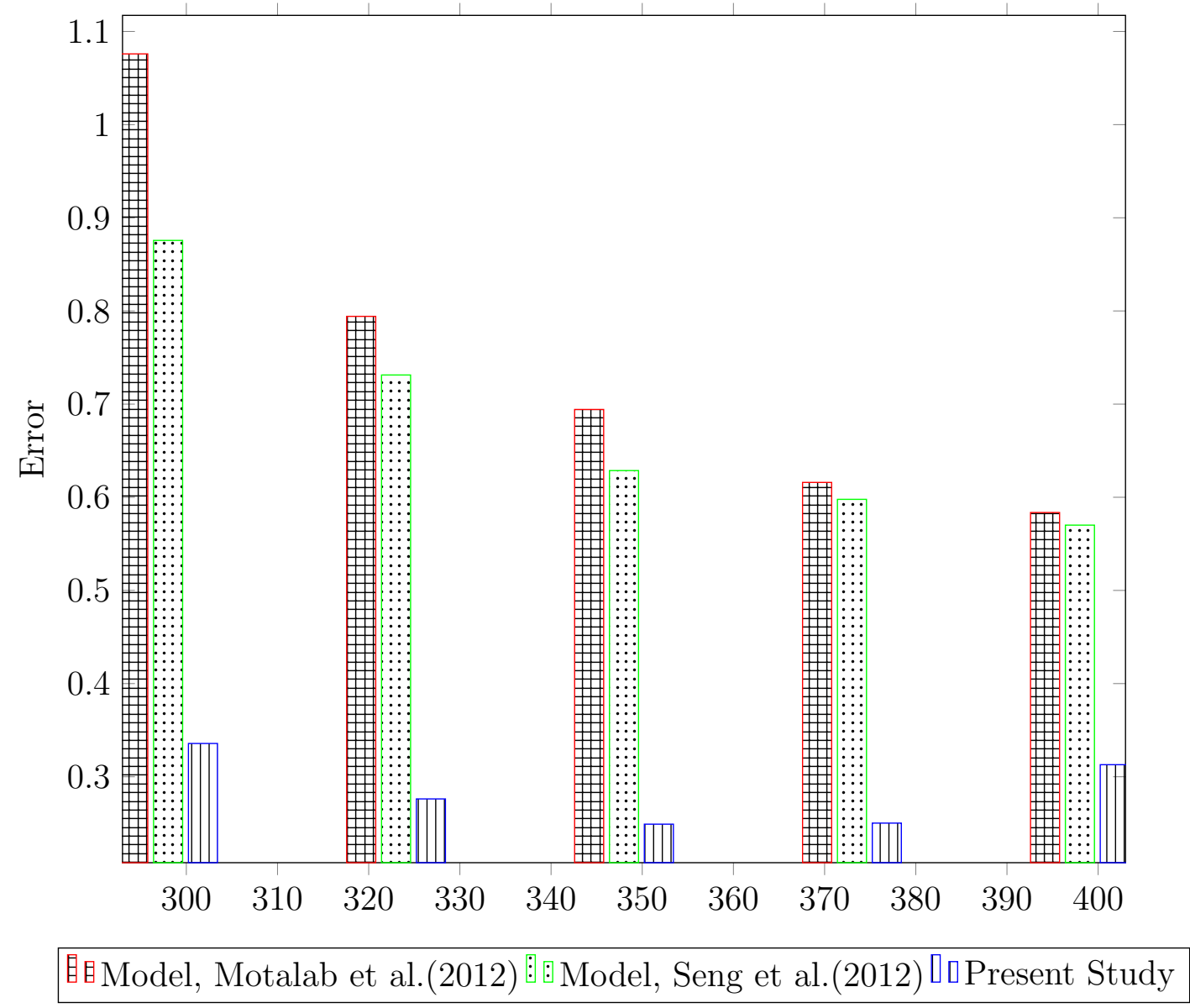

Figure 2.18: Error between Anand parameters and Experimental Data at strain rate of $.00001 / \mathrm{s}$ vs Temperature(K) 


\section{Chapter 3}

\section{Simulation}

\subsection{Finite Element Model}

A simple Ball Grid Array (BGA) package is considered for the study.

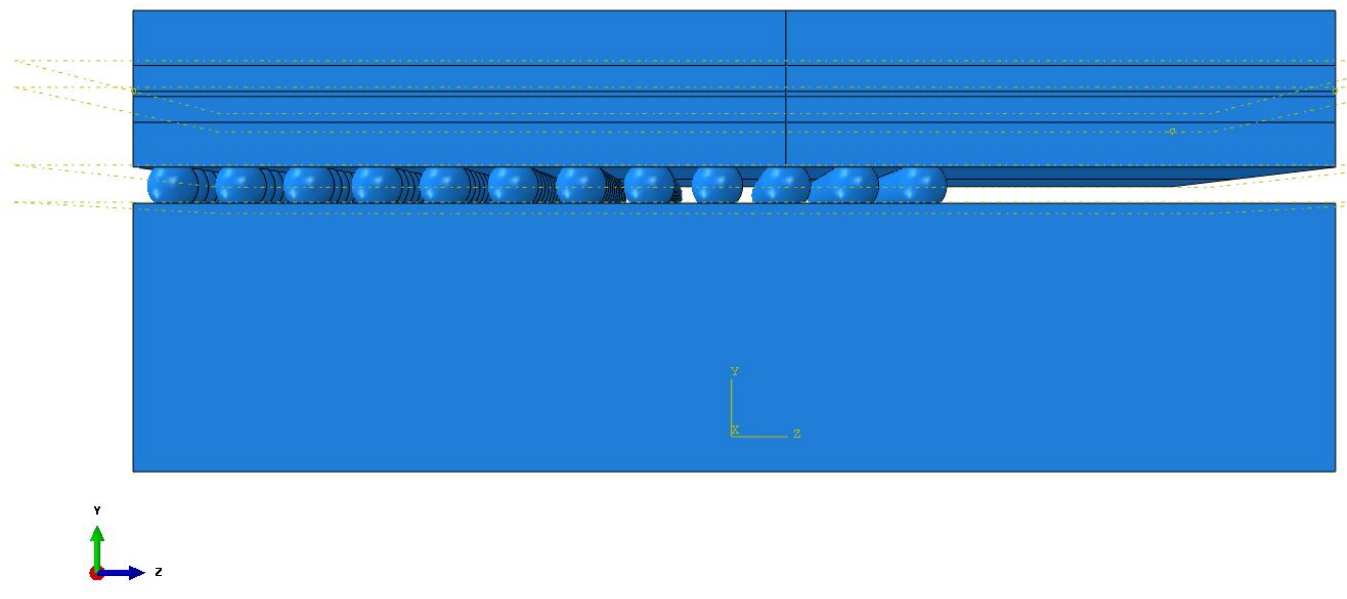

Figure 3.1: Embedded device geometry used for analysis

Individual parts were created on SolidWorks and assembled in ABAQUS. Due to geometric symmetry about the y-axis (vertical axis) only a quarter of the device is modeled to save computational time and cost. The Assembly is meshed using the 8-node linear brick element with reduced integration (C3D8R). Substrate and PCB (Printed Circuit Board) are assumed to be orthotropic due to their laminate structure and are identical in the $\mathrm{x}$ and $\mathrm{z}$ direction. Solder Joint is assumed to have both elastic and viscoplastic mechanical properties. All other elements of the package are assumed 
to be elastic and isotropic [9].

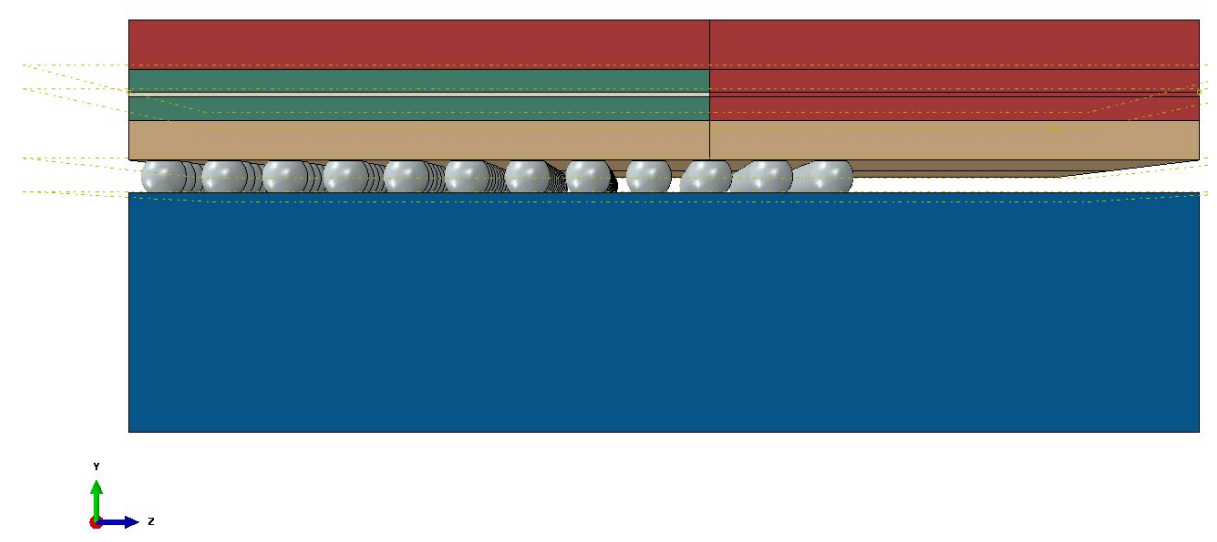

Figure 3.2: Sections of Embedded device geometry used for analysis

The parts of the embedded device were color coded to show the elements of the package. Blue part is the PCB, Red (Molding Compound), Green (Die), White (Die attach), Grey (Solder Joints) and Beige (Substrate).

Table 3.1: Dimensions of Geometry

\begin{tabular}{|l|l|l|l|l|}
\hline \multicolumn{5}{|c|}{ Dimensions } \\
\hline Part & Thickness & Length & Width & \\
\hline Molding Com- & $0.65 \mathrm{~mm}$ & $7 \mathrm{~mm}$ & $7 \mathrm{~mm}$ & \\
pound & & & & \\
Die & $0.12 \mathrm{~mm}$ & $3.8 \mathrm{~mm}$ & $3.8 \mathrm{~mm}$ & \\
Substrate & $0.26 \mathrm{~mm}$ & $7 \mathrm{~mm}$ & $7 \mathrm{~mm}$ & \multirow{2}{*}{ Pitch= } \\
Solder joints & $0.21 \mathrm{~mm}$ & $0.3 \mathrm{~mm}$ & $0.3 \mathrm{~mm}$ & $0.4 \mathrm{~mm}$ \\
& & & $7 \mathrm{~mm}$ & \\
PCB & $1.56 \mathrm{~mm}$ & $7 \mathrm{~mm}$ & 7 & \\
\hline
\end{tabular}


Table 3.2: Material Properties

\begin{tabular}{|l|l|l|l|l|}
\hline \multicolumn{5}{|c|}{ Material Properties } \\
\hline Material & $\begin{array}{l}\text { Young's Modu- } \\
\text { lus (Mpa) }\end{array}$ & $\begin{array}{l}\text { Poisson's } \\
\text { Ratio }\end{array}$ & CTE(ppm/K) & $\begin{array}{l}\text { Additional informa- } \\
\text { tion }\end{array}$ \\
\hline $\begin{array}{l}\text { Molding- } \\
\text { compound }\end{array}$ & 15000 & 0.3 & 16 & \\
\hline Die & $1.305 \mathrm{e} 5$ & 0.2785 & $2.78343 \mathrm{e}-6$ & $\begin{array}{l}200 \mathrm{~K} \\
\end{array}$ \\
& & & $3.0004 \mathrm{e}-6$ & $250 \mathrm{~K}$ \\
& $1.298 \mathrm{e} 5$ & 0.2782 & $3.14811 \mathrm{e}-6$ & $293 \mathrm{~K}$ \\
& & & $3.16888 \mathrm{e}-6$ & $300 \mathrm{~K}$ \\
& $1.298 \mathrm{e} 5$ & 0.278 & $3.30238 \mathrm{e}-6$ & $350 \mathrm{~K}$ \\
& $\mathrm{x}=26000$ & $\mathrm{x}, \mathrm{z}=0.11$ & $\mathrm{x}=15$ & $400 \mathrm{~K}$ \\
\hline Substrate & $\mathrm{z}=26000$ & $\mathrm{x}, \mathrm{y}=0.11$ & $\mathrm{z}=15$ & $\mathrm{G}_{x y}(M p a)=8250$ \\
& $\mathrm{y}=78600$ & $\mathrm{z}, \mathrm{y}=0.3$ & $\mathrm{y}=57$ & $\mathrm{G}_{y z}(M p a)=8250$ \\
& 50439 & 0.36 & $2.42 \mathrm{e}-5$ & $218 \mathrm{~K}$ \\
Solder ball 5 & 0.36 & $2.56 \mathrm{e}-5$ & $300 \mathrm{~K}$ \\
Sn3Ag0.5Cu & 41419 & 0.36 & $2.79 \mathrm{e}-5$ & $398 \mathrm{~K}$ \\
(SAC305) & 30639 & $\mathrm{x}, \mathrm{z}=0.11$ & $\mathrm{x}=14.5$ & $\mathrm{G}_{x y}(M p a)=5535$ \\
\hline PCB & $\mathrm{x}=18000$ & $\mathrm{x}, \mathrm{y}=0.11$ & $\mathrm{z}=14.5$ & $\mathrm{G}_{y z}(M p a)=5535$ \\
& $\mathrm{z}=18000$ & $\mathrm{z}, \mathrm{y}=0.39$ & $\mathrm{y}=67.2$ & $\mathrm{G}_{x z}(M p a)=11712$ \\
\hline Die attach & 1800 & 0.3 & $80 \mathrm{e}-6$ & \\
\hline
\end{tabular}




\subsubsection{Temperature Cycles}

Solder joints experience both rate-independent plastic behavior and creep (timedependent strain), when exposed to thermal cycling. During fast temperature ramp rates the stress and strain on the solder joints increase due to the solder's rate dependent behavior. During temperature ramp up and down, creep develops. Therefore temperature profile is important to the lifetime of the solder joint.

JEDEC 'Condition G' profile is used as the temperature profile for this study. with temperature $(\mathrm{T})$ ranging from $T_{\text {initial }}=25^{\circ} \mathrm{C}, T_{\text {high }}=125^{\circ} \mathrm{C}, T_{\text {low }}=-40^{\circ} \mathrm{C}$, dwell time $=10 \mathrm{mins}$ and ramp-rate of $10\left({ }^{\circ} \mathrm{C} / \mathrm{min}\right)$.

"JEDEC" is an independent semiconductor engineering trade organization and standardization body, and Condition $\mathrm{G}$ profile is commonly used for reliability studies. The absolute melting temperature of the SAC305 solder joint is $T_{m}=490 K\left(217^{\circ} \mathrm{C}\right)$ therefore the maximum temperature in the JEDEC condition G profile works. 


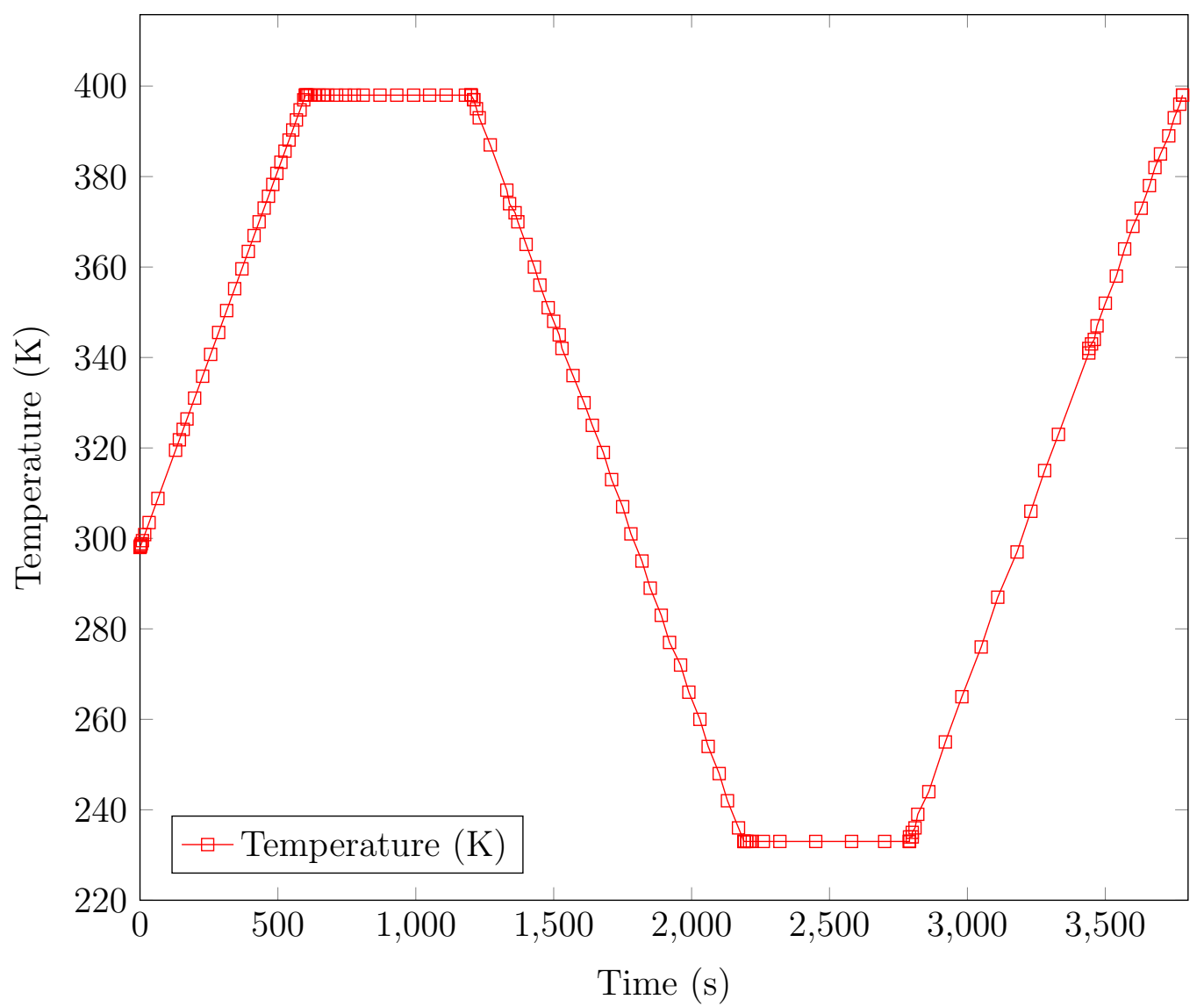

Figure 3.3: Temperature Cycle vs Time(s)

\subsubsection{Finite Element Modeling}

A global model is created to identify the location of the critical joint. A fixed boundary condition ( $\mathrm{U} 1=\mathrm{U} 2=\mathrm{U} 3=0)$ is applied at the bottom edge of the $\mathrm{PCB}$, and a symmetric boundary condition about the $\mathrm{x}$-axis $(\mathrm{U} 1=\mathrm{UR} 2=\mathrm{UR} 3=0)$ and z-axis $(\mathrm{U} 3=\mathrm{UR} 1=\mathrm{UR} 2=0)$. The temperature is set to be initially at room temperature $\mathrm{T}_{\text {initial }}=25^{\circ} \mathrm{C}$. 


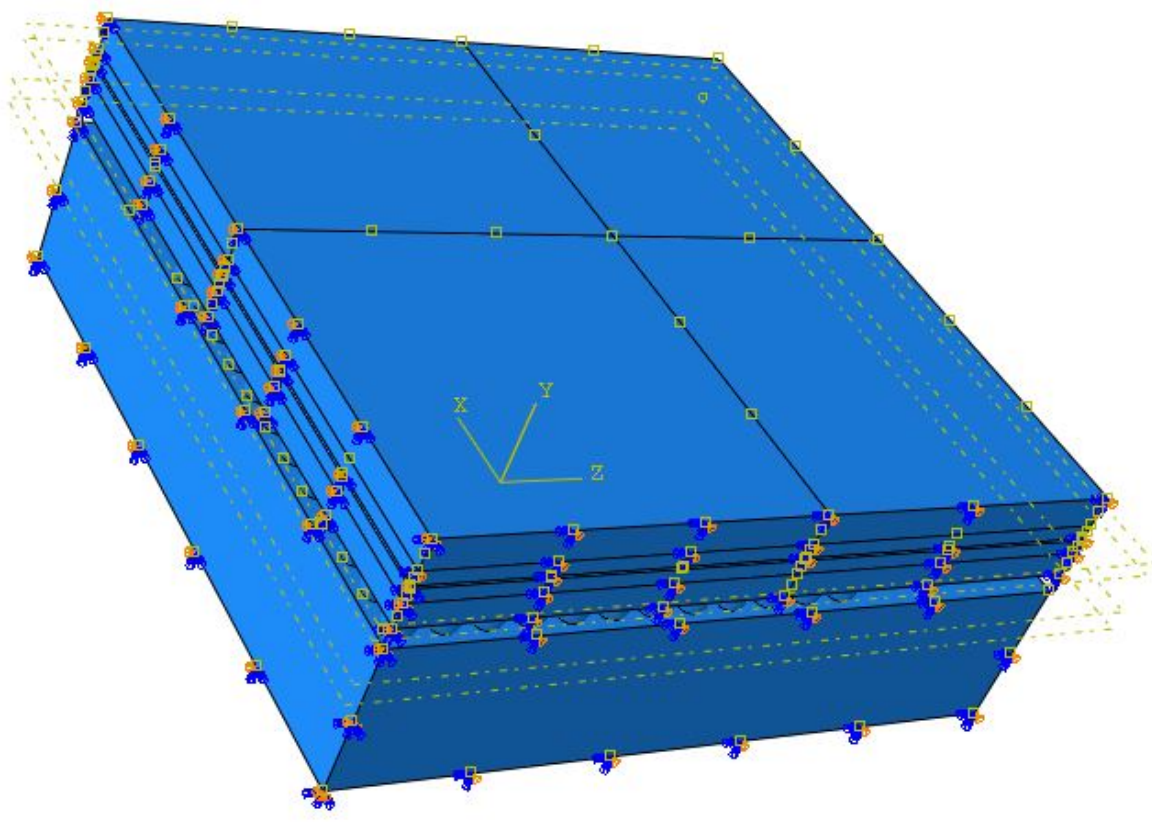

Figure 3.4: Boundary condition applied to embedded device

\section{Sine Hyperbolic law}

The sine hyperbolic law is used to model the creep behavior of the solder joint. The sine hyperbolic creep law is a simplified version of the Anand model. It approximates the steady state (secondary) creep. Anand parameters for this present study are seen in Table 2.1

Sine Hyperbolic creep law

$$
\epsilon_{c r}^{\cdot}=A(\sinh B \tilde{q})^{n}
$$

Anand Model

$$
\dot{\epsilon}_{p}=A e^{\left(-\frac{Q}{R T}\right)}\left[\sinh \left(\xi \frac{\sigma}{s}\right)\right]^{\frac{1}{m}}
$$




\section{Chapter 4}

\section{Results}

The solder joint is numbered for easy identification. The columns goes from column A- L and rows from 1-12

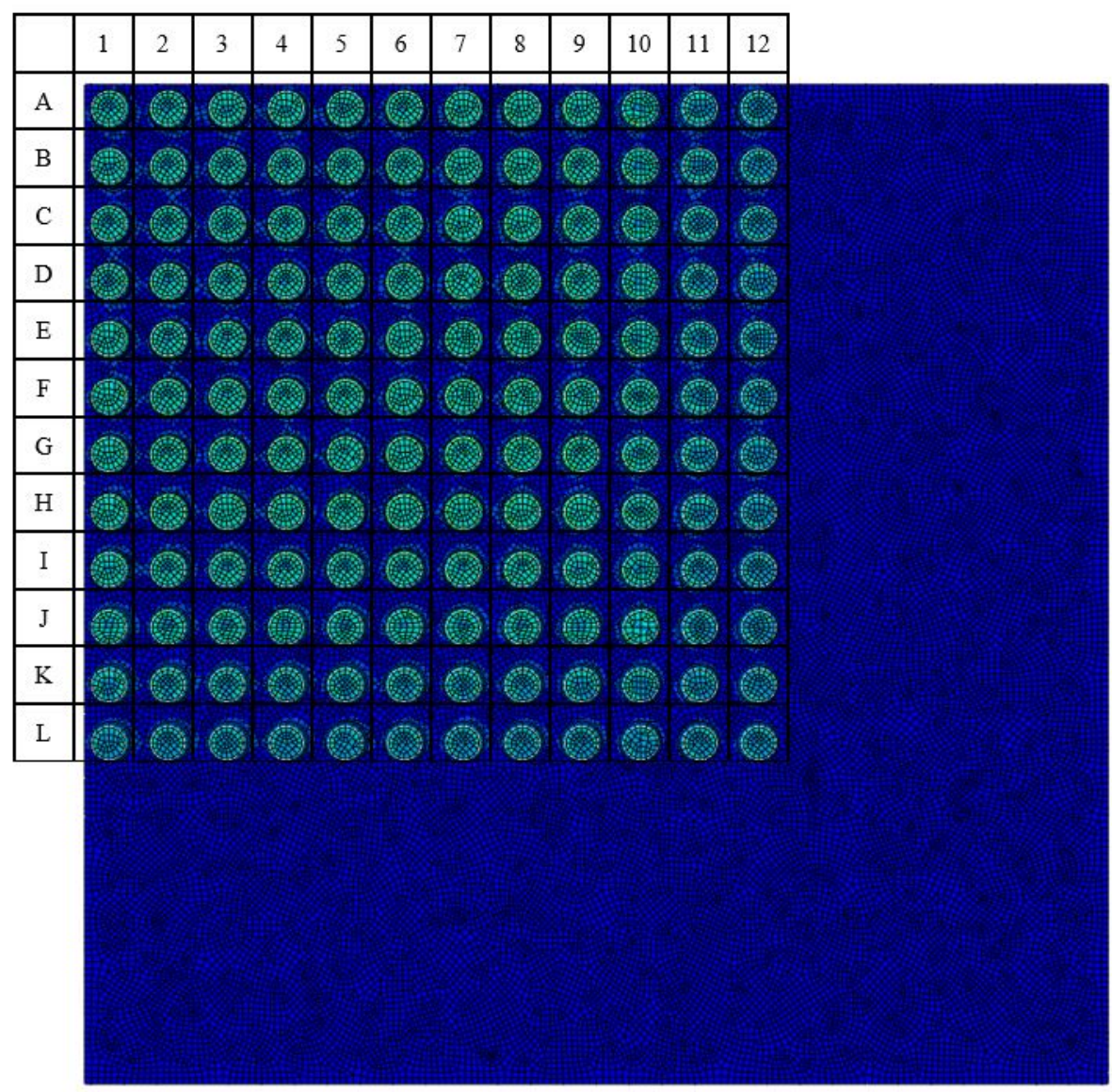

Figure 4.1: Numbering(Identifying) Solder joint 

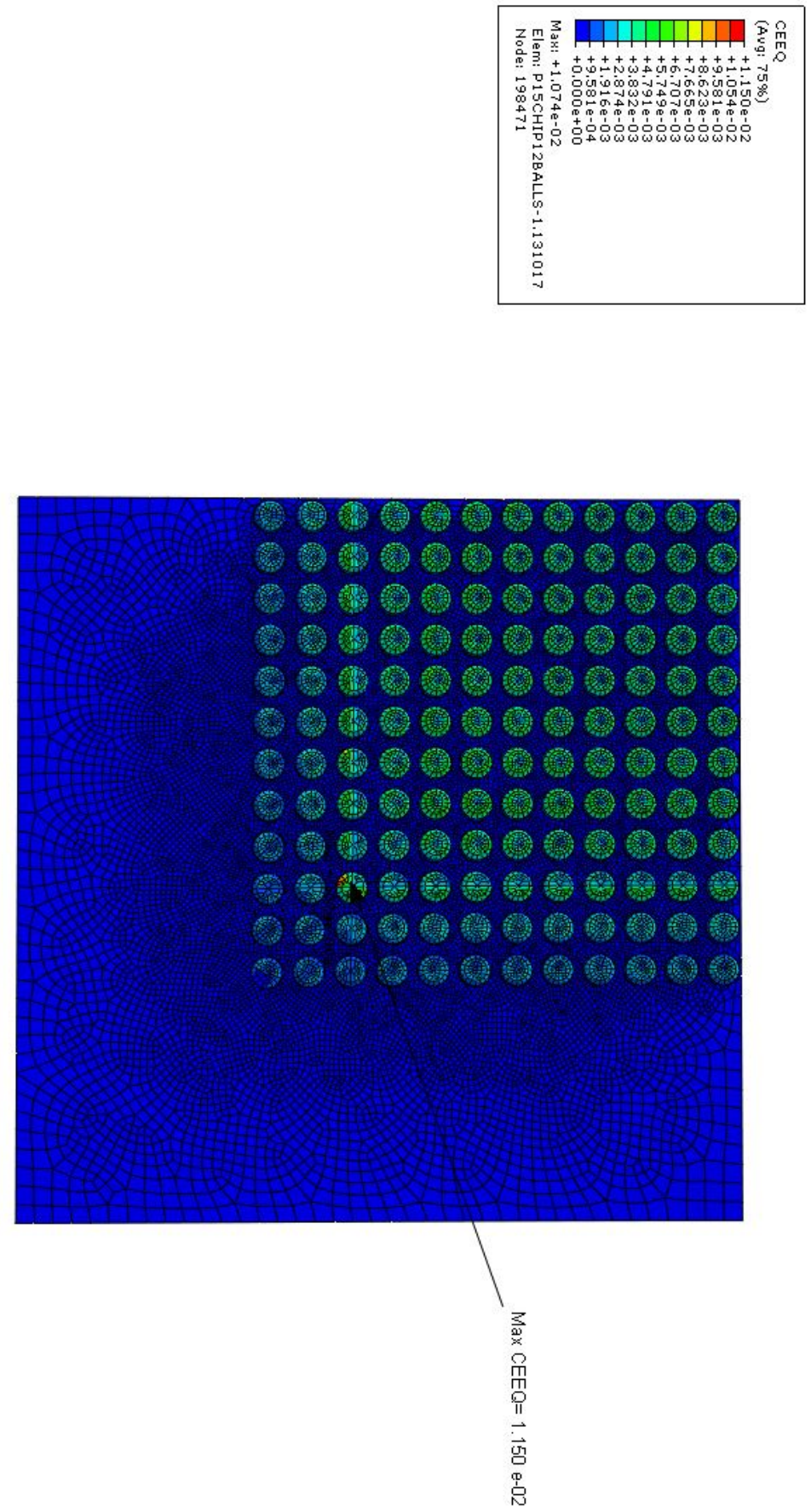

Figure 4.2: Solder joint on PCB

As shown in the above diagram critical solder joint is located at the top corner of the $J 10^{\text {th }}$ solder joint underneath the die, with maximum equivalent creep strain of .01150. 
The results below show the six components of stress in a three dimensional casethree normal stresses which are S11, S22, and S33 or Sxx, Syy, Szz and the shear stress components S12, S13, S23 or Sxy, Sxz, and Syz. These stress values show the magnitude of stress imposed on the $J 10^{\text {th }}$ (critical) solder joint and when the joint experiences tensile and compressive stress in the case of the normal stress. 


\subsection{Case 1 (2 Dies in the molding compound both $.12 \mathrm{~mm})$}

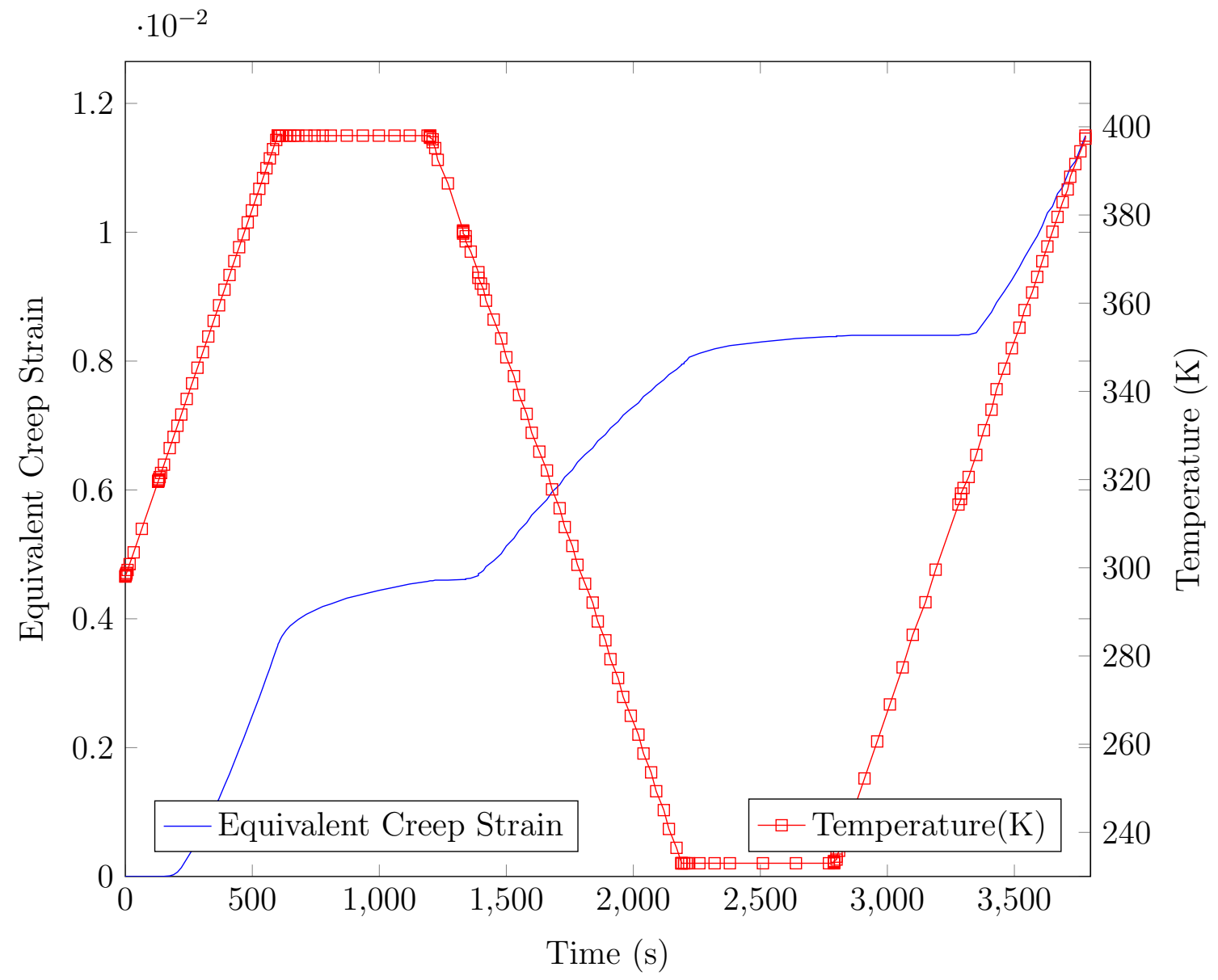

Figure 4.3: Creep Strain on Solder joint J10, Temperature Cycle vs Time(s)

Equivalent Creep Strain amplitude is $0.00358 \mathrm{~mm} / \mathrm{mm}$. It remains slightly constant during dwell time and increases during temperature ramp up and ramp down. It can be seen that when homologous temperature, actual temperature/melting temperature is greater than 0.4 creep increases rapidly. While it increases at a very slow pace at higher homologous temperatures. 


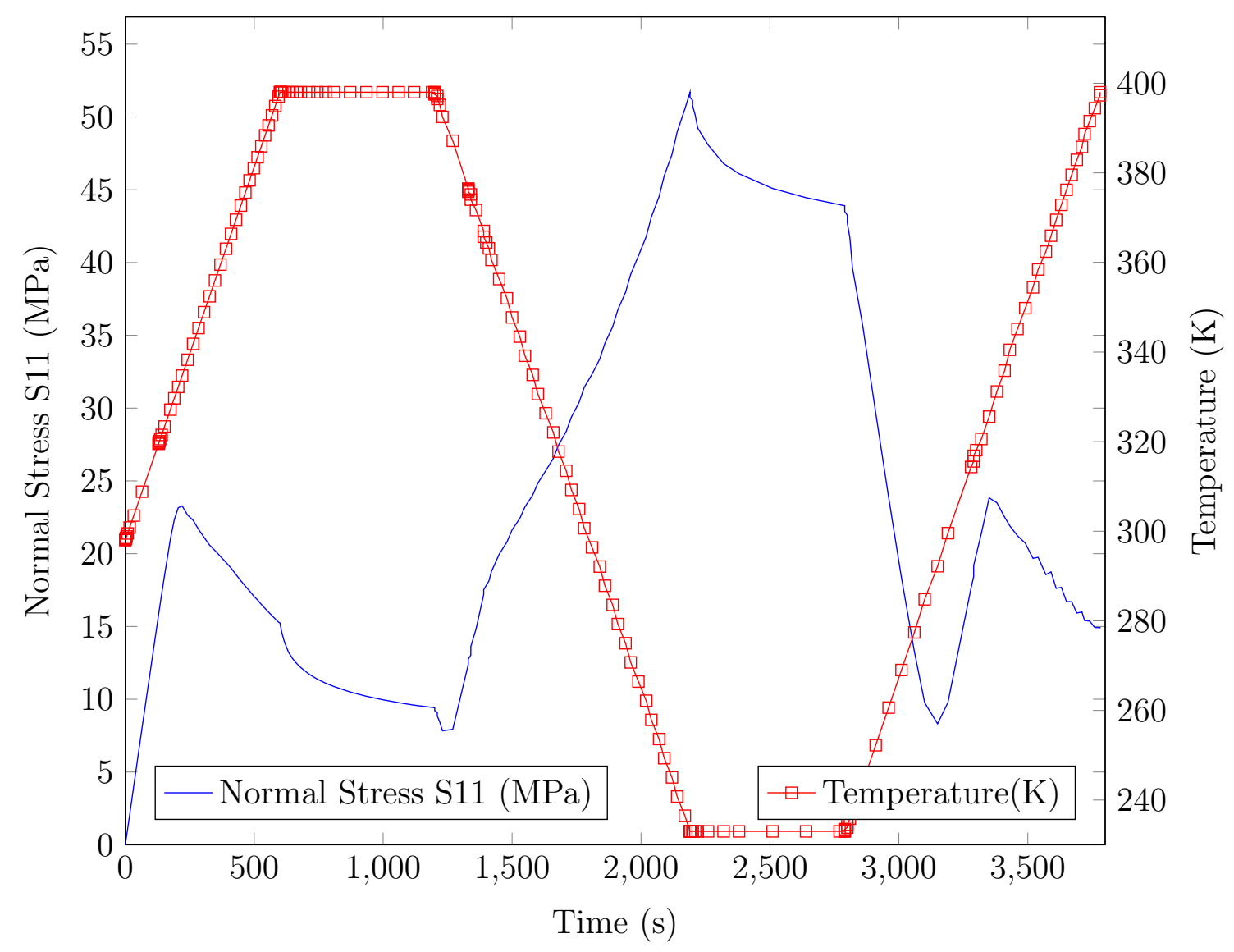

Figure 4.4: Normal Stress (S11) on Solder joint J10, Temperature Cycle vs Time(s)

The $J 10^{t h}$ solder joint mostly experiences tensile force in this cycle, the magnitude of stress is positive. 


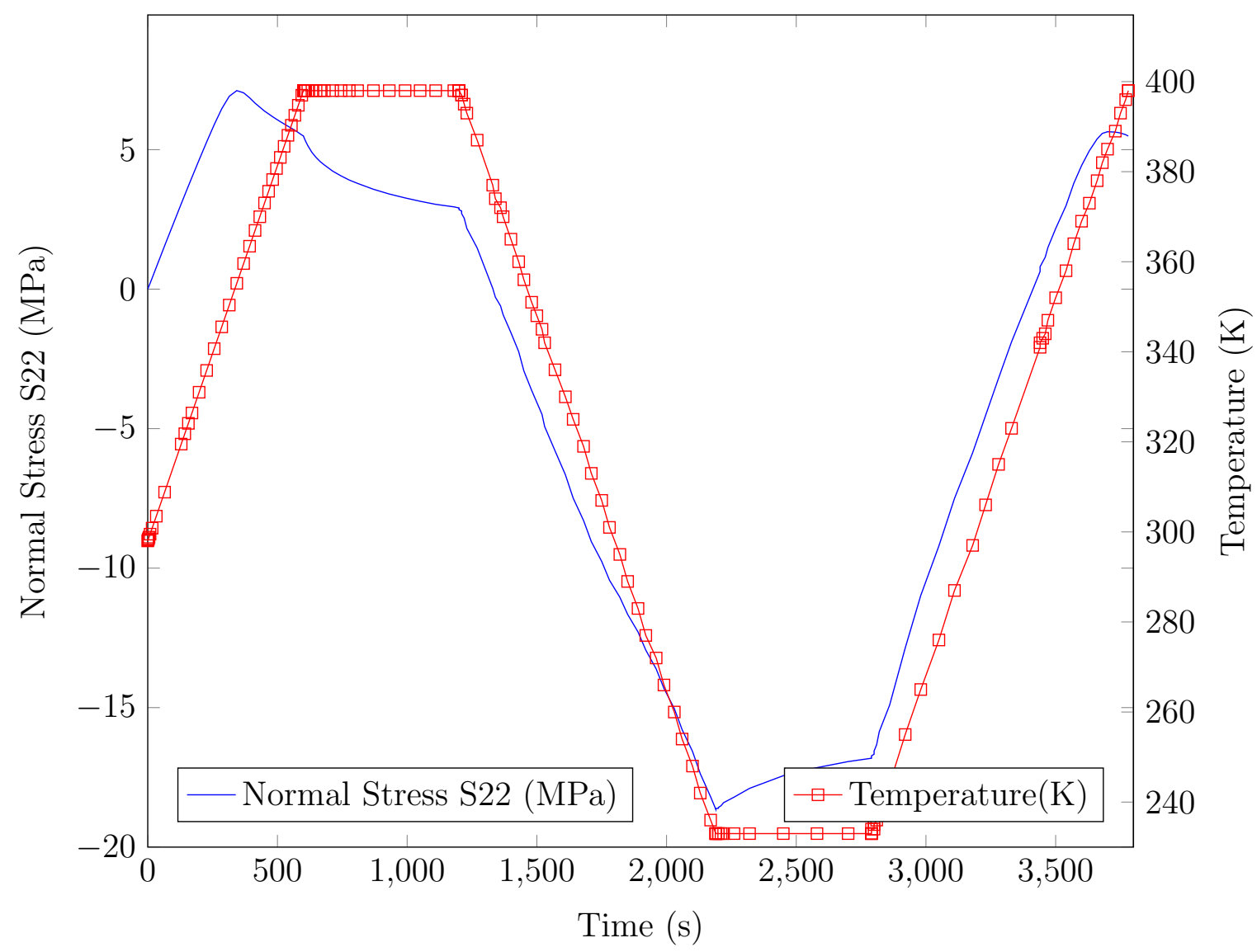

Figure 4.5: Normal Stress (S22) on Solder joint J10, Temperature Cycle vs Time(s)

The $J 10^{t h}$ solder joint starts experiencing tensile force and then compression force and goes back to tensile force in this cycle, the behavior of stress changes almost the same as temperature cycle. 


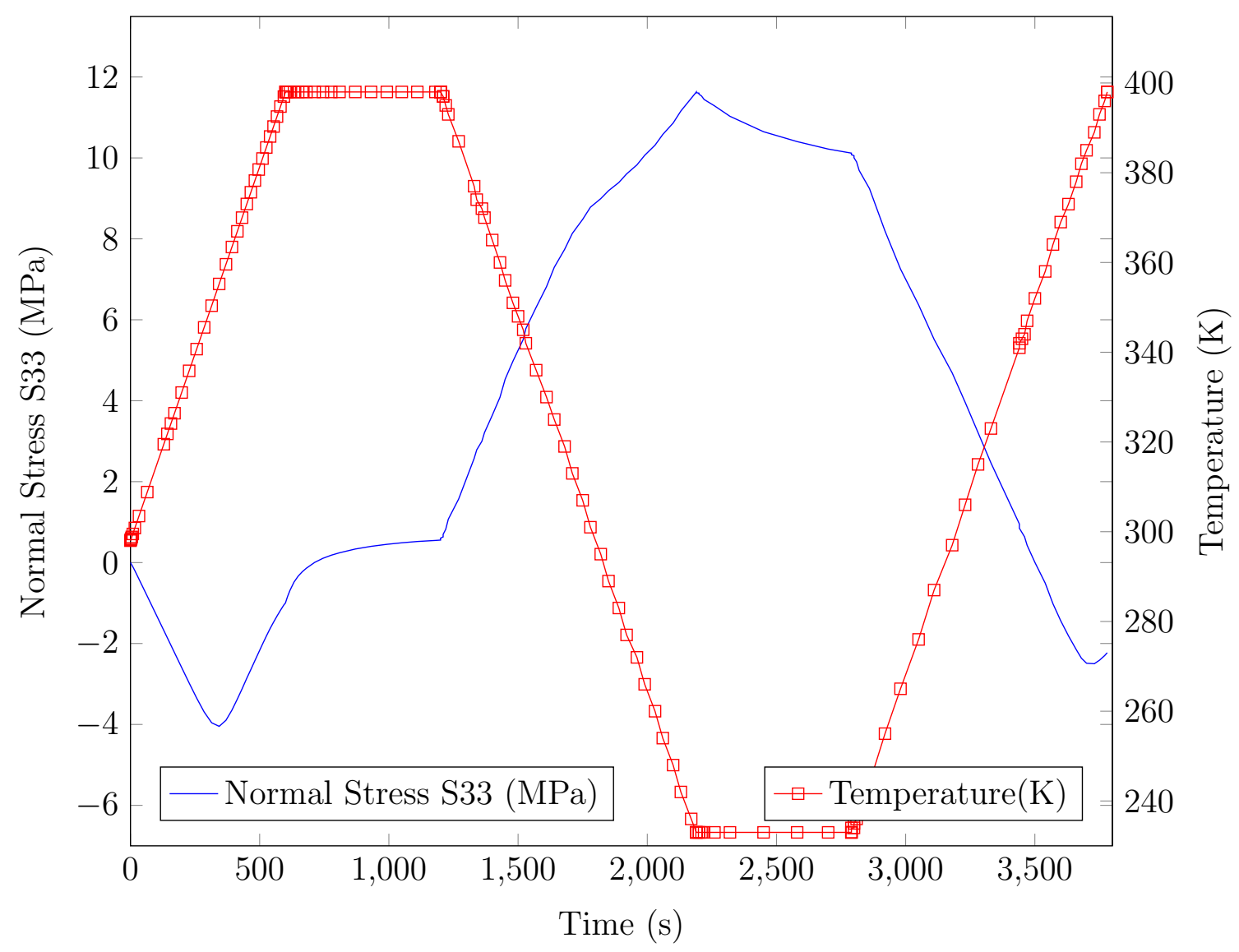

Figure 4.6: Normal Stress (S33) on Solder joint J10, Temperature Cycle vs Time(s)

That the $J 10^{t h}$ solder joint mostly experiences tensile force in this cycle, the magnitude of stress is positive. 


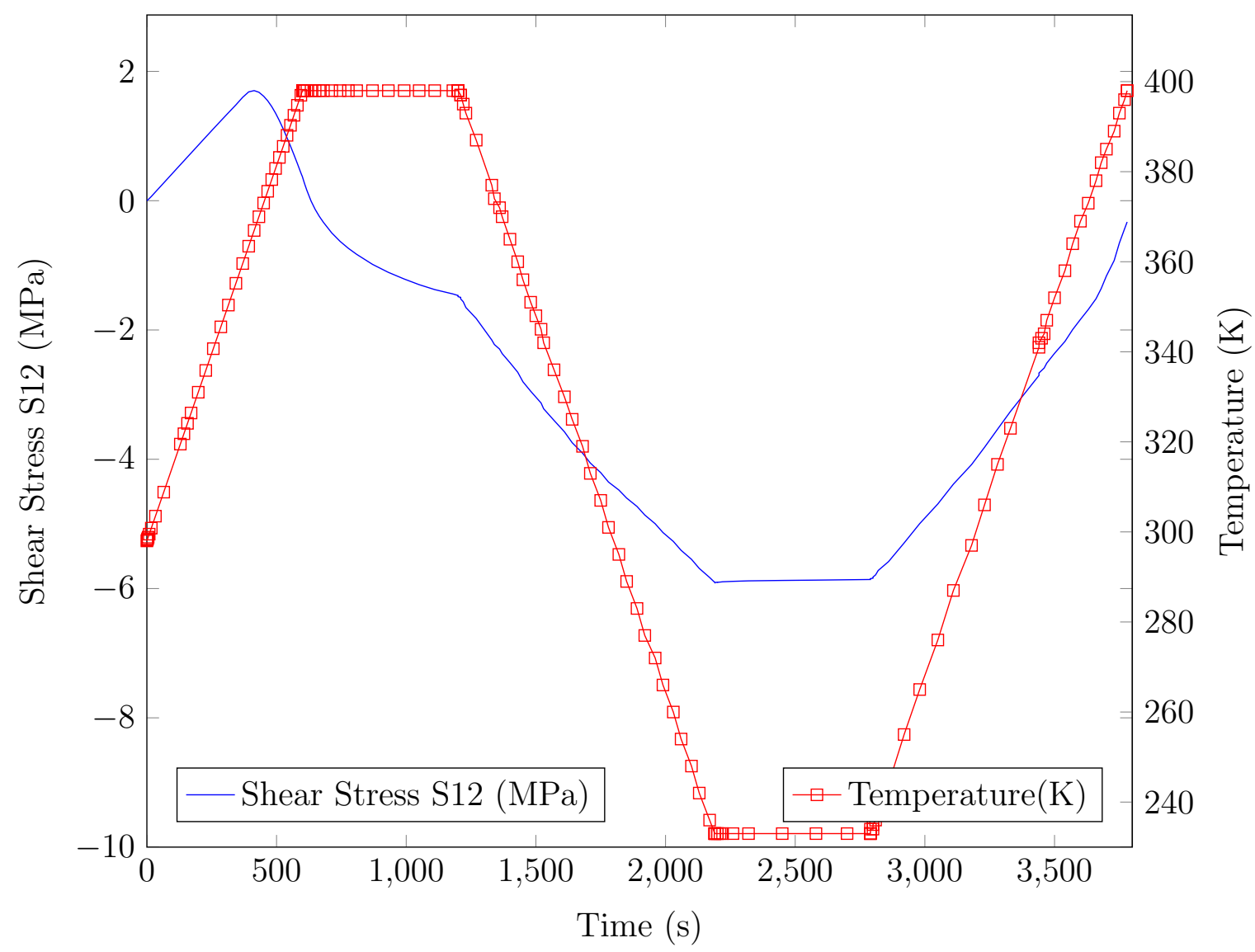

Figure 4.7: Shear Stress (S12) on Solder joint J10, Temperature Cycle vs Time(s)

The magnitude of shear stress in the solder joint during this cycle can be seen to be little. with the highest stress being around $-5.5 \mathrm{Mpa}$ and heading back towards 0 Mpa at the end of the cycle. 


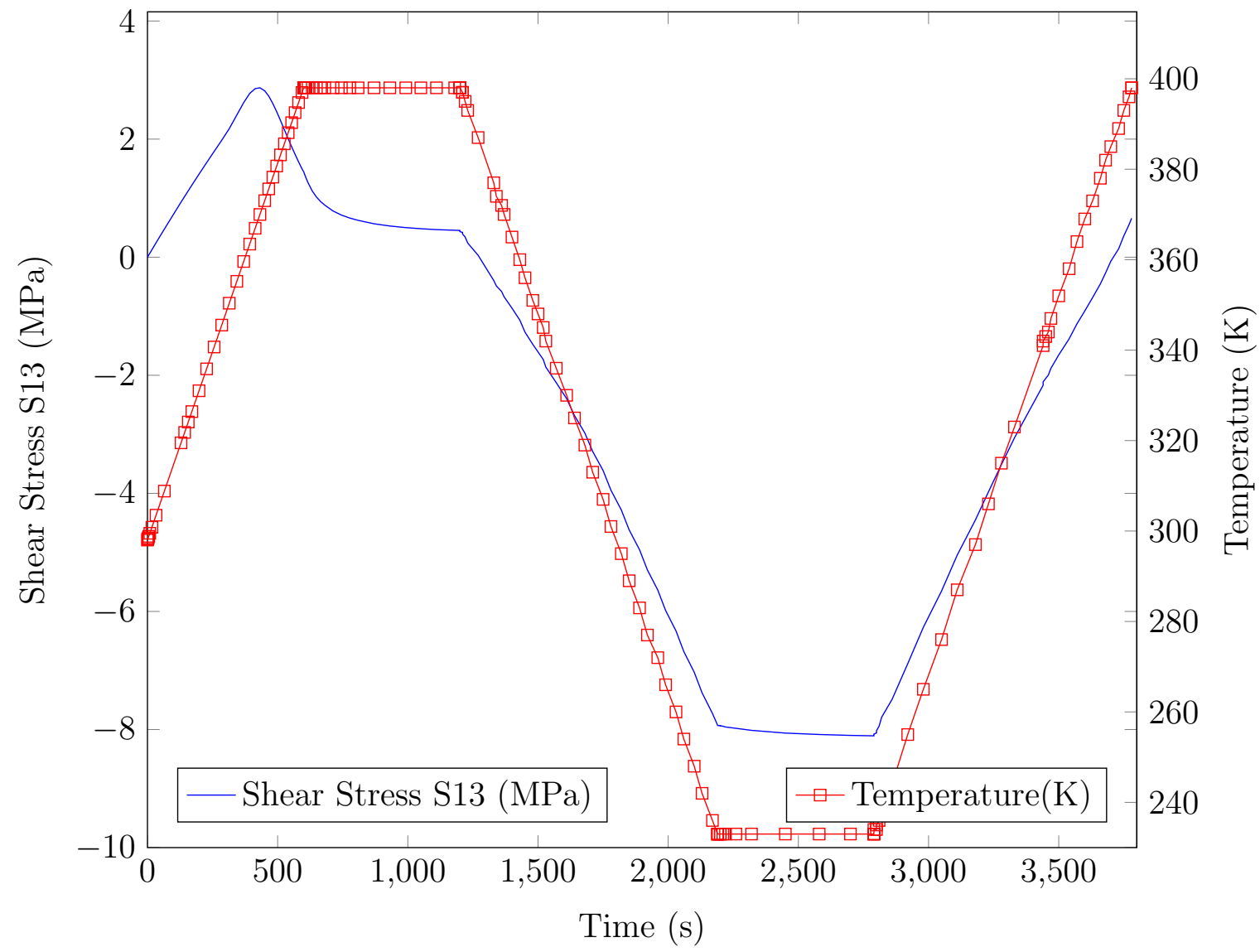

Figure 4.8: Shear Stress (S13) on Solder joint J10, Temperature Cycle vs Time(s)

The shear stress experienced by the solder joint in this cycle is similar to the temperature profile of the cycle. 


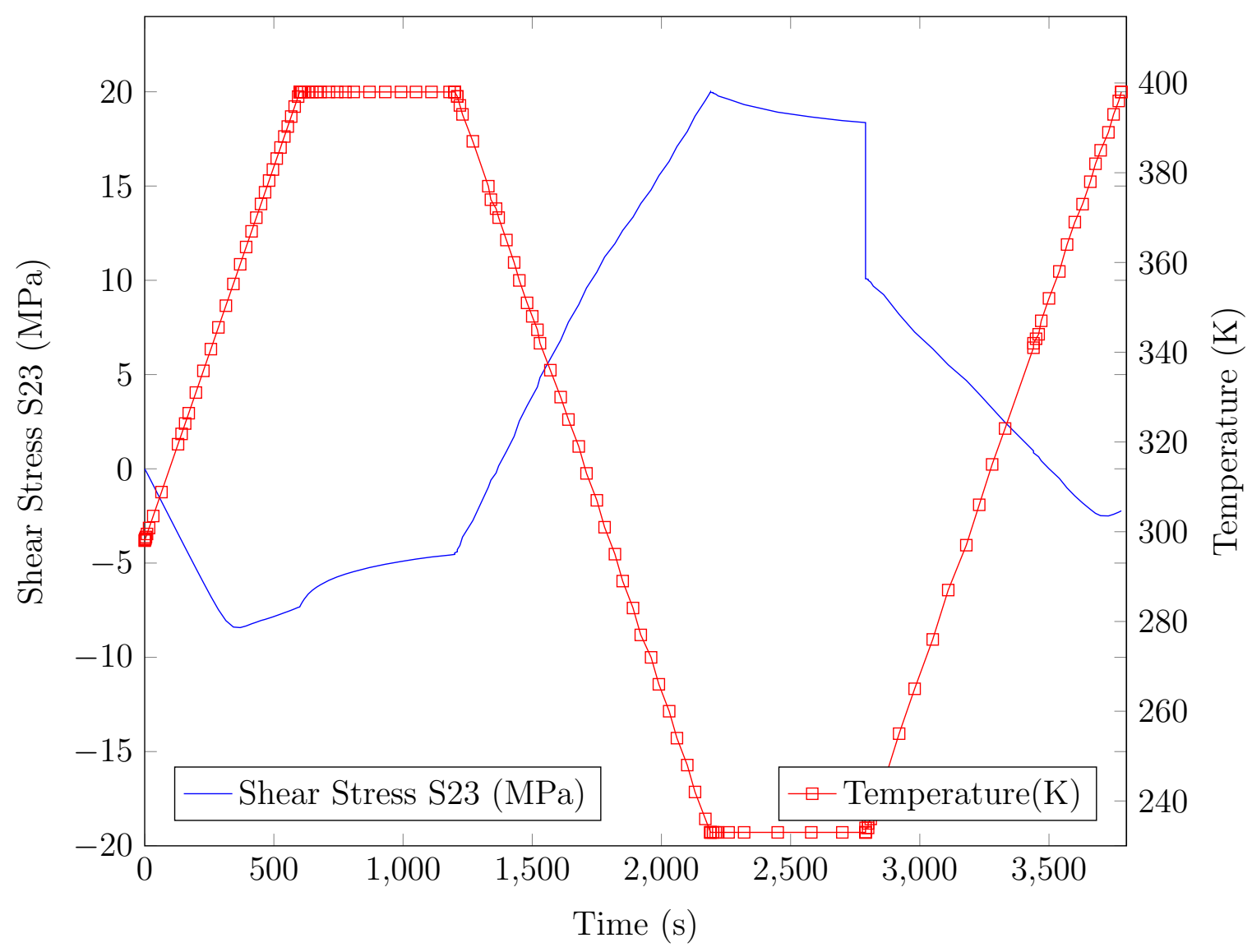

Figure 4.9: Shear Stress (S23) on Solder joint J10, Temperature Cycle vs Time(s)

The shear stress on the $\mathrm{y}-\mathrm{z}$ axis start off in the opposite direction and switches during dwell time. During Dwell time the stress increases at a slower pace than during temperature ramping which is expected. 


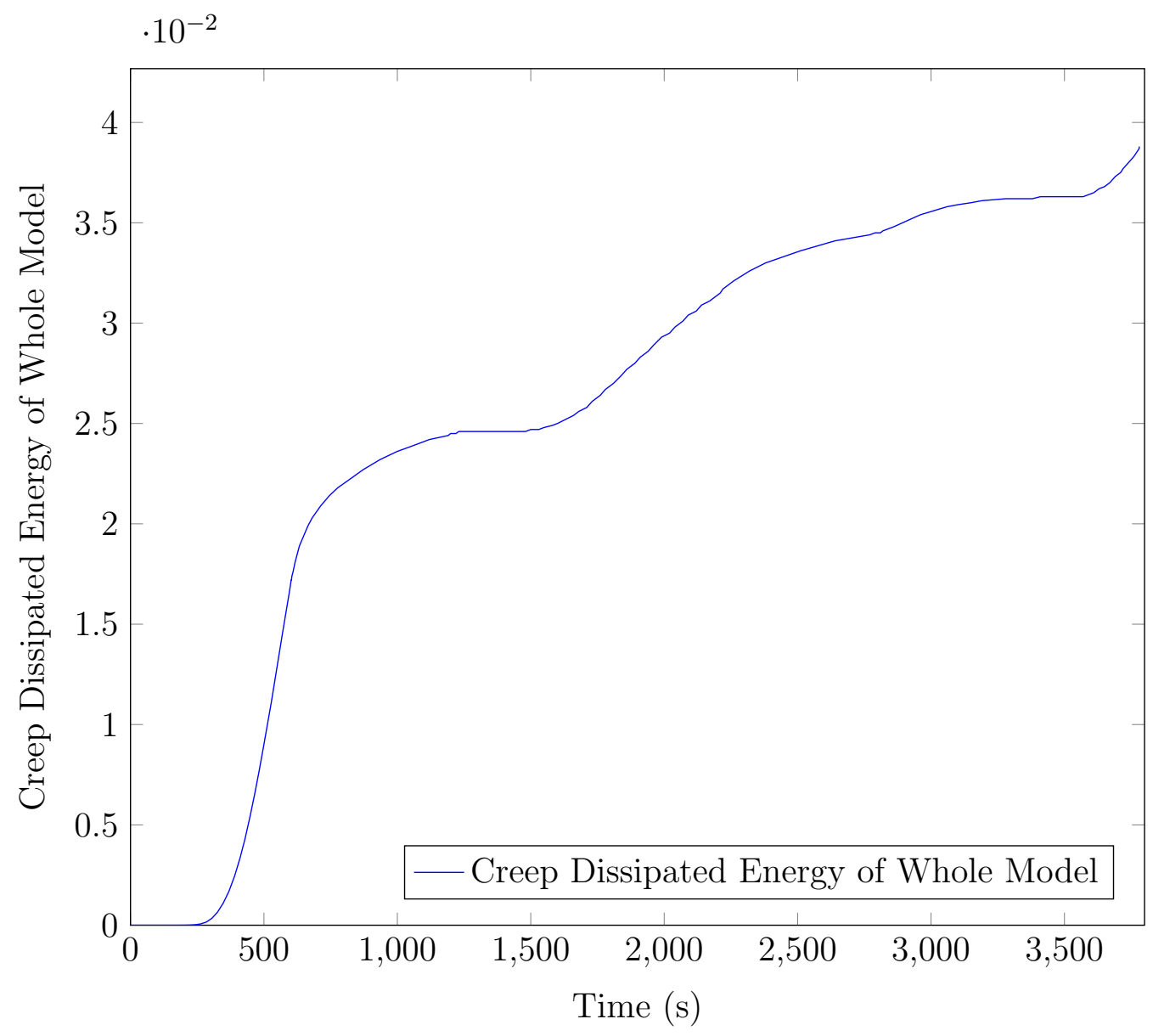

Figure 4.10: Creep Dissipation Energy for the whole model vs Time(S) 


\subsection{Case 2 (2 Dies in the molding compound both $.15 \mathrm{~mm})$}

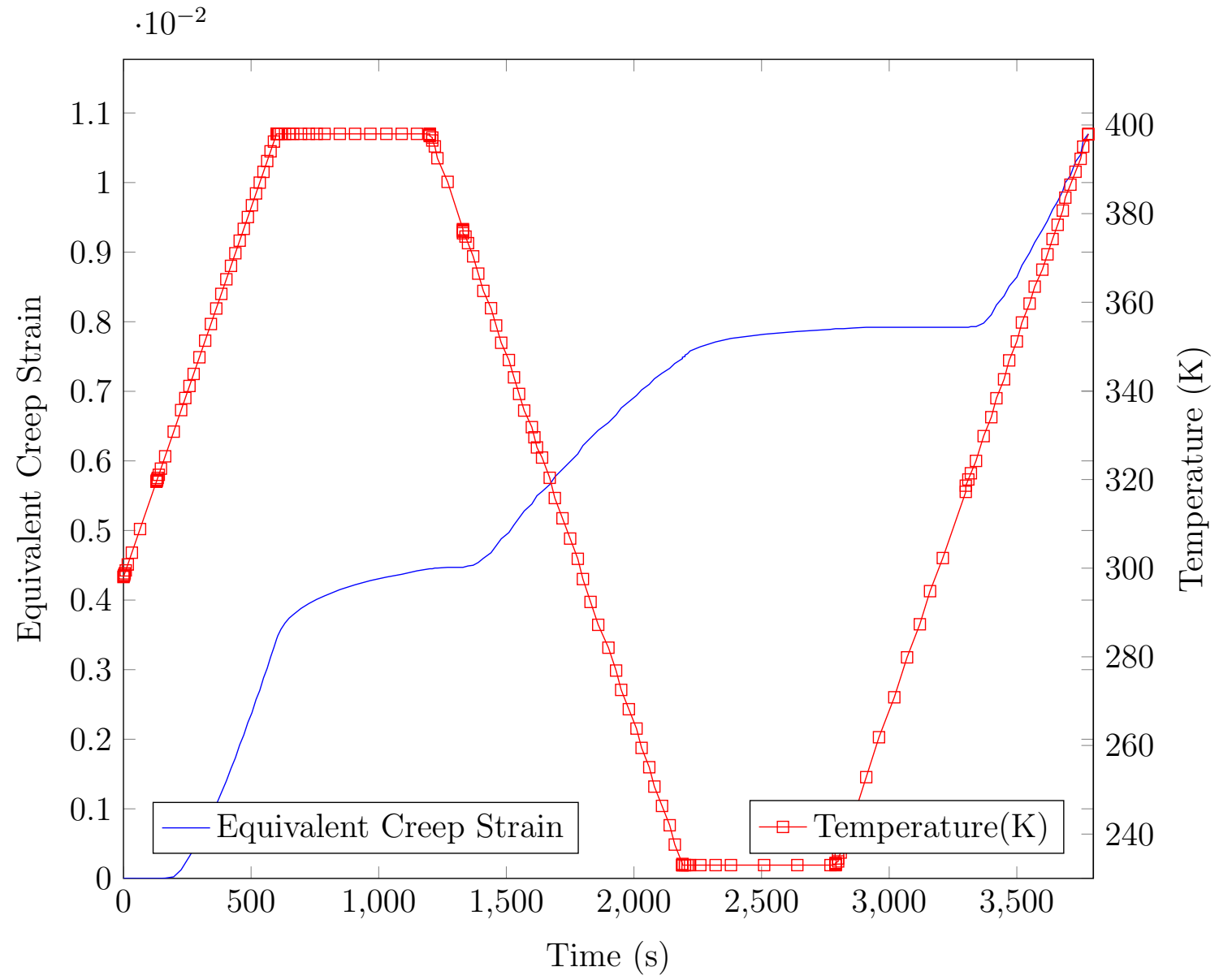

Figure 4.11: Creep Strain on Solder joint J10, Temperature Cycle vs Time(s)

Equivalent Creep Strain amplitude is $0.00344851 \mathrm{~mm} / \mathrm{mm}$. It remains slightly constant during dwell time and increases during temperature ramp up and ramp down. It can be seen that when homologous temperature, actual temperature/ melting temperature is greater than 0.4 creep increases rapidly. While it increases at a very slow pace at higher homologous temperatures. 


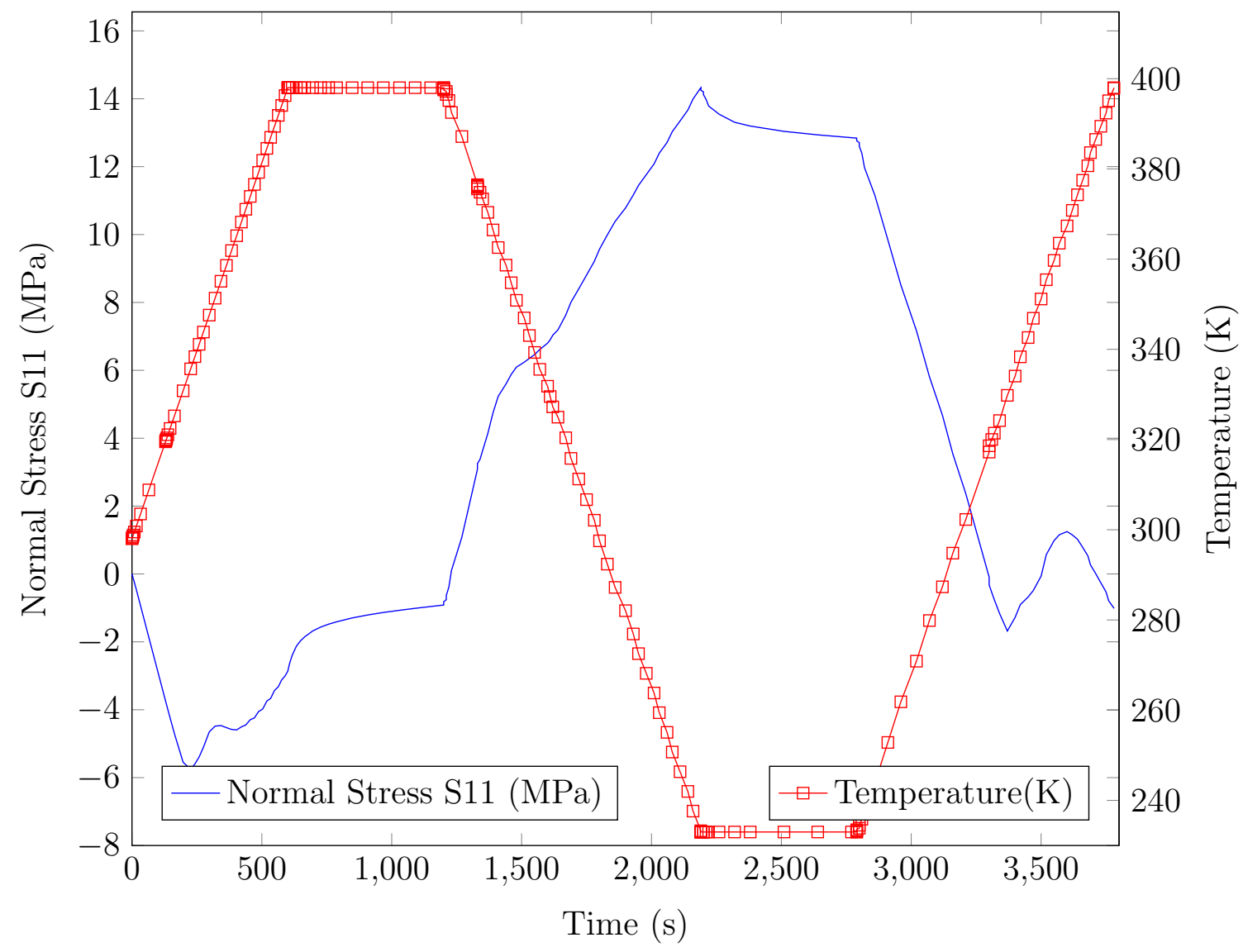

Figure 4.12: Normal Stress (S11) on Solder joint J10, Temperature Cycle vs Time(s)

The solder joint experiences mostly tensile force, the behavior of the stress is opposite the behavior of the temperature cycle. 


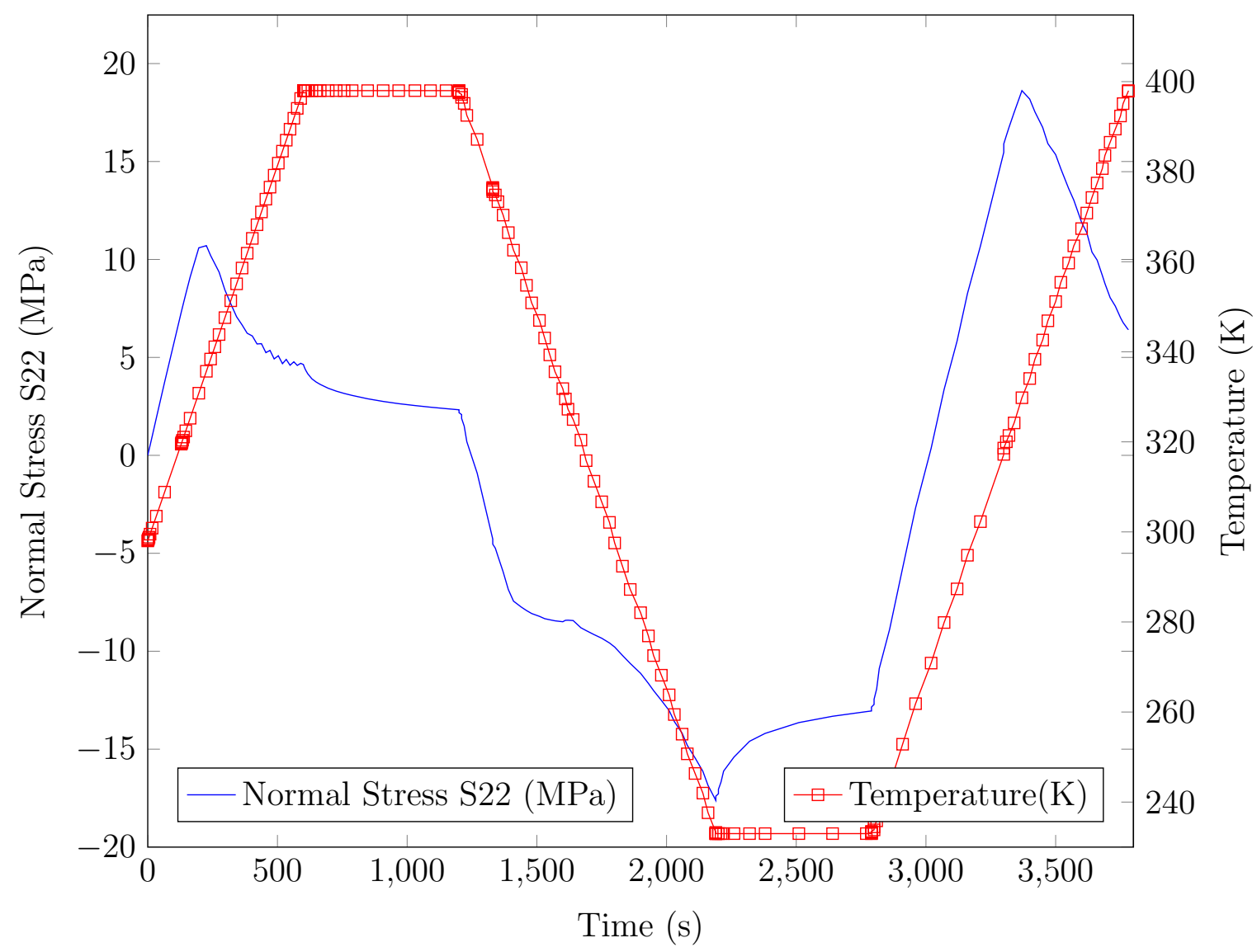

Figure 4.13: Normal Stress (S22) on Solder joint J10, Temperature Cycle vs Time(s)

The $J 10^{t h}$ solder joint starts experiencing tensile force and then compression force and goes back to tensile force in this cycle, the behavior of stress changes almost the same as temperature cycle. 


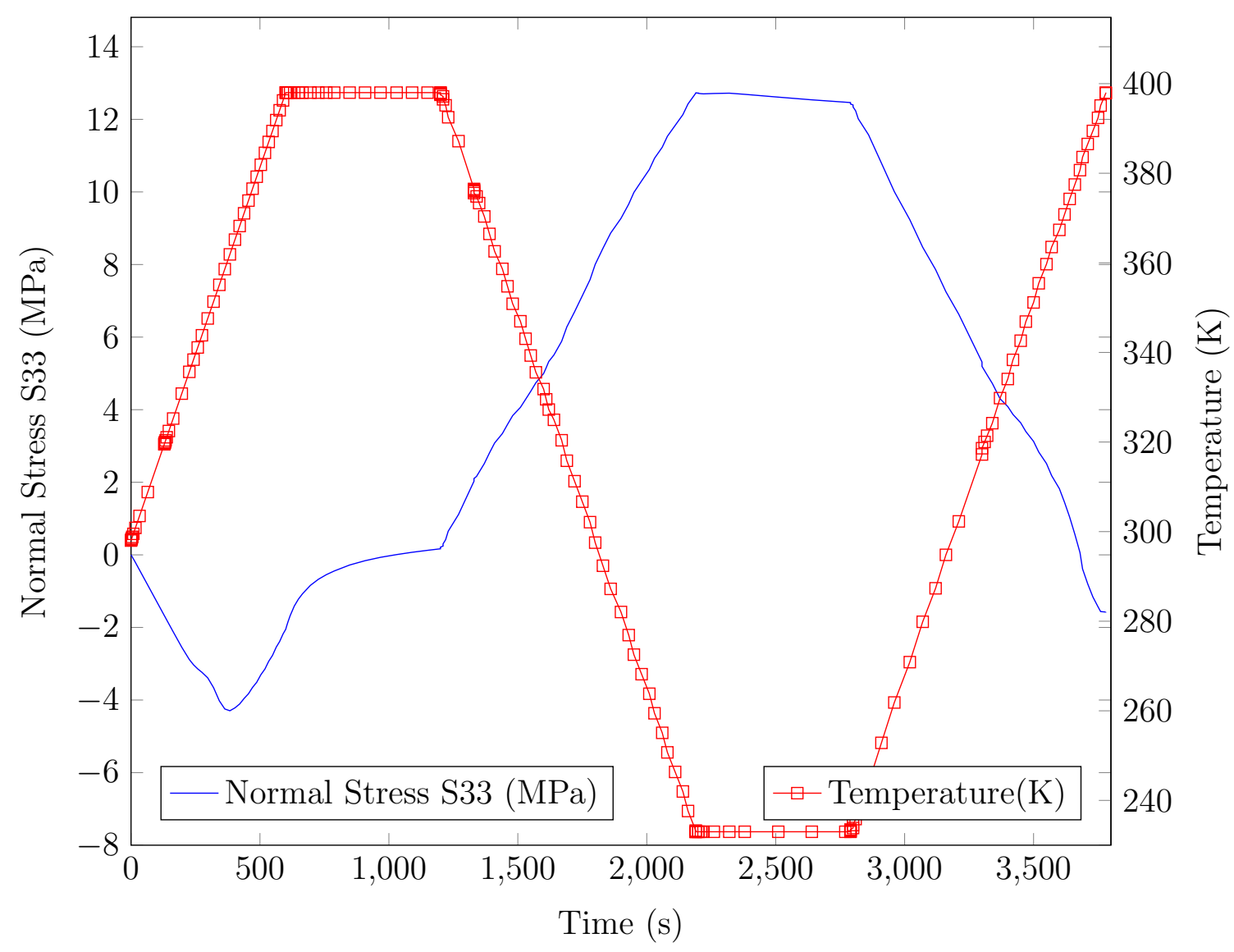

Figure 4.14: Normal Stress (S33) on Solder joint J10, Temperature Cycle vs Time(s)

The solder joint experiences mostly tensile force, the behavior of the normal stress in the $\mathrm{z}-\mathrm{z}$ axis is opposite the behavior of the temperature cycle. 


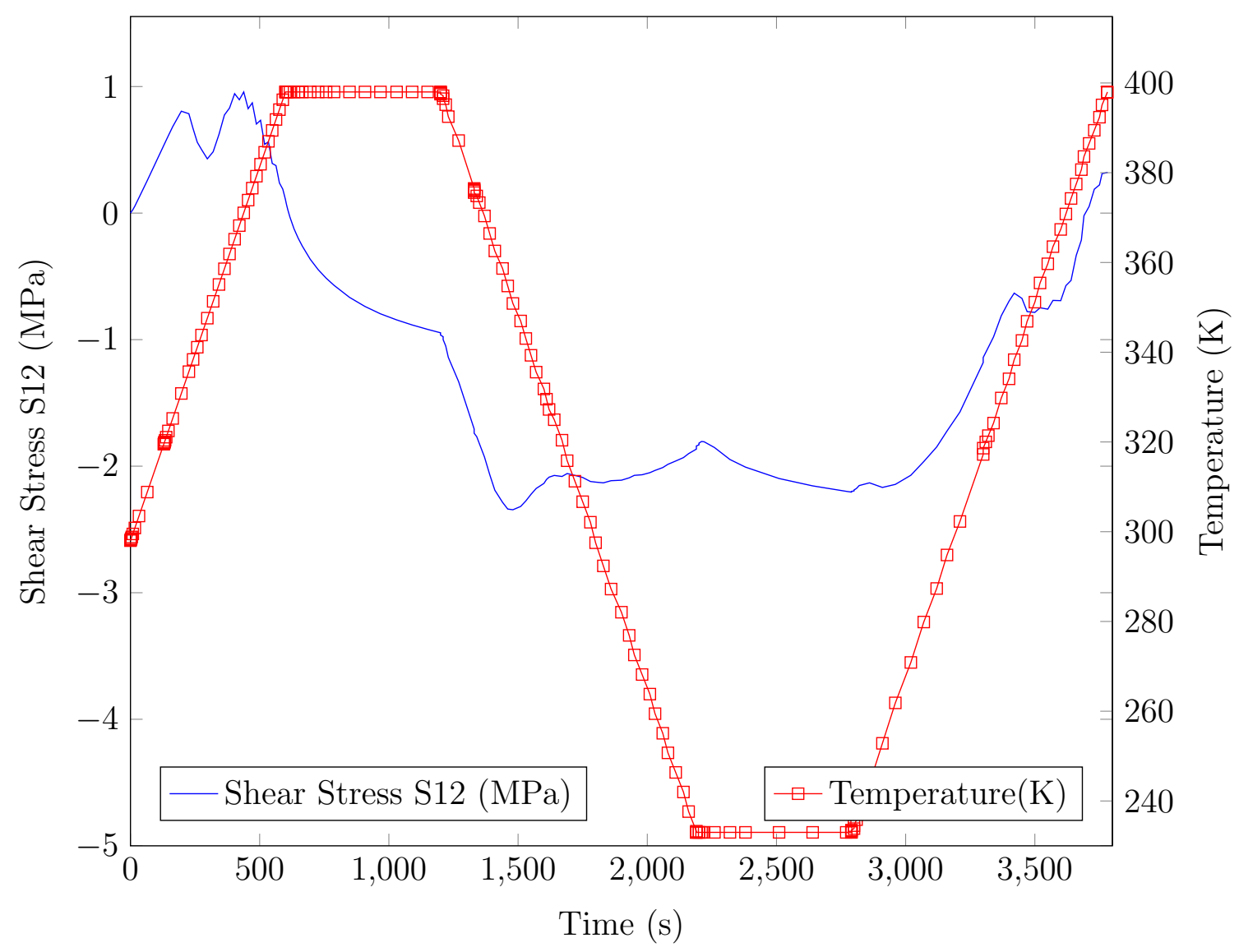

Figure 4.15: Shear Stress (S12) on Solder joint J10, Temperature Cycle vs Time(s)

The solder joint experiences shear stress in the opposite direction on the $\mathrm{x}-\mathrm{y}$ axis with a maximum magnitude around -2.5 Mpa. 


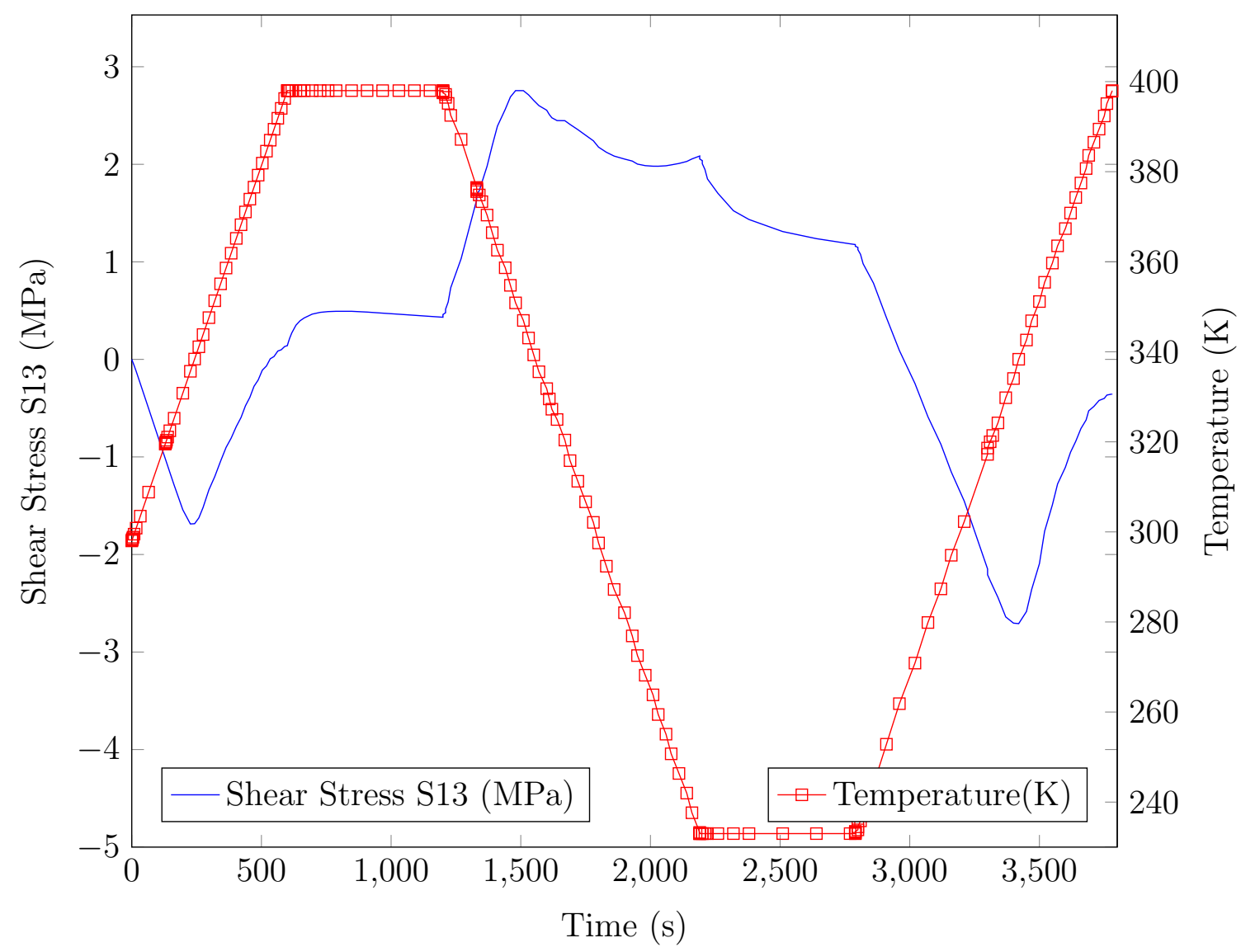

Figure 4.16: Shear Stress (S13) on Solder joint J10, Temperature Cycle vs Time(s) 


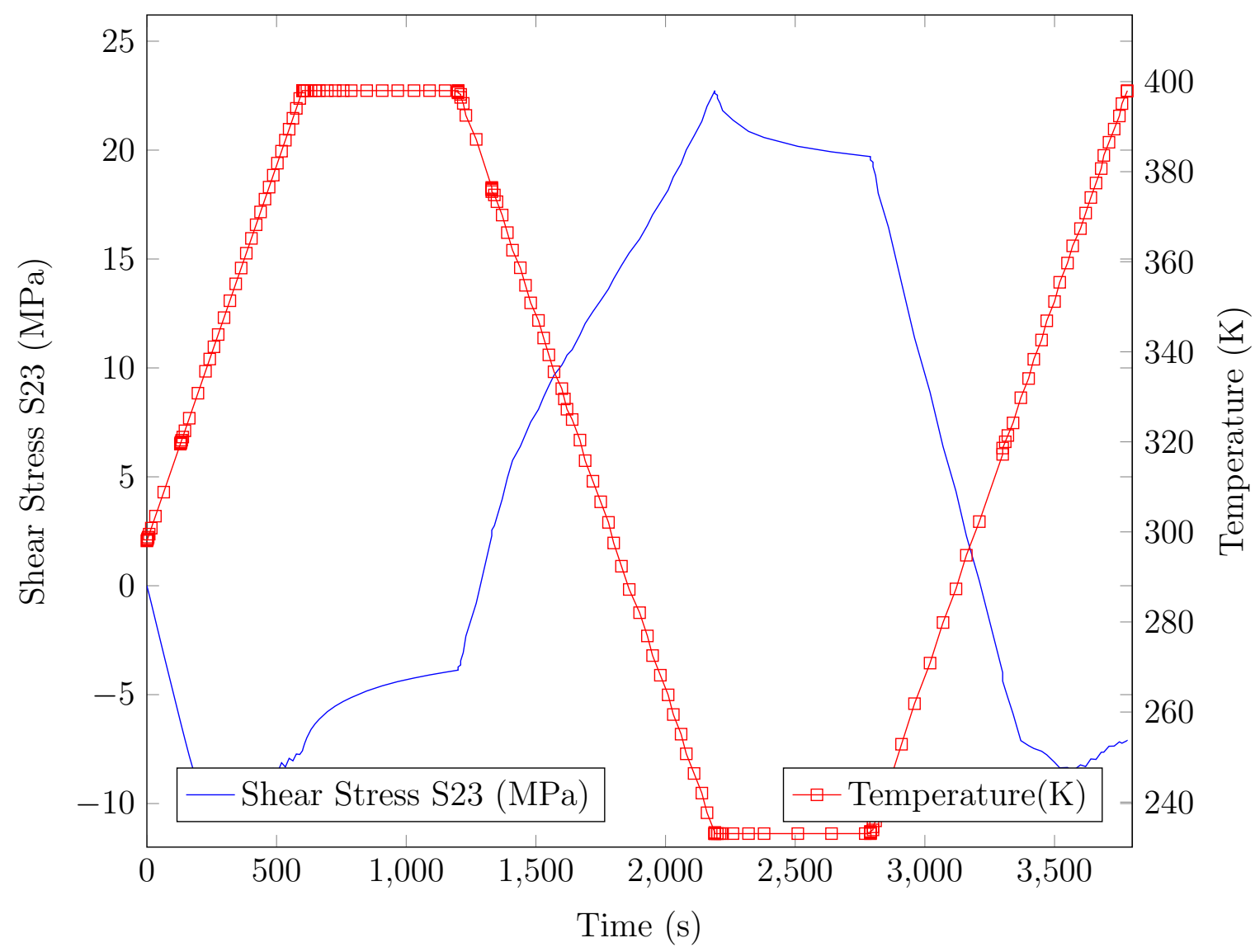

Figure 4.17: Shear Stress (S23) on Solder joint J10, Temperature Cycle vs Time(s)

Solder joint experiences shear stress in the $\mathrm{y}-\mathrm{z}$ axis opposite the behavior of the temperature cycle. The stress begins rising or dropping depending on the change in temperature during dwell time. 


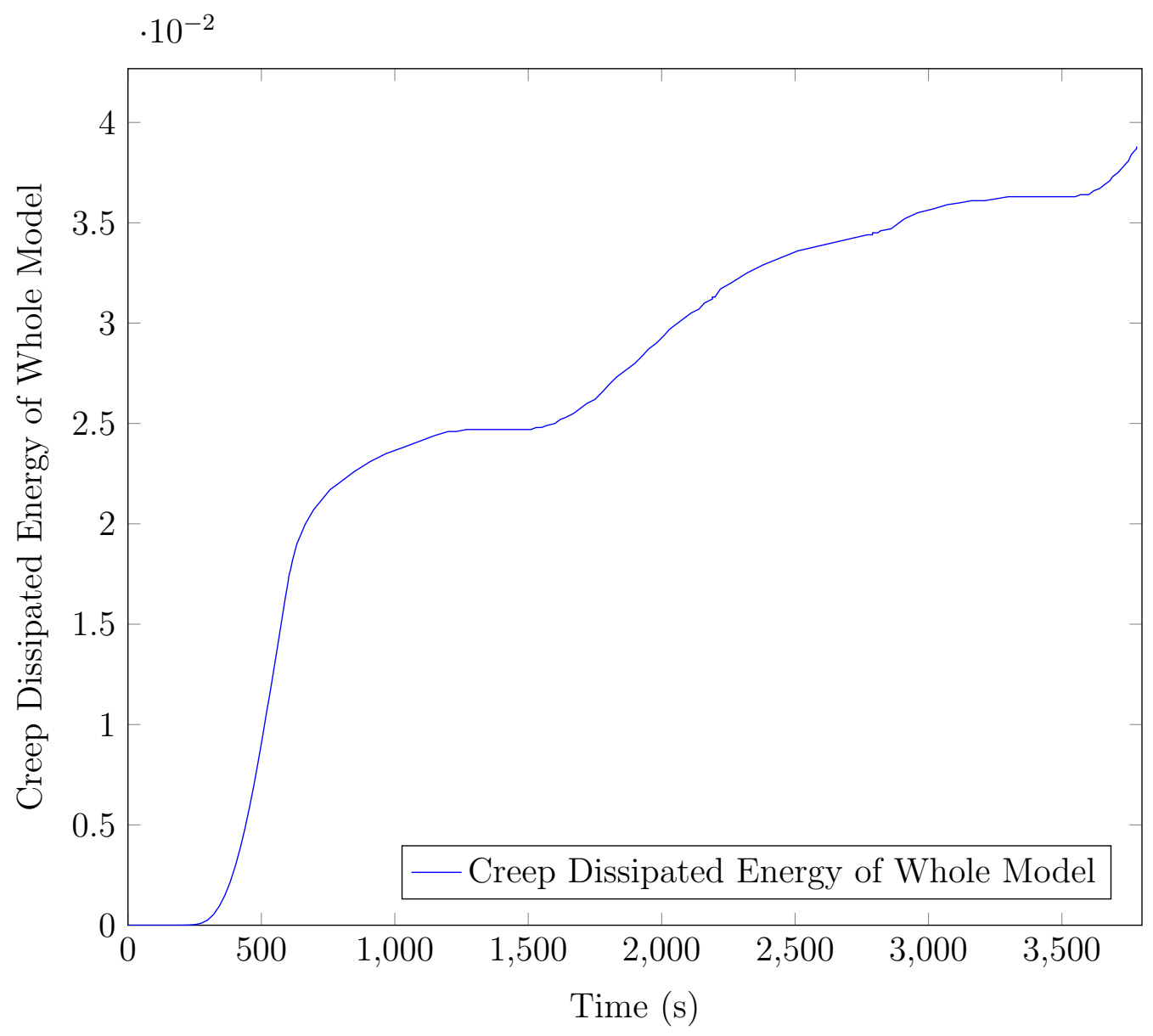

Figure 4.18: Creep Dissipation Energy for the whole model vs Time(S) 


\subsection{Case 3 (2 Dies in the molding compound both $.18 \mathrm{~mm})$}

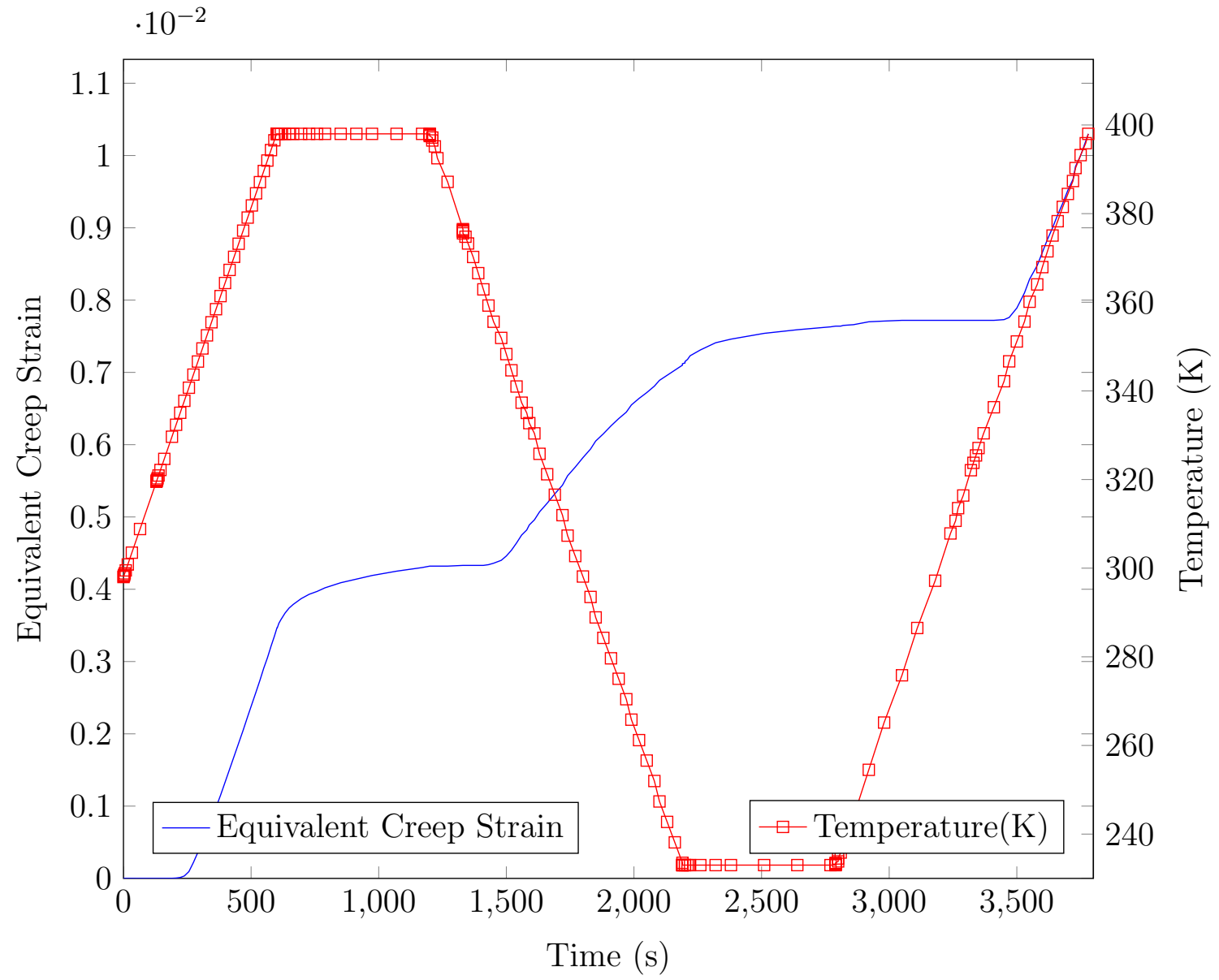

Figure 4.19: Creep Strain on Solder joint J10, Temperature Cycle vs Time(s)

Equivalent Creep Strain amplitude is $0.00344619 \mathrm{~mm} / \mathrm{mm}$. It remains slightly constant during dwell time and increases during temperature ramp up and ramp down. It can be seen that when homologous temperature, actual temperature/ melting temperature is greater than 0.4 creep increases rapidly. While it increases at a very slow pace at higher homologous temperatures. 


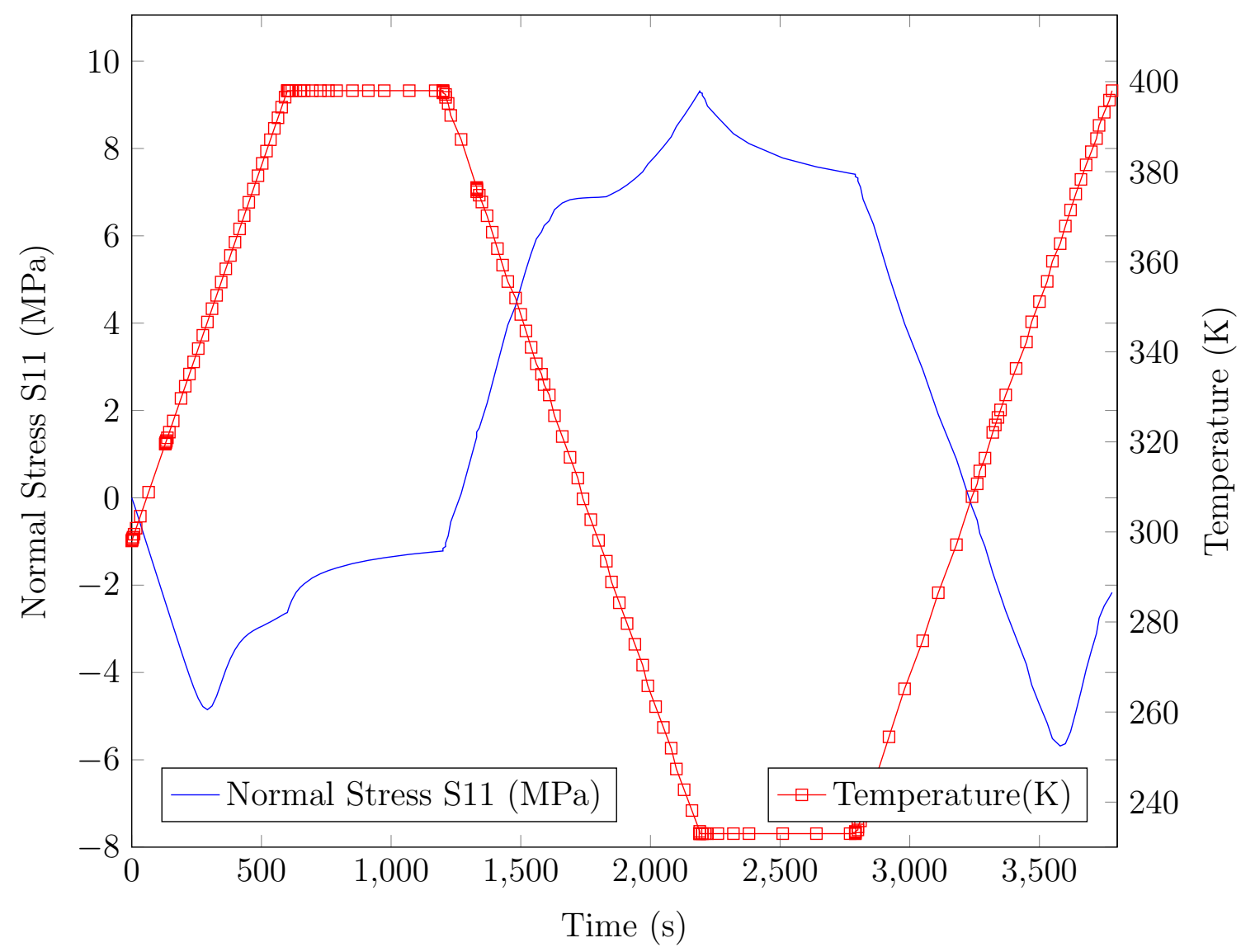

Figure 4.20: Normal Stress (S11) on Solder joint J10, Temperature Cycle vs Time(s)

Magnitude of Normal stress on the $\mathrm{x}-\mathrm{x}$ axis is tensile and opposite the behavior of the change in temperature. 


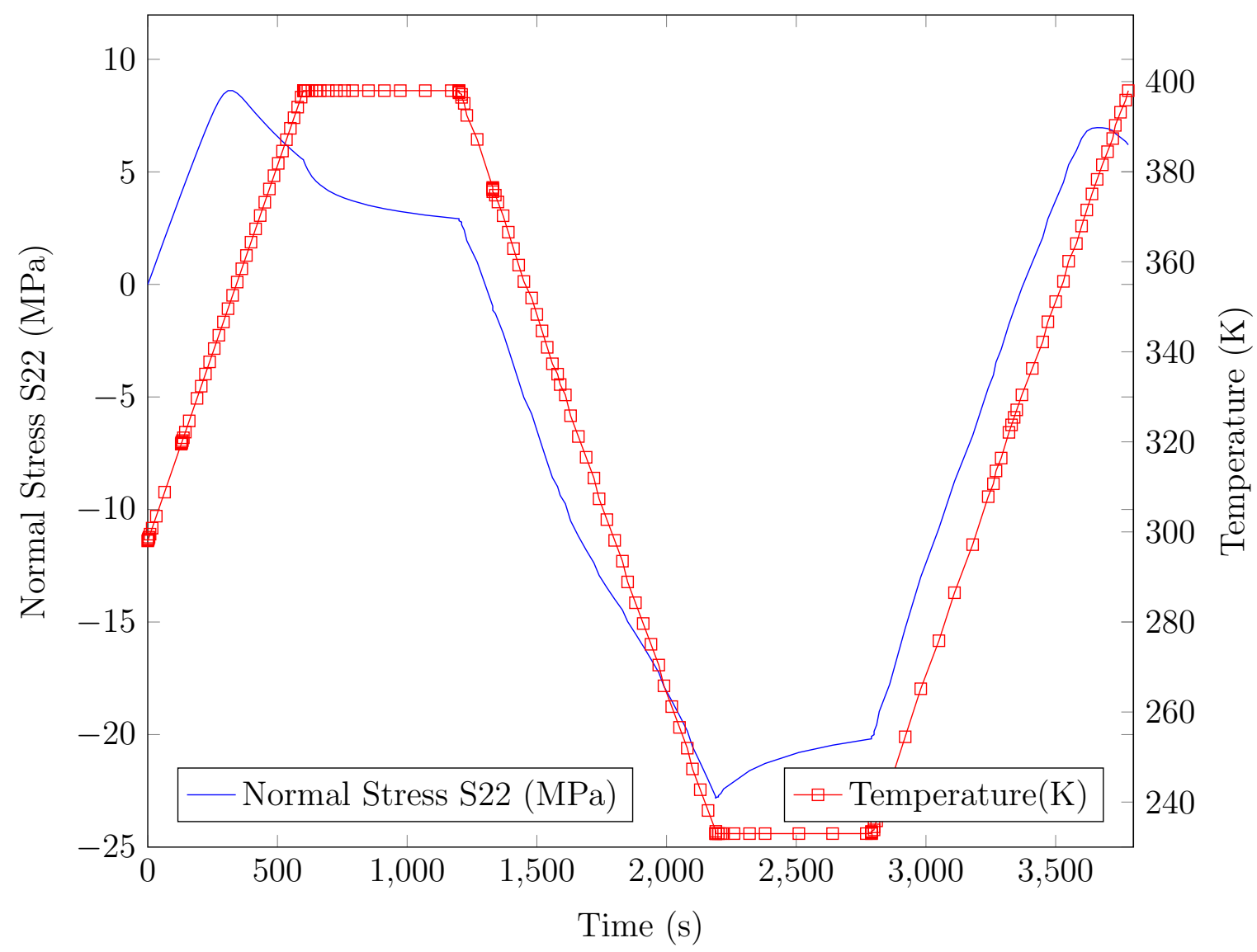

Figure 4.21: Normal Stress (S22) on Solder joint J10, Temperature Cycle vs Time(s)

The $J 10^{\text {th }}$ solder joint starts experiencing tensile force and then compression force and goes back to tensile force in this cycle, the behavior of stress changes almost the same as temperature cycle. 


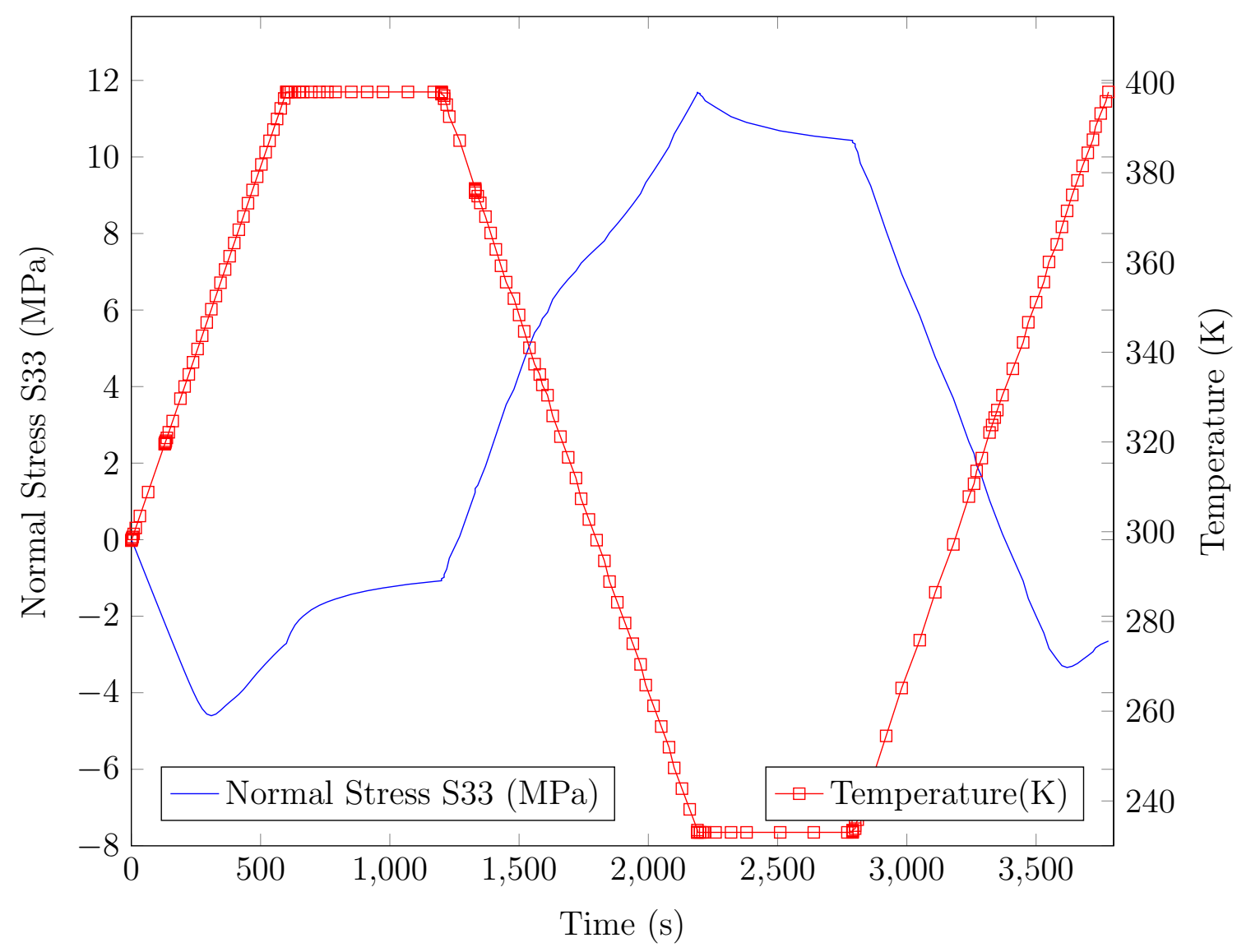

Figure 4.22: Normal Stress (S33) on Solder joint J10, Temperature Cycle vs Time(s)

Magnitude of Normal stress on the z-z axis is tensile and opposite the behavior of the change in temperature. 


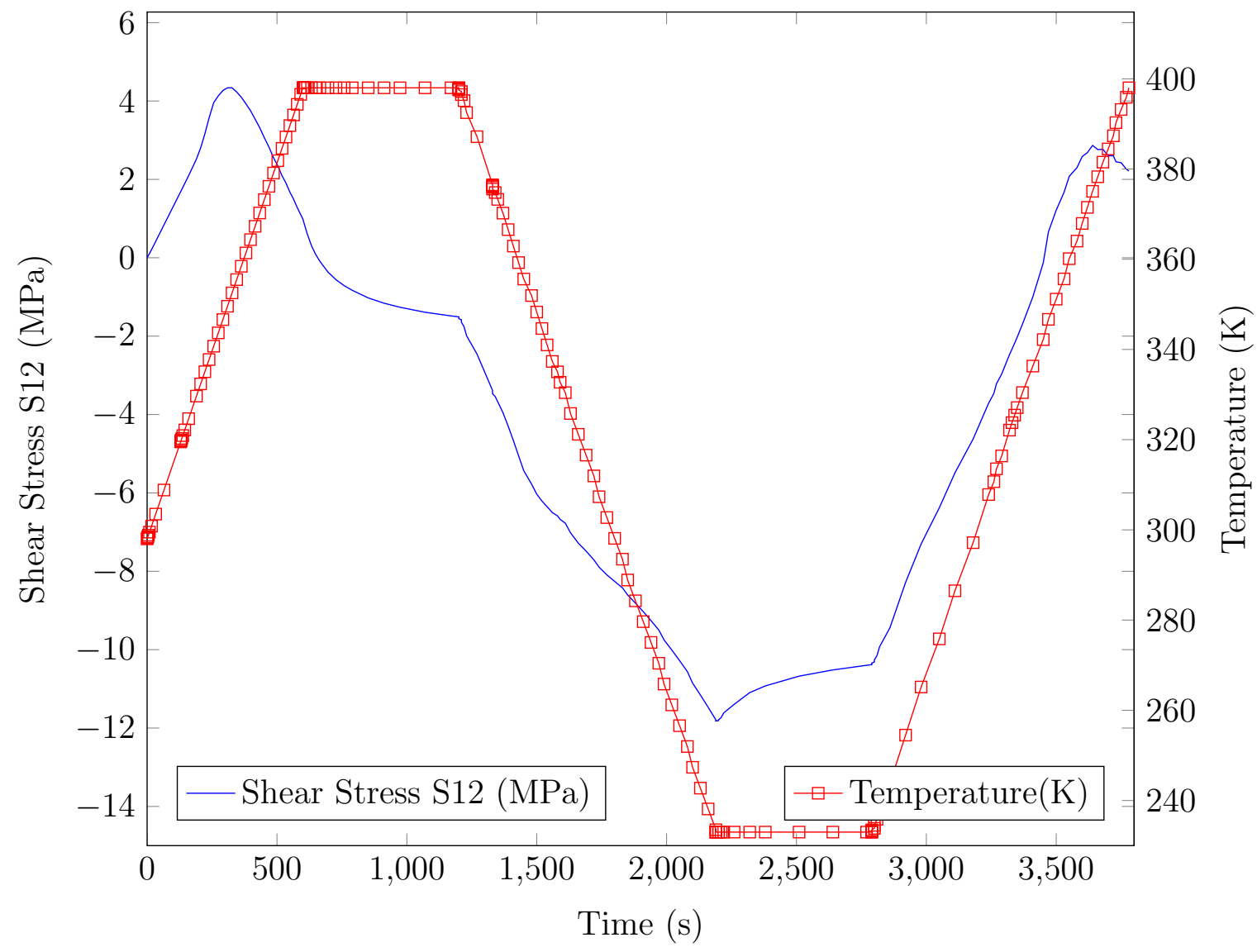

Figure 4.23: Shear Stress (S12) on Solder joint J10, Temperature Cycle vs Time(s)

Shear stress on the solder joint is opposite the axis in the $\mathrm{x}-\mathrm{y}$ axis. 


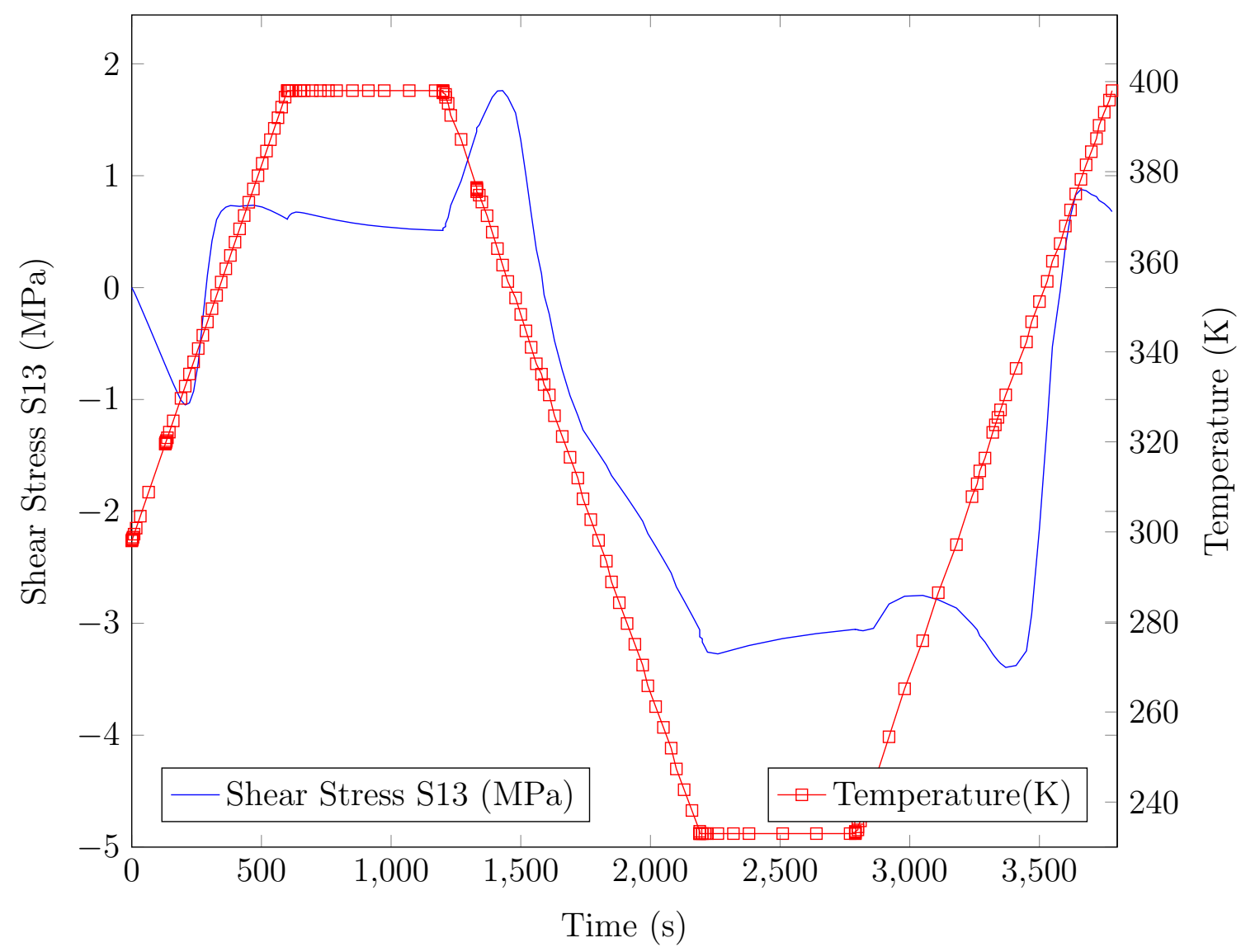

Figure 4.24: Shear Stress (S13) on Solder joint J10, Temperature Cycle vs Time(s) 


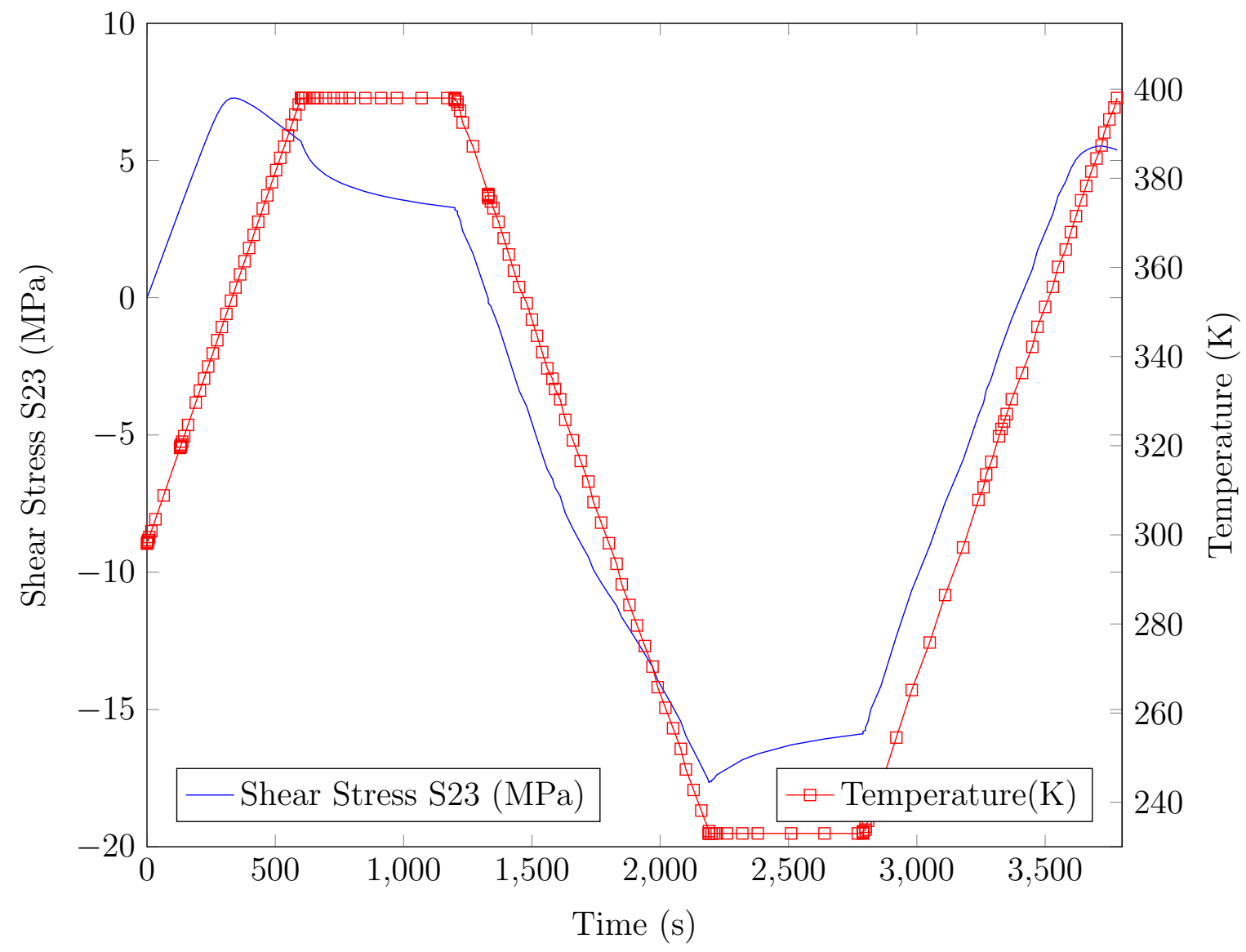

Figure 4.25: Shear Stress (S23) on Solder joint J10, Temperature Cycle vs Time(s)

Shear stress in the $\mathrm{y}-\mathrm{z}$ axis exhibits similar behavior as the temperature cycle. 


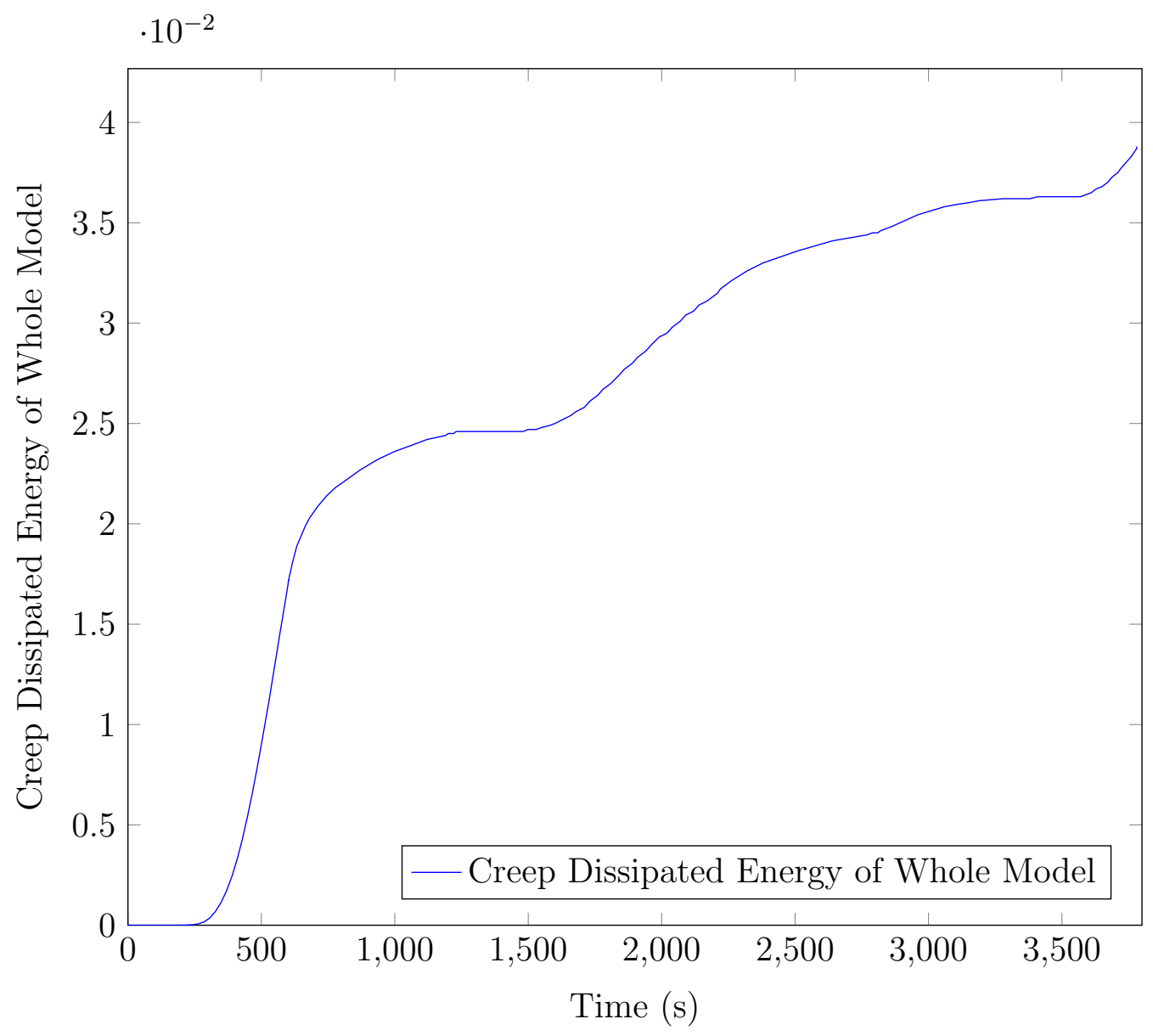

Figure 4.26: Creep Dissipation Energy for the whole model vs Time(S) 
Table 4.1: Percentage Difference in Equivalent Creep Strain Amplitude between cases

\begin{tabular}{|l|l|l|}
\hline \multicolumn{3}{|c|}{ Percentage Difference in Equivalent Creep Strain Amplitude between cases } \\
\hline Case & Compared case & Percentage difference \\
\hline Case $1(2$ dies $.12 \mathrm{~mm})$ & Case $2(2$ dies $.15 \mathrm{~mm})$ & $3.87221 \%$ \\
Case 2 (2 dies $.15 \mathrm{~mm})$ & Case $3(2$ dies .18mm) & $0.0672981 \%$ \\
\hline
\end{tabular}

The results show that the percent difference between the $.12 \mathrm{~mm}$ die and $.15 \mathrm{~mm}$ die was higher than that of the $.15 \mathrm{~mm}$ die and $.18 \mathrm{~mm}$ die. The creep strain amplitude for all three cases slightly increased with the increase in die thickness. 


\section{Chapter 5}

\section{Fatigue Life Prediction}

\subsection{Fatigue Life Prediction of Solder joints}

Predicting the solder joint fatigue failure will require a proper ability to accurately model the solder joint. Factors to consider are:

1. Constitutive equation and material properties for the applicable range of stress condition. (This study uses the Anand model to represent the behavior of the solder joints. The Anand model parameters are included in Chapter 3).

2. The constitutive equation "Anand model" is translated into ABAQUS using the "Sine hyperbolic law" and a model created.

3. Simulation is used to calculate the response of solder joint under different stress conditions.

4. FEA results are used to create a model predicting the number of cycles to failure, $\mathrm{N}_{f}$.

The total strain equation which is separated into three components- elastic, plastic, and creep-can prove to be a challenge in actual life testing and leads to inconsistencies in the final results.

$$
\epsilon_{\text {total }}=\epsilon_{\text {elastic }}+\epsilon_{\text {plastic }}+\epsilon_{\text {creep }}
$$

The failure mechanism for the solder joints are characterized by low Fatigue Cyclic testing. The solder is subjected to temperature above half its melting point (homologous temperature), that is $398 \mathrm{k}\left(125^{\circ} \mathrm{C}\right)$. The melting temperature for the SAC305 
solder alloy is $490 \mathrm{k}\left(217^{\circ} \mathrm{C}\right)$.

\subsubsection{Plastic Strain Fatigue Model (Total Strain Fatigue Model)}

This is a combination of the Coffin Manson fatigue model and the Basquin's fatigue model. This model is applicable to all types of packages and covers both high and low fatigue cycles.

$$
\begin{gathered}
\frac{\triangle \epsilon}{2}=\frac{\sigma \prime_{f}}{E}\left(2 N_{f}\right)^{b}+\epsilon I_{f}\left(2 N_{f}\right)^{c} \\
\frac{\triangle \epsilon_{t}}{2}=\frac{\triangle \epsilon_{e}}{2}+\frac{\triangle \epsilon_{p}}{2}
\end{gathered}
$$

where the total strain amplitude is

$$
\frac{\triangle \epsilon_{t}}{2}
$$

The elastic strain amplitude is

$$
\frac{\triangle \epsilon_{e}}{2}
$$

And the plastic strain amplitude is

$$
\frac{\triangle \epsilon_{p}}{2}
$$

\section{Coffin Mason Fatigue Model}

The Coffin Manson fatigue model is perhaps the best known and widely used approach today. The total number of cycles of failure, $N_{f}$ is depicted as being dependent on the plastic strain amplitude $\triangle \epsilon_{p}$, the fatigue ductility coefficient $\epsilon_{f}$, and the 
fatigue ductility exponent, c.

The relationship among these variables are given by [10]

$$
\frac{\triangle \epsilon_{p}}{2}=\epsilon_{f}\left(2 N_{f}\right)^{c}
$$

where the fatigue ductility exponent varies between -0.5 and -0.7 and the fatigue ductility coefficient is approximately equal to the true fracture ductility $\epsilon_{f}[11]$.

The Coffin Manson model assumes fatigue due to plastic deformation only and the elastic deformation negligible.

\section{Basquin's Fatigue Model}

The total number of cycles to failure $N_{f}$ is depicited as being dependent on the elastic strain amplitude $\Delta \epsilon_{e}$, the fatigue strength coefficient $\sigma \prime_{f}$, and the fatigue strength exponent b. The relationship among these variables are given by [10]:

$$
\frac{\triangle \epsilon_{e}}{2}=\frac{\sigma_{f}^{\prime}}{E}\left(2 N_{f}\right)^{b}
$$

where $\mathrm{E}$ is the Young's modulus.

$2 N_{f}=1$ reversal to failure and 1 reversal $=\frac{1}{2}$ cycles.

Both the Coffin Mason fatigue model and the Basquin's fatigue model are added together to get a total strain equation that accounts for both plastic and elastic deformations.

The Total Strain-Life Parameters for SAC305 is obtained from Suh et al. ([12] 
Table 5.1: Strain-Life Parameters for SAC305

\begin{tabular}{|l|l|l|}
\hline \multicolumn{3}{|c|}{ Strain-Life Parameters for SAC305 } \\
\hline Constant & Parameter & SAC305 \\
\hline$\epsilon \prime_{f}$ & fatigue ductility coefficient & 0.325 \\
$\mathrm{c}$ & fatigue ductility exponent & -0.57 \\
$\sigma_{f}$ & fatigue strength coefficient & 64.8 \\
$\mathrm{~b}$ & fatigue strength exponent & -0.1443 \\
\hline
\end{tabular}

Based on the above parameters, the number of cycles to failure and reversals to failure can be plotted and predicted using the total strain equation as

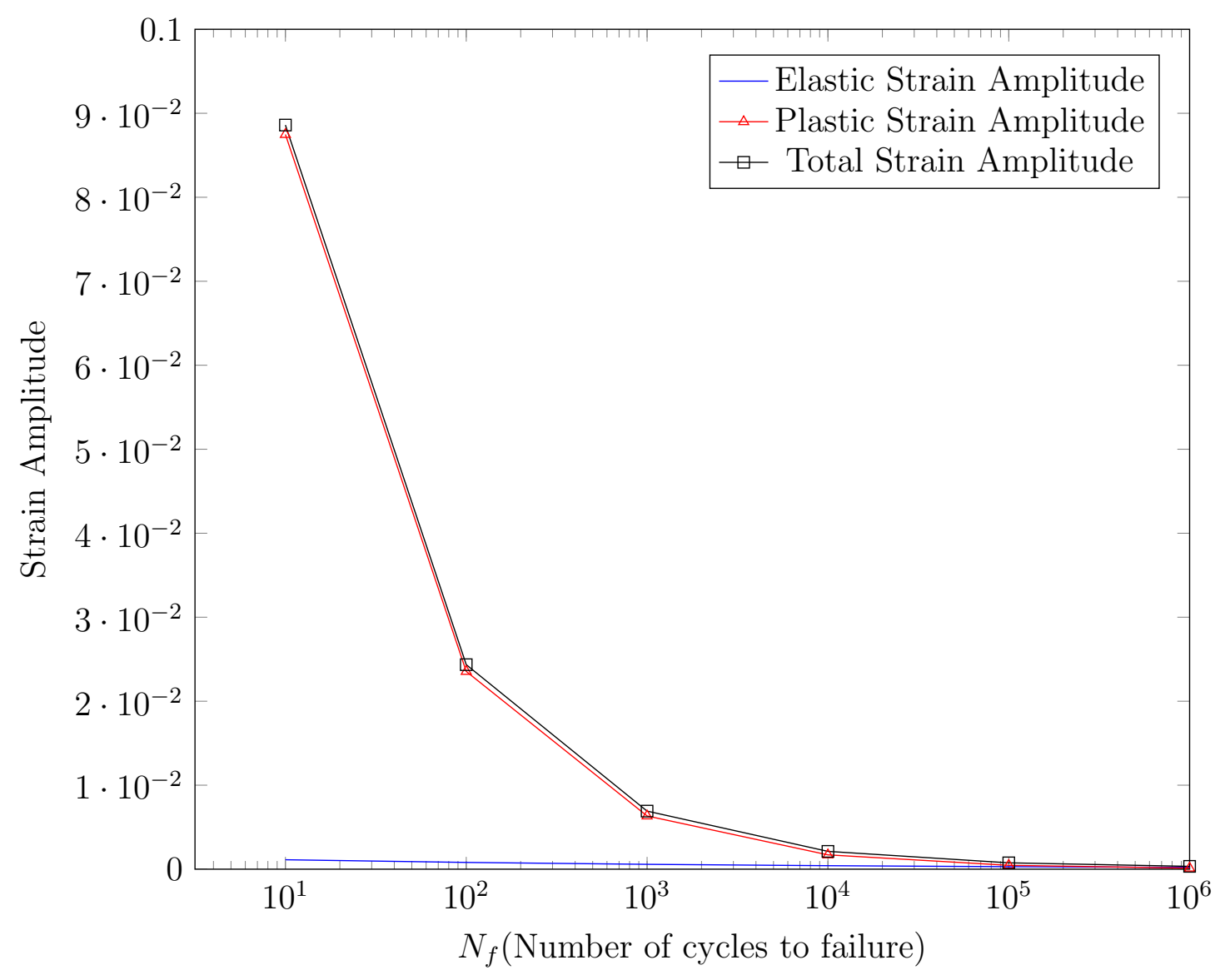

Figure 5.1: Number of cycles to failure $\mathrm{N}_{f}$ 


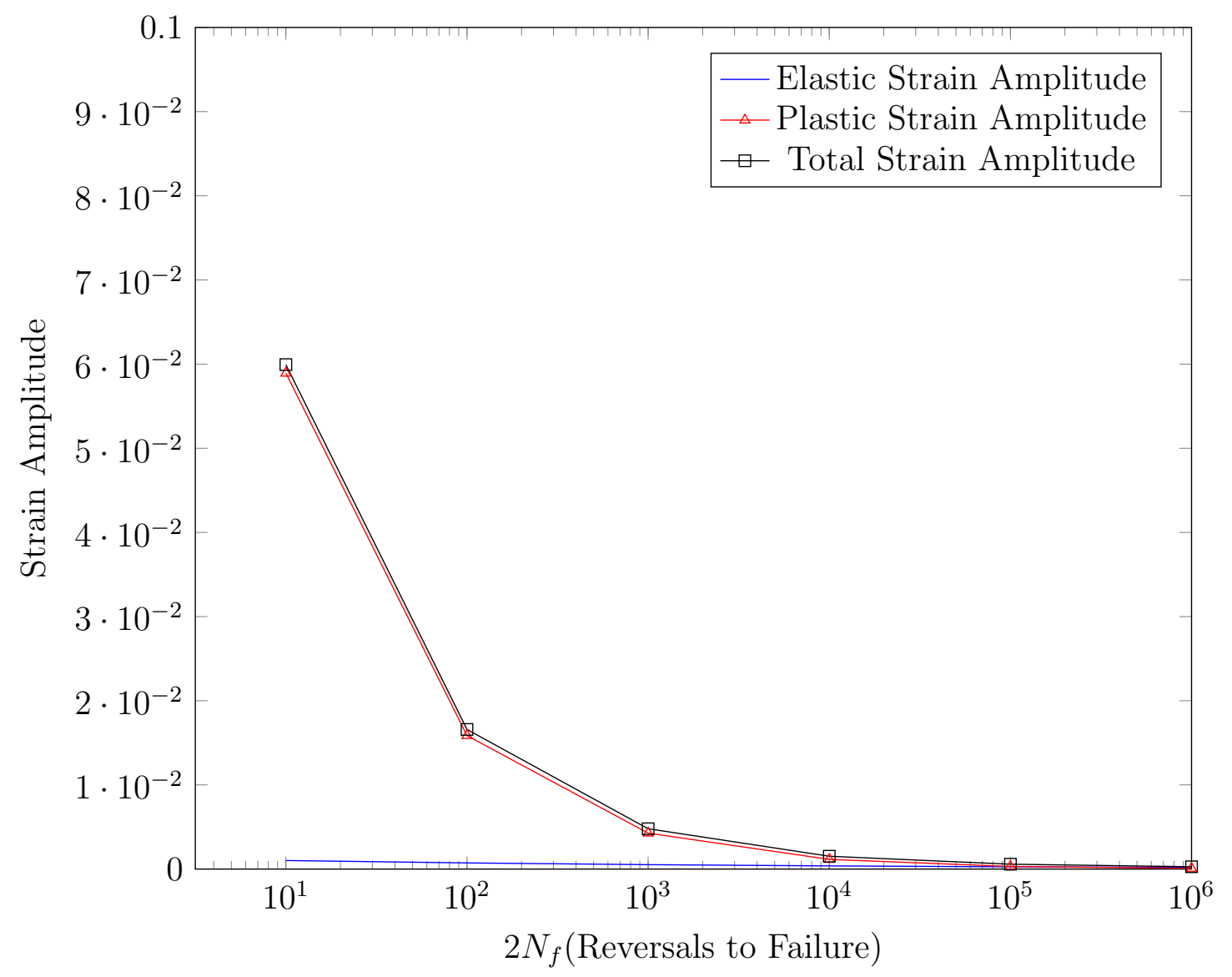

Figure 5.2: Number of reversals to failure $2 \mathrm{~N}_{f}$

Using the Coffin-Mason Fatigue model equation, $\mathrm{Eq}(5.2)$ and (plastic) strain amplitude from the various cases, we can predict the number of cycles to failure for each case.

Table 5.2: Number of cycles to failure for individual cases

\begin{tabular}{|l|l|l|}
\hline \multicolumn{3}{|c|}{ Number of cycles to failure for individual cases } \\
\hline Case & $\begin{array}{l}\text { Creep Strain Ampli- } \\
\text { tude }\end{array}$ & $\begin{array}{l}N_{f} \text { (Number of cycles to } \\
\text { failure })\end{array}$ \\
\hline Case 1(2 dies .12mm) & 0.00358468 & 10,000 cycles \\
Case 2(2 dies .15mm) & 0.00344851 & 10,000 cycles \\
Case 3(2 dies .18mm) & 0.00344619 & 10,000 cycles \\
\hline
\end{tabular}

The plastic strain amplitude in the critical solder joint "J10" for all the different 
cases are evaluated to predict the number of cycles the joint undergoes before failure. Assuming the first joint that fails in the system is most likely the critical joint. 10,000 cycles is a reasonable number for low cycle fatigue which is the cycle considered for this study. 


\section{Chapter 6}

\section{Conclusions}

Ball geometry and component material play an important role in solder joint reliability. Therefore, ball geometry and component materials are considered to best suit the package. The most common cause of solder joint failure is thermo-mechanical fatigue. Instability of the micro structure of solder joints causes it to evolve due to temperature, time, and strain.

Solder joints experience time dependent deformation creep due to the different coefficient of thermal expansion (CTE) of the materials. It is seen in the simulation results that creep strain increases slightly as the thicknesses of the dies embedded in the molding compound increase. The critical solder joint remain the J10th solder joint. The equivalent creep strain in the package is highly nonlinear and relaxes during the dwell time. During temperature ramp up and down creep formation begins.

Understanding the micro-structure of the solder joint and representing the behavior of the solder joint with an accurate constitutive equation is important. The Anand visco-plastic model was used to predict the behavior of the SAC305 material at different temperatures below its melting temperature of 490k.

Using the total strain fatigue model which was a combination of the Coffin Manson's fatigue model and Basquin's fatigue model, the number of cycles to failure were able to be predicted using the equivalent strain amplitude obtained from the ABAQUS results. The solder joint goes through a low cycle fatigue with 10,000 cycle to failure. 


\section{Bibliography}

[1] Emil Lechovic, Erika Hodulova, Beata Szewczykova, Ingrid Kovarikova, and Koloman Ulrich. Solder joint reliability. Technical report, Institute of Production Technologies, Faculty of Materials Science and Technology, Slovak University of Technology, 2008.

[2] Dhafer Abdulameer Shnawah, Mohd Faizul Mohd Sabri, and Irfan Anjum Badruddin. A review on thermal cycling and drop impact reliability of sac solder joint in portable electronic products. Microelectronics Reliability, 52(1): 90-99, 2012.

[3] Xingsheng Liu. Processing and Reliability Assessment of Solder Joint Interconnection for Power Chips. PhD thesis, Virginia Technical Institute, 2001.

[4] W.W.Lee, L.T.Nguyen, and G.S.Selvaduray. Solder joint fatique models: review and applicability to chip scale packages. Microelectronic Reliability, 40 (2):231-244, February 2000.

[5] Lead-free Solder Interconnect Reliability. Materials Park, OH : ASM International, 2005.

[6] Chun-Sean Lau, M.Z. Abdullah, M Abdul Mujeebu, and Nadiahnor Md Yusop. Finite element analysis on the effect of solder joint geometry for the reliability of ball grid array assembly with flexible and rigid pcbs. Journal of Engineering Science and Technology, 9(1):47-63, February 2014.

[7] Mohammad Motalab, Zijie Cai, Jeffrey C. Suhling, and Pradeep Lall. Determination of anand constants for sac solders using stress-strain or creep data. 13th IEEE ITHERM Conference, May 2012.

[8] Seng Guan Chow, Yaojian Lin, Eric Ouyang, and Billy Ahn. A finite element analysis of board level temperature cycling reliability of embedded wafer level bga (ewlb) package. IEEE TRANSACTIONS ON DEVICES AND MATERIALS RELIABILITY, pages 1448-1454, February 2012.

[9] J.W. Jr. Morris, H.G. Song, and F. Hua. Creep resistance of sn-rich solder joints. In Proceedings of 53rd Electronic Components and Technology Conference, pages 54-57. 
[10] Solder joint reliability theory and applications, chapter 13. Springer US, 1991.

[11] Mechanical Metallurgy. New York:McGraw-Hill, 1986.

[12] I.-W Suh, H.-S Jung, Y.-H Lee, and S.-H Choa. Numerical prediction of solder fatigue life in a high power igbt module using ribbon bonding. Journal of Power Electronics, 16(5):1843-1850, September 2016.

[13] Ahmer Syed. Predicting solder joint reliability for thermal, power, bend cycle within 25In Proceedings - Electronic Components and Technology Conference, pages 255 - 263, 02 2001. ISBN 0-7803-7038-4.

[14] Sadhana Radhakrishnan. Stress analysis of embedded devices under thermal cycling. Dissertations and theses, Portland State University, 2018.

[15] F.X.Che and John.H.L.Pang. Fatique reliability analysis of sn-ag-cu solder joints subjected to thermal cycling. IEEE TRANSACTIONS ON DEVICES AND MATERIALS RELIABILITY, 13(1):36-48, March 2013.

[16] W.D.Zhuang, P.C.Chang, F.Y.Chou, and R.K.Shiue. Effect of solder creep on the reliability of large area die attach. Microelectronic Reliability, 41(12): 2011-2021, 2001.

[17] Fundamentals of metal fatigue Analysis. Pearson, 1990.

[18] Mateusz Stec. Modeling thermal fatigue in nonlinear materials, 2014. URL https : //www . comsol.com/blogs/ modeling-thermal-fatigue-nonlinear-materials/.

[19] E. Suhir, R. Ghaffarian, and Sung Yi. Probabilistic palmgren-miner rule with application to solder materials experiencing elastic deformations. Journal of Materials Science: Materials in Electronics., Volume 28(Issue 3):pp 2680-2685, 2017.

[20] Sung Yi. Shear strengths of cbga/pbga solder ball joints with lead-free solder pastes. International Journal of Materials and Structural Integrity, Vol.8 (No.1/2/3):pp.62-75, 2014.

[21] Y. F. Chu, Sung Yi, and Phil Geng. Thermal fatigue life prediction of solder joints of plastic ball grid array packages. International Journal of Materials and Structural Integrity, Vol.8(No.1/2/3):pp.3-20, 2014.

[22] Sung Yi, KyungO Kim, Dongwan Lee, Hongwon Kim, and Taesung Jung. Embedded passive device technology for wireless mobile devices. Microelectronics International, Vol.30,Iss:1, 2013. 
[23] S. Gao, J.P. Hong, Kim J.S., D.J. Yoo, T.S. Jeong, S.M. Choi, and Sung Yi. Development of an ultra-slim system in package (sip). Journal of the Microelectronics and Packaging Society, Vol.15(No.1):pp.7-18, 2008.

[24] C. Y. Xiong, J. Zhang, M. Li, J. Fang, and Sung Yi. Fourier and wavelet transform analysis of moiré fringe patterns in electronic packaging. Microelectronics International, Vol.21(No.2):pp. 45-51, 2004.

[25] Sung Yi, GX Luo, and Kerm Chian. Viscoplastic micro-deformation mechanism of eutectic solders. 124:92-96, 062002.

[26] Chong Hua Zhong and Sung Yi. Solder joint reliability of plastic ball grid array packages. Soldering and Surface Mount Technology, 11(1):44-48, 1999.

[27] T. Snyder and S. Yi. Thermal performance of embedded active chips. In 2014 9th International Microsystems, Packaging, Assembly and Circuits Technology Conference (IMPACT), pages 209-212, Oct 2014.

[28] Sung Yi and Tatiana M. Lam. Analysis of warpage and residual stress in plastic ball grid array package after post mold cure. Microelectronics International, 29(3):163-171, 2012.

[29] Lianxi Shen, Sung Yi, J. Caers, X. Zhao, and K. Zhang. A damage parameter based on fracture surface for fatigue life prediction of csp solder joints. In Advances in Electronic Materials and Packaging 2001 (Cat. No.01EX506), pages 412-416, 2001. doi: 10.1109/EMAP.2001.984019. 